\title{
Estudos espectroscópicos da hemoglobina extracelular de Glossoscolex paulistus (HbGp).
}

Dissertação apresentada ao Instituto de Química de São Carlos da Universidade de São Paulo como parte dos requisitos para obtenção do título de mestre em Ciências. Área de concentração: Físicoquímica.

Orientador: Prof. Dr. Marcel Tabak

São Carlos - SP 
“Não vos inquieteis com nada! Em todas as circunstâncias apresentai a Deus as vossas preocupações, mediante a oração, as súplicas e ação de graças. E a paz de Deus, que excede toda a inteligência, haverá de guardar vossos corações e vossos pensamentos, em Cristo Jesus."

Filipenses, 4,6-7. 
À minha Família. 


\section{AGRADECIMENTOS}

À Deus, pela sabedoria, discernimento, amparo nos momentos difíceis e principalmente pela força, motivo pelo qual nunca desisti de trilhar esse caminho;

Ao meu orientador Professor Dr Marcel Tabak por sua orientação segura, apoio e presença efetiva durante a realização deste trabalho;

À minha família em especial minha mãe Josefa Barbosa Barros e meu pai João de Barros Barbosa pelo amor, pelo apoio incondicional e pela confiança em mim depositada. Aos meus irmãos, irmãs, cunhado (a)s e sobrinho (a)s por terem sido o apoio contínuo no decorrer destes anos. Sem vocês nada disso seria possível;

Ao casal Thallysson Josué e Andreia Barbosa pelo estímulo e contribuições em todos os momentos da minha caminhada rumo ao título de mestre;

A todos os amigos (irmãos) do grupo de Biofísica molecular, em especial ao Pós-doutorando Francisco Adriano de Oliveira Carvalho, dedico meu mais profundo afeto e gratidão pela imensa paciência nas orientações do laboratório e pelas valiosas discussões, ao Professor Dr José Wilson Pires Carvalho pela assessoria em assuntos computacionais e aleatórios e as Pós-doutorandas Célia Sulzbacher Caruso e Fernanda Rosa Alves pela convivência e amizade;

Ao técnico Ézer Biazin que sempre se mostrou muito prestativo quando solicitado e pela amizade;

À Professora Dra. Carla Cristina Schmitt Cavalheiro e ao Professor Dr. Amando Siuiti Ito, por disponibilizarem seus laboratórios para a realização dos experimentos;

À Professora Dra. Patrícia Soares Santiago pelos conselhos e pela amizade;

À Marina Berardi, Alessandra Poli e Silvano Valandro pela ajuda no manuseio dos equipamentos;

Ao Professor Dr João Sammy Nery de Souza por ser um grande incentivador na superação dos meus limites;

Aos meus amigos Ayaz Hassan, Aline Oliveira, Adriane Damasceno, Nayane Borges, Sumária, Anderson Arandas, Estefani Kelly, Eunice Abreu, Caio Josué e ao Pe Ranilson Belém, pela amizade e incentivos realizados e, principalmente, pela compreensão nos momentos difíceis;

Aos demais amigos que não mencionei aqui, mas que estão guardados em meu coração; 
Este trabalho foi possível graças ao apoio financeiro da Prefeitura Municipal de Ipaumirim-Ce, ao suporte intelectual proporcionado pelo Programa de Pós-graduação do Instituto de Química de São Carlos (IQSC) da Universidade de São Paulo (USP). 


\section{RESUMO}

A hemoglobina de Glossoscolex paulistus ( $\mathrm{HbGp}$ ) é caracterizada por uma massa molecular de $3.600 \mathrm{kDa}$, alta estabilidade oligomérica, resistência a auto-oxidação, e alta afinidade em ligar oxigênio. A estrutura quaternária desta proteína apresenta 144 cadeias com grupo heme (globinas) e 36 cadeias sem grupo heme (linkers), dispostos em duas camadas hexagonais. No presente trabalho, foi realizado o estudo da estabilidade da oxiHbGp frente aos processos de dissociação oligomérica e desnaturação, utilizando duas classes de desnaturantes, ou seja, o surfactante brometo de dodeciltrimetilamônio (DTAB), e os agentes caotrópicos cloridrato de guanidina $(\mathrm{GuHCl})$ e ureia. Convém mencionar ainda, que este estudo foi desenvolvido através do uso de duas sondas fluorescentes, 1-Anilino-8naftaleno-sulfonato (1,8-ANS) e fluoresceína isotiocianato (FITC), usando as técnicas de absorção óptica, fluorescência estática, espalhamento de luz dinâmico (DLS) e fluorescência resolvida no tempo. Os resultados de fluorescência estática mostram que o DTAB induz um aumento na intensidade de emissão de fluorescência da sonda ANS, com o deslocamento do máximo de emissão para o azul de 517 para $493 \mathrm{~nm}$. Duas transições são observadas, em 2,5 e 9,5 mmol/L de DTAB, e estão associadas à interação da sonda ANS com agregados prémicelares e micelas, respectivamente. $\mathrm{Na}$ oxi-HbGp, ANS liga a sítios menos expostos ao solvente, quando comparado às micelas de DTAB, caracterizados pela emissão em 467-472 nm. A adição de DTAB ao sistema oxi-HbGp-ANS, no pH 7,0, induz a agregação da proteína, a dissociação oligomérica e desenovelamento da oxi-HbGp. No pH 5,0, a formação de agregados não foi observada. Além disso, o processo de desenovelamento induzido pelo DTAB apresenta duas transições, a primeira em virtude da dissociação oligomérica, e a segunda, provavelmente, devido à desnaturação das subunidades dissociadas. Por outro lado, $\mathrm{GuHCl}$ e ureia com concentrações acima de 1,5 e 4,0 mol/L respectivamente, induzem a desnaturação completa da oxi-HbGp, com redução dos grupos hidrofóbicos na superfície da proteína, e o deslocamento do ANS para o meio aquoso, detectado pela redução de intensidade de fluorescência. A técnica de fluorescência resolvida no tempo permitiu avaliar os valores dos tempos de vida para a sonda 1,8-ANS, bem como, para oxi-HbGp. Por último, a oxi-HbGp foi marcada com a sonda covalente fluoresceína isotiocianato (FITC) em dois valores de $\mathrm{pH}$ 7,0 e 9,0, e nas proporções sonda:heme de 1:5 e 2:1. A quantidade de FITC efetivamente ligada a oxi-HbGp por heme foi estimada a partir dos dados de absorção óptica. Supondo que o rendimento quântico de FITC no tampão é $100 \%$, os rendimentos quânticos de FITC ligada a oxi-HbGp também foram encontrados. Além disso, estudos preliminares de dissociação e desnaturação da oxi-HbGp marcada com FITC, na presença do surfactante DTAB, foram realizados. 


\section{ABSTRACT}

Glossoscolex paulistus hemoglobin (HbGp) is characterized by a molecular mass of $3,600 \mathrm{kDa}$, a high oligomeric stability, resistance to oxidation and a high affinity to oxygen. The quaternary structure of this macromolecule consists of 144 globin chains, and 36 additional chains lacking the heme group, named linkers, organized in a double-layered hexagonal structure. In this study, the oxy-HbGp stability, as well as, the oligomeric dissociation and unfolding processes were studied, using two types of denaturants, the surfactant Dodecyl-trimethylammonium bromide (DTAB), and chaotropic agents guanidine hydrochloride $(\mathrm{GuHCl})$ and urea. Moreover, this study was developed based on 8-anilino-1naphtalene-sulfonic acid (ANS) and fluorescein isothiocyanate (FITC) fluorescence probes, using the techniques of optical absorption, static fluorescence, dynamic light scattering (DLS) and time resolved fluorescence. The results of static fluorescence show that dodecyltrimethylammonium bromide (DTAB) induces an increase in ANS fluorescence emission intensity, with maximum emission wavelength blue-shifted from 517 to $493 \mathrm{~nm}$. Two transitions are noticed, at 2.50 and $9.50 \mathrm{mmol} / \mathrm{L}$ of DTAB, assigned to ANS interaction with pre-micellar aggregates and micelles, respectively. In oxy-HbGp, ANS binds to protein sites less exposed to solvent, as compared to DTAB micelles, characterized by emission at 467 $472 \mathrm{~nm}$. At pH 7.0, the addition of DTAB to the oxy-HbGp-ANS system induced the protein aggregation, oligomeric dissociation and unfolding of oxy-HbGp. At $\mathrm{pH}$ 5.0, no formation of aggregates was observed. Moreover, DTAB-induced unfolding process displays two transitions, one due to oligomeric dissociation and the second one, probably, due to the denaturation of dissociated subunits. On the other hand, guanidine hydrochloride $(\mathrm{GuHCl})$ and urea, at concentrations above 1.5 and $4.0 \mathrm{~mol} / \mathrm{L}$, respectively, induce the full $\mathrm{HbGp}$ denaturation, with reduction of ANS-bound oxy-HbGp hydrophobic patches on the surface of the proteins. The shift of ANS to the aqueous medium was detected by the reduction in the fluorescence intensity. Time resolved fluorescence technique allowed to evaluate the lifetimes of ANS, as well as, for oxy-HbGp. Finally, oxy-HbGp was labeled with covalent probe fluorescein isothiocyanate (FITC), at $\mathrm{pH}$ values 7.0 and 9.0, and at probe: heme ratios of 1:5 and 2:1. The quantity of FITC effectively bound to oxy-HbGp, on the heme basis was estimated from the optical absorption data. Assuming a 100\% quantum yield for FITC in buffer, the quantum yield of FITC bound to oxy-HpGp was also estimated. In addition, preliminary studies of dissociation and denaturation of oxy-HbGp labeled with FITC, in the presence of DTAB surfactant, were accomplished. 


\section{LISTA DE FIGURAS}

Figura 1: Estrutura da hemoglobina humana e estrutura do grupo heme ..............19 Figura 2: Representação da estrutura cristalógrafica da $\mathrm{HbGp}$ e de suas subunidades em ordem hierárquica.

Figura 3: Estrutura química do surfactante brometo de dodeciltrimetilamônio (DTAB).

Figura 4: Estruturas químicas das sondas 2,6-ANS (I) e 1,8-ANS (II) ........................ 28

Figura 5: Estrutura química da fluoresceína isotiocianato (FITC). .............................. 29

Figura 6: Fotografia do anelídeo Glossoscolex paulistus ................................................. 34

Figura 7: Diagrama representativo dos níveis de energia eletrônica molecular ......... 39

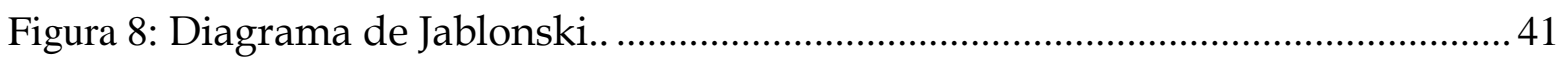

Figura 9: (A) Espectros de absorção óptica da oxi-HbGp na presença da sonda ANS. (B) Gráfico da absorbância na banda de Soret em função da concentração de ANS.48

Figura 10: (A) Espectros de emissão de fluorescência da oxi-HbGp na presença da sonda ANS. (B) Gráficos das áreas do pico II em função da concentração da sonda ANS. (C) e (D) Gráficos da Intensidade de emissão do pico I e do máximo de emissão de fluorescência referente ao pico II em função da concentração da sonda ANS. 50

Figura 11: (A) Espectros de absorção óptica da sonda ANS com DTAB. (B) e (C) Gráficos da variação do comprimento de onda das respectivas bandas da sonda ANS em função da concentração de DTAB.....

Figura 12: (A) Espectros de emissão de fluorescência da sonda ANS na presença e na ausência de DTAB. (B) Gráfico da área total de emissão de fluorescência normalizada a partir da área observada na concentração de 0,0 mmol/L de DTAB em função da concentração de surfactante. (C) Gráficos do deslocamento do máximo de emissão de fluorescência $\left(\lambda_{e m}^{\max }\right)$ e da área da curva de emissão de fluorescência em função da concentração de DTAB.

Figura 13: (A) Espectros de absorção óptica da oxi-HbGp com diferentes concentrações de DTAB na presença de ANS. (B) Gráficos da absorbância na banda de Soret e do deslocamento do máximo de absorção desta banda em função da concentração de DTAB. (C) Gráfico da absorbância em $700 \mathrm{~nm}$ em função da concentração de DTAB.. 
Figura 14: (A) Espectros de absorção óptica da oxi-HbGp com diferentes concentrações de DTAB na presença de ANS. (B) Inserto da Figura (A) mostrando a região das bandas $Q$ ampliada. (C) Gráficos da absorbância na banda de Soret e do deslocamento do comprimento de onda do máximo de absorção desta banda, em função da concentração de DTAB. 56

Figura 15: Espectros de emissão de fluorescência da oxi-HbGp com diferentes concentrações de DTAB na presença de ANS, com excitação em (A) 295 nm e (B) $350 \mathrm{~nm}$. (C) Gráficos das áreas correspondentes ao pico I em função da concentração de DTAB. (D) Gráficos das áreas correspondentes ao pico II com excitação em 295 nm e 350 nm em função da concentração de DTAB.

Figura 16: (A) Gráficos das intensidades de espalhamento de luz e do deslocamento do comprimento de onda do máximo de emissão de fluorescência em função da concentração de DTAB. (B) Gráficos das áreas referentes ao pico II normalizadas a partir da concentração de 0,0 mmol/L de DTAB. (C) Gráficos das áreas referentes ao pico I normalizadas a partir da concentração de $0,0 \mathrm{mmol} / \mathrm{L}$ de DTAB.

Figura 17: (A) Diâmetro hidrodinâmico (nm) para oxi-HbGp em função da concentração de DTAB. (B) Curvas de Distribuição de intensidade de espalhamento. (C) Curvas de distribuição do número de partículas.

Figura 18: (A) Espectros de absorção óptica da oxi-HbGp em diferentes concentrações de $\mathrm{GuHCl}$ e na presença de ANS. (B) Gráficos da absorbância na banda de Soret e do máximo de absorção desta banda, em função da concentração de $\mathrm{GuHCl}$

Figura 19: (A) Espectros de emissão de fluorescência da oxi-HbGp em diferentes concentrações de $\mathrm{GuHCl}$ e na presença de ANS. (B) Gráficos da área total de emissão de fluorescência e espalhamento (pico I) em função da concentração de GuHCl. (C) Gráficos da variação do comprimento de onda de emissão de fluorescência dos picos I e II em função da concentração de GuHCl. (D) Gráficos da intensidade de emissão de fluorescência do ANS em função da concentração de $\mathrm{GuHCl}$. 65

Figura 20: (A) Gráficos da área normalizada correspondente ao pico I e da (B) intensidade de emissão de fluorescência normalizada a partir da concentração de 0,0 mmol/L de GuHCl em função da concentração de desnaturante.

Figura 21: (A) Espectros de absorção óptica da oxi-HbGp em diferentes concentrações de ureia e na presença de ANS. (B) Gráficos da absorbância na banda de Soret e do comprimento de onda do máximo de absorção desta banda em função da concentração de ureia.

Figura 22: (A) Espectros de emissão de fluorescência da oxi-HbGp em diferentes concentrações de ureia e na presença de ANS. (B) Gráficos da área total (pico I) de 
emissão de fluorescência e espalhamento em função da concentração de ureia. (C) Gráficos da variação do comprimento de onda de emissão de fluorescência dos picos I e II em função da concentração de ureia. (D) Gráficos da intensidade de emissão de fluorescência a $480 \mathrm{~nm}$ em função da concentração de ureia 70

Figura 23: Gráficos (A) da área correspondente ao pico I e (B) da intensidade de emissão de fluorescência normalizados a partir da concentração de $0,0 \mathrm{mmol} / \mathrm{L}$ de ureia em função da concentração de desnaturante. 71

Figura 24: (A) Espectros de absorção óptica da oxi-HbGp em diferentes valores de pH e na presença de ANS. (B) e (C) Gráficos da absorbância na banda de Soret e da variação do comprimento de onda nessa banda em função dos valores de $\mathrm{pH}$........ 73

Figura 25: (A) Espectros de emissão de fluorescência da oxi-HbGp em diferentes valores de $\mathrm{pH}$. (B) Gráfico da área de emissão de fluorescência do pico I normalizada para o pH 7,03. (C) Gráfico de espalhamento de luz em diferentes valores de $\mathrm{pH}$. (D) Gráficos das áreas do pico II normalizadas para o $\mathrm{pH} 7,03 \ldots . . .74$

Figura 26: Espectros de absorção óptica de FITC pura (preto), oxi-HbGp pura (vermelho) e oxi-HbGp marcada com FITC nas razões de 1:5 (azul) e 2:1 (verde).. 85

Figura 27: Espectros de emissão de fluorescência de FITC pura e oxi-HbGp marcada com FITC nas proporções de 1:5 e 2:1 86

Figura 28: (A) Espectros de absorção óptica da oxi-HbGp marcada com FITC na presença de diferentes concentrações de DTAB. (B) Gráficos da absorbância em 700 nm e variação do comprimento de onda da banda de Soret em função da concentração de DTAB. 88

Figura 29: (A) Espectros de emissão de fluorescência da oxi-HbGp marcada com FITC na presença de diferentes concentrações de DTAB. (B) Gráficos das áreas normalizadas referentes ao pico I e pico II a partir da concentração de $0,0 \mathrm{mmol} / \mathrm{L}$ de DTAB. (C) Gráficos das intensidades de espalhamento de luz e do deslocamento do comprimento do máximo de emissão de fluorescência do pico I em função da concentração de DTAB. 89 


\section{LISTA DE TABELAS}

Tabela 1: Parâmetros espectroscópicos da sonda ANS, no $\mathrm{pH}$ 7,0, na presença de DTAB ..53 Tabela 2: Parâmetros espectroscópicos para oxi-HbGp, nos valores de $\mathrm{pH}$ 7,0 e 5,0, em DTAB.

Tabela 3: Parâmetros espectroscópicos para a sonda ANS, em pH 7,0, na presença da oxiHbGp e DTAB.

Tabela 4: Propriedades hidrodinâmicas da HbGp $(0,3 \mathrm{mg} / \mathrm{mL})$, em pH 7,0 e $20{ }^{\circ} \mathrm{C}$, em concentrações indicadas de DTAB, obtidas dos dados de DLS.

Tabela 5: Parâmetros espectroscópicos para oxi-HbGp, no pH 7,0, em GuHCl e ANS. 66

Tabela 6: Parâmetros espectroscópicos para a sonda ANS, em pH 7,0, na presença da oxiHbGp e GuHCl.

Tabela 7: Parâmetros espectroscópicos para oxi-HbGp, no $\mathrm{pH}$ 7,0, na presença de ureia e ANS.

Tabela 8: Parâmetros espectroscópicos para a sonda ANS, em pH 7,0, na presença da oxiHbGp e ureia.

Tabela 9: Parâmetros da fluorescência resolvida no tempo para a sonda 1,8-ANS $10 \mu \mathrm{mol} / \mathrm{L}$ em tampão fosfato $\mathrm{pH} 7,0$, em diferentes concentrações de DTAB. $\lambda$ ex $=370 \mathrm{~nm}$ e $\lambda \mathrm{em}=$ $475 \mathrm{~nm}$......

Tabela 10: Parâmetros da fluorescência resolvida no tempo para a sonda 1,8-ANS em diferentes concentrações, na presença da oxi-HbGp $(1,0 \mathrm{mg} / \mathrm{mL}) . \lambda$ ex $=370 \mathrm{~nm}$ e $\lambda$ em $=475$ $\mathrm{nm}$

Tabela 11: Parâmetros da fluorescência resolvida no tempo para oxi-HbGp $(1,0 \mathrm{mg} / \mathrm{mL})$ em diferentes concentrações da sonda 1,8-ANS . $\lambda \mathrm{ex}=280 \mathrm{~nm}$ e $\lambda \mathrm{em}=320 \mathrm{~nm}$

Tabela 12: Parâmetros de fluorescência resolvida no tempo da sonda ANS em tampão fosfato $30 \mathrm{mmol} / \mathrm{L}, \mathrm{pH} 7,0$, na presença de diferentes sistemas. $\lambda$ exc $=294 \mathrm{~nm}$ e $\lambda \mathrm{em}=470$ nm.

Tabela 13: Parâmetros de fluorescência resolvida no tempo da oxi-HbGp $(1,0 \mathrm{mg} / \mathrm{mL})$ em tampão fosfato $30 \mathrm{mmol} / \mathrm{L}$, em diferentes valores de $\mathrm{pH}$. $\lambda$ exc $=294 \mathrm{~nm}$ e $\lambda \mathrm{em}=340 \mathrm{~nm} . .81$

Tabela 14: Parâmetros de fluorescência resolvida no tempo da oxi-HbGp $(1.0 \mathrm{mg} / \mathrm{mL})$ em tampão fosfato $30 \mathrm{mmol} / \mathrm{L}, \mathrm{pH} 7,0$, na presença de diferentes sistemas. $\lambda$ exc $=294 \mathrm{~nm} \mathrm{e}$ $\lambda \mathrm{em}=340 \mathrm{~nm}$

Tabela 15: Quantidade de FITC efetivamente ligada a oxi-HbGp, por heme e por subunidade, nos valores de pH 7,0 e 9,0, estimada a partir das absorbâncias em $492 \mathrm{~nm}$ (FITC) e 415 nm (oxi-HbGp). Rendimento quântico (\%) da sonda ligada a oxi-HbGp ..... 87 


\section{LISTA DE ABREVIAÇÕES E SÍMBOLOS}

$\boldsymbol{a}$-Cadeia polipeptídica globínica (a) da hemoglobina de Glossoscolex paulistus.

$\boldsymbol{a b c}$ - Espécie trimérica da hemoglobina de Glossoscolex paulistus.

abcd - Subunidade tetramérica da hemoglobina de Glossoscolex paulistus.

$(\boldsymbol{a b c d})_{3}$ - Dodecâmero da hemoglobina de Glossoscolex paulistus.

1,8-ANS - 1-Anilino-8-naftaleno-sulfonato.

$\boldsymbol{b}$ - Cadeia polipeptídica globínica (b) da hemoglobina de Glossoscolex paulistus.

BSA - Albumina do soro bovino.

c - Cadeia polipeptídica globínica (c) da hemoglobina de Glossoscolex paulistus.

cmc - Concentração micelar crítica.

CTAC - Cloreto de cetiltrimetilamônio.

$\boldsymbol{d}$-Cadeia polipeptídica globínica (d) da hemoglobina de Glossoscolex paulistus.

DLS - Espalhamento dinâmico de luz do inglês "Dynamic light scattering"

DMSO - Dimetil sulfóxido.

DSC - Calorimetria diferencial de varredura do inglês " Differential scanning calorimetry".

DTAB - brometo de dodeciltrimetilamônio.

FITC - fluoresceína isotiocianato.

Fn - fibronectina.

HbAm - Hemoglobina do anelídeo Arenicola marina.

HbGp - Hemoglobina do anelídeo Glossoscolex paulistus.

HbLt - Hemoglobina do anelídeo Lumbricus terrestis.

HPS - N-hexadecil-N-N-dimetil-3-amônio-1-propano sulfonato.

$\mathrm{k}$ - Constante de Boltzman.

$\mathrm{k}_{\mathrm{F}}$ - Constante associada à fluorescência. 
$\mathrm{k}_{\mathrm{Q}}-$ Constante de supressão.

$\mathrm{k}_{\mathrm{IC}}-$ Constante associada a conversão interna.

$\mathrm{k}_{\mathrm{ISC}}-$ Constante relativa ao cruzamento intersistemas.

$\mathrm{k}_{\mathrm{ET}}-$ Constante devido a transferência de energia.

MALDI-TOF-MS - do inglês "Matrix assisted laser desorption time-of-flight mass spectrometry".

$M M$ - Massa molecular.

NADH - Nicotinamida adenina dinucleotídeo reduzido.

ns - nanosegundo.

$\eta$ - Viscosidade.

pI - Ponto isoelétrico.

ps - picosegundo.

$\mathrm{R}_{\mathrm{h}}-$ Raio hidrodinâmico.

SLS - Espalhamento estático de luz do inglês " Static Light Scattering”.

$\mathrm{T}-$ Temperatura absoluta.

$\tau-$ Tempo de vida.

TCSPC - Contagem de fóton único correlacionado no tempo do inglês " Time Correlated Single Photon Counting". 


\section{SUMÁRIO}

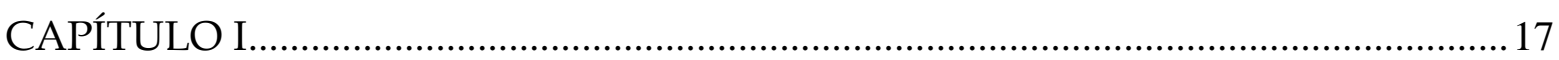

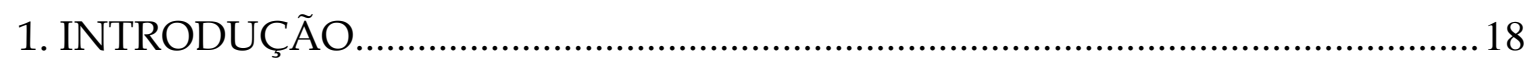

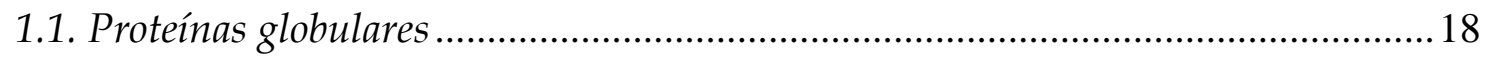

1.2. Hemoglobina extracelular de Glossoscolex paulistus (HbGp) ..............................20

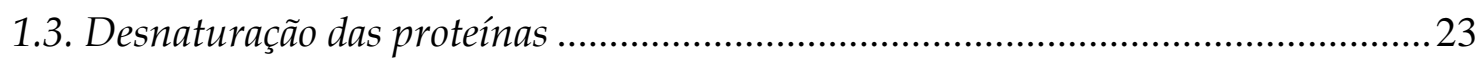

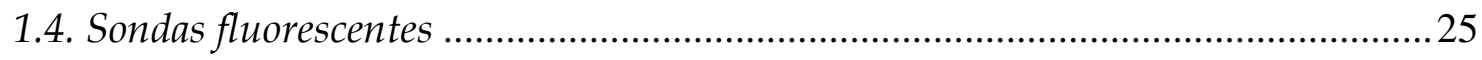

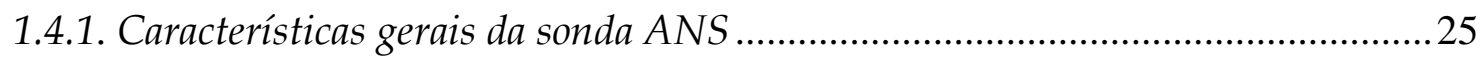

1.4.2. Características gerais da sonda Fluoresceína isotiocianato (FITC). ...................29

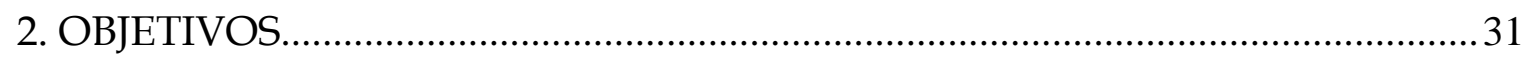

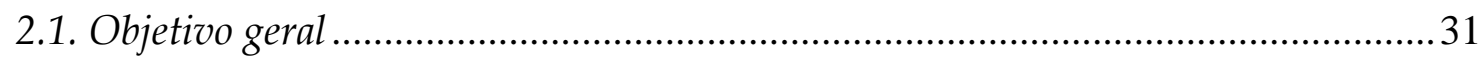

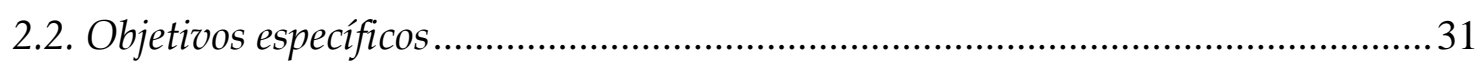

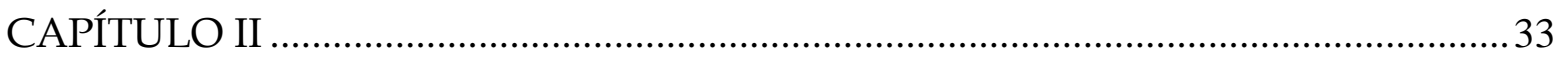

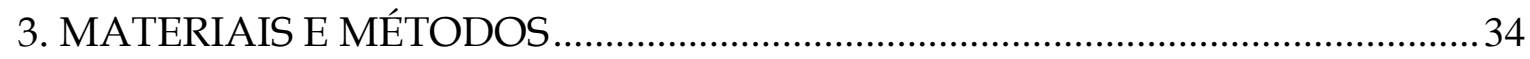

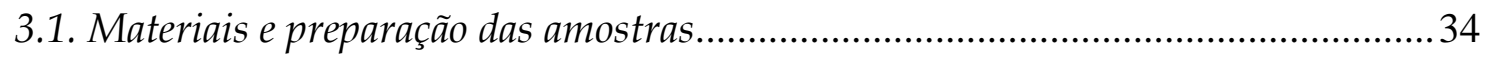

3.1.1. Obtenção e purificação da Hemoglobina de Glossoscolex paulistus ..................... 34

3.1.2. Preparação das amostras na presença e na ausência da sonda ANS.................... 35

3.1.3. Preparação das amostras da oxi-HbGp marcada com FITC.................................. 36

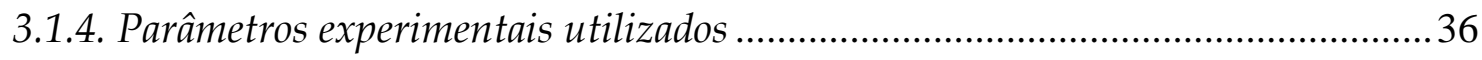

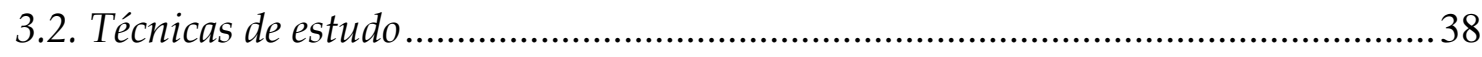

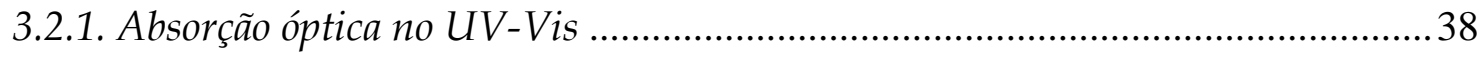

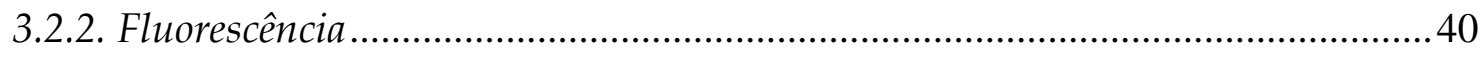

3.2.3. Espalhamento dinâmico de luz .................................................................... 44

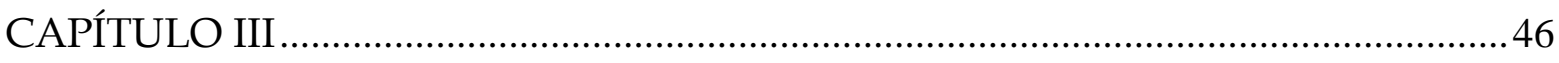

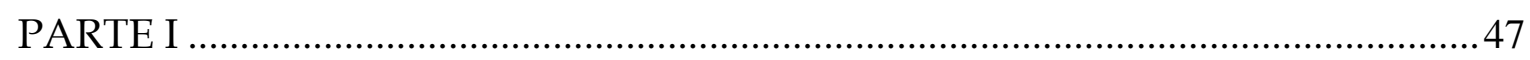




\subsection{ESTUDOS ESPECTROSCÓPICOS DA ESTABILIDADE DA OXI-HbGp} MONITORADOS PELA SONDA ANS.

4.1.1. Oxi-HbGp em concentrações diferentes de ANS. .48

4.1.2. Efeitos das diferentes concentrações de DTAB na sonda ANS, no $p H$ 7,0......50

4.1.2.1. Dados de absorção óptica. .50

4.1.2.2. Dados de emissão de fluorescência. .51

4.1.3. Efeitos do DTAB na estrutura oligomérica da oxi-HbGp, nos valores de $p H$ 7,0 e 5,0 .

4.1.3.1. Dados de absorção óptica 54

4.1.3.2. Dados de emissão de Fluorescência e espalhamento 56

4.1.4. Dados de DLS 61

4.1.5. Efeitos do Cloridrato de Guanidina (GuHCl) na estrutura oligomérica da oxi$\mathrm{HbGp}$, em $\mathrm{pH} 7,0$. 63

4.1.5.1. Dados de absorção óptica.. 63

4.1.5.2. Dados de emissão de fluorescência 64

4.1.6. Efeitos da ureia na estrutura da oxi-HbGp, em $p H$ 7,0. 68

4.1.6.1. Dados de absorção óptica 68

4.1.6.2. Dados de emissão de fluorescência 69

4.1.7. Oxi-HbGp em diferentes valores de $p H$, na presença da sonda ANS. .72

4.1.7.1. Dados de absorção óptica 72

4.1.7.2. Dados de emissão de fluorescência 73

4.1.8. Tempos de vida de diferentes concentrações da sonda ANS e da oxi-HbGp $(1,0$ $\mathrm{mg} / \mathrm{mL}$ ) na presença e na ausência de DTAB.

4.1.9. Medidas de tempos de vida realizadas em um espectrofluorímetro de alta resolução. .78

PARTE II 84

4.2. ESTUDO PRELIMINAR DA INTERAÇÃO DA FLUORESCEÍNA ISOTIOCIANATO (FITC) COM A OXI-HbGP. 
4.2.1. Oxi-HbGp marcada com FITC 85

4.2.1.1. Experimentos controle de absorção óptica e fluorescência 85

4.2.2. Oxi-HbGp marcada com FITC, na presença de DTAB. 87

4.2.2.1. Dados de absorção óptica e fluorescência 87

CAPÍTULO IV 90

5. Conclusões 91

5.1. Perspectivas... 93

6. REFERÊNCIAS BIBLIOGRÁFICAS. 94 
CAPÍTULO I

INTRODUÇÃO 


\section{INTRODUÇÃO}

\subsection{Proteinas globulares}

As proteínas são macromoléculas carregadas que podem se enovelar em estruturas compactas que são muito sensíveis às condições do ambiente químico em que se encontram. Neste contexto, destacam-se as proteínas globulares que são moléculas condensadas em forma esférica, devido ao enovelamento de diferentes segmentos de uma cadeia polipeptídica ou múltiplas cadeias polipeptídicas [1,2]. Essas proteínas desempenham as mais diversas funções entre elas catálise enzimática, sendo que a maior parte das reações químicas que ocorrem nos sistemas biológicos é catalisada por macromoléculas específicas denominadas enzimas, e proteção imunitária, desempenhada em sua maioria pelas imunoglobulinas também conhecidas por anticorpos. Essas proteínas ligam-se a bactérias, vírus ou corpos identificados como estranhos, e os marcam para serem eliminados [2,3]. Vale destacar dentre as funções dessas macromoléculas, a de transporte, uma vez que muitas moléculas pequenas são transportadas por proteínas específicas. Por exemplo, a hemoglobina, que está presente nas hemácias (no caso dos cordados), transporta oxigênio dos pulmões, das brânquias ou da pele dos animais para os capilares para ser utilizado na respiração [1]. A mioglobina que está localizada no músculo facilita o transporte de oxigênio dentro do músculo [3]. Tanto a hemoglobina como a mioglobina são moléculas consideradas carreadoras de oxigênio e pertencem a classe das hemoproteínas.

As hemoproteínas são caracterizadas por apresentarem cadeias polipeptídicas, e um grupo cromóforo, não peptídico, denominado grupo heme. Esse grupo encontra-se no interior da macromolécula, isto é, num bolsão hidrofóbico da proteína, e sua estrutura é composta por um átomo de ferro ligado a quatro anéis pirrólicos coplanares, ligados entre si, por pontes metênicas [3]. O átomo de ferro é responsável pela coloração marrom avermelhada característica das hemoproteínas em solução aquosa [1].

O átomo de ferro do grupo heme possui seis coordenações possíveis como mostra a Figura 1, onde quatro são ocupadas pelos átomos de nitrogênio localizados no centro do anel protoporfirínico. A quinta coordenação é ocupada pela histidina proximal, que serve como ponto de fixação do grupo heme à cadeia polipeptídica da proteína, e a sexta coordenação 
encontra-se livre para ser coordenada por um ligante [3]. Quando o ligante é a molécula de oxigênio $\left(\mathrm{O}_{2}\right)$ a hemoproteína está no estado nativo, encontrando-se na forma "oxi”, enquanto que se a sexta coordenação permanecer vazia tem-se a forma "desoxi”. Por outro lado, se a molécula de água atuar como ligante obtém-se a forma "meta ou aquometa" e quando o íon cianeto $\left(\mathrm{CN}^{-}\right)$estiver ocupando a sexta posição de coordenação tem-se a forma "cianometa".

Figura 1: Estrutura da hemoglobina humana (A) e estrutura do grupo heme (B) (figura adaptada da referência [1]).

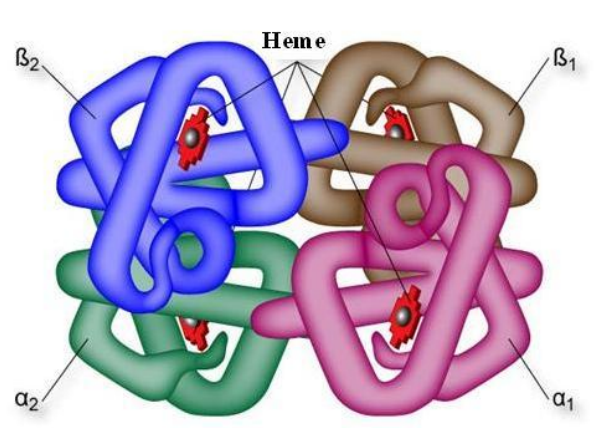

(A)

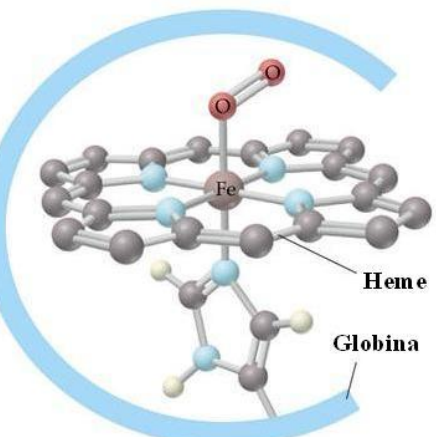

(B)

Fonte: Voet, D.; Voet, J.G. Bioquímica. Porto Alegre. Artemed, 2006. Tradução de A.B.G. da Veiga. et all. $3^{\mathrm{a}}$ ed.1616 p.

Como discutido por Ren e colaboradores [4] as hemoglobinas são as proteínas mais especializadas existentes na natureza, responsáveis pelo transporte de oxigênio molecular em vertebrados e em invertebrados. Dentro deste contexto, destacam-se as hemoglobinas extracelulares gigantes de diversas espécies, como a hemoglobina de Glossoscolex paulistus (HbGp), Lumbricus terrestris (HbLt) e Arenicola marina (HbAm) .

Convém mencionar, que além de possuir alta estabilidade oligomérica e resistência à oxidação, estas hemoglobinas são altamente cooperativas e auto-organizáveis, como demonstram estudos de reassociação [5,6]. Em vista disso, esta classe de hemoglobinas vem sendo amplamente estudada, uma vez que tem sido considerada como modelo para desenvolver substitutos sanguíneos [7]. 


\subsection{Hemoglobina extracelular de Glossoscolex paulistus (HbGp)}

A hemoglobina de Glossoscolex paulistus (HbGp), apresenta uma massa molecular $(M M)$ de $3.600 \mathrm{kDa}$, determinada por ultracentrifugação analítica [8], sendo este valor semelhante ao encontrado para outras hemoglobinas extracelulares. Além disso, estudos físico-químicos e cristalográficos apontam que a $\mathrm{HbGp}$, HbLt e $\mathrm{HbAm}$ têm cadeias polipeptídicas e estruturas oligoméricas bastante similares [9-13].

Essa proteína possui uma elevada semelhança estrutural com a HbLt, uma vez que apresenta uma disposição consideravelmente organizada envolvendo 144 cadeias polipeptídicas com grupo heme e 36 cadeias polipeptídicas sem grupos heme $[14,15]$. A estrutura oligomérica da HbGp é constituída de dois discos hexagonais, que formam uma espécie de bicamada hexagonal, e a dissociação dessa estrutura origina a formação de doze unidades de massa molecular $1 / 12$ da molécula íntegra [16,17]. No que diz respeito a essas estruturas, são compostas por quatro subunidades que contém o grupo heme, as globinas, nomeadas de cadeias $\boldsymbol{a}, \boldsymbol{b}, \boldsymbol{c}$ e $\boldsymbol{d}$, onde $\boldsymbol{a}, \boldsymbol{b}$ e $\boldsymbol{c}$ estão ligadas por ligações dissulfeto formando um heterotrímero $(\boldsymbol{a b c})$ e a subunidade $\boldsymbol{d}$ mantém-se por ligação não covalente (Fig. 2D, [11,18] ). A HbGp também possui três cadeias polipeptídicas díspares que não têm grupo heme, denominadas de linkers ( $\boldsymbol{L}$, Fig. 2B). Provavelmente, a função das subunidades linkers está relacionada com a manutenção da estrutura íntegra na forma de bicamada hexagonal [1417].

Outra analogia pertinente da HbGp com a HbLt baseia-se em estudos de microscopia eletrônica onde a presença de estruturas hexagonais, em $\mathrm{pH}$ 7,3 correspondentes à proteína nativa, e a sua ausência em pH 8,6, foi evidenciada [19]. Através de estudos envolvendo a técnica de MALDI-TOF-MS foi possível obter informação detalhada sobre as massas moleculares de algumas subunidades [9]. Observou-se que o monômero $\boldsymbol{d}$ possui massa molecular em torno de $16 \mathrm{kDa}$, o trímero $\boldsymbol{a b c}$ apresenta MM de $52 \mathrm{kDa}$ e as cadeias linkers são observadas com massa molecular na faixa de 26-32 kDa [9]. Além disso, duas isoformas majoritárias do monômero $\boldsymbol{d}\left(\boldsymbol{d}_{\boldsymbol{1}}\right.$ e $\left.\boldsymbol{d}_{2}\right)$ de proporções idênticas com massas de 16,355 \pm 25 e $16,428 \pm 24 \mathrm{Da}$, respectivamente, e duas isoformas menores $\left(\boldsymbol{d}_{\mathbf{3}}\right.$ e $\left.\boldsymbol{d}_{\mathbf{4}}\right)$ com massas em torno de $16,6 \mathrm{kDa}$ foram caracterizadas. 
Figura 2: Representação esquemática da hierarquia da estrutura oligomérica da $\mathrm{HbGp}$, obtida por estudos cristalográficos. A estrutura da HbGp íntegra (A) é composta por doze protômeros (B), cada um deles contendo uma estrutura dodecamérica de globinas, e três subunidades sem grupo heme (linkers), $(\boldsymbol{a} b \boldsymbol{c} \boldsymbol{d})_{3} \boldsymbol{L}_{3}$. A estrutura dodecamérica (C) é composta por quatro tipos de cadeias de globina: $\boldsymbol{a}, \boldsymbol{b}, \boldsymbol{c}$ e $\boldsymbol{d}$. As quatro cadeias globinas estão associados como um hetero-tetrâmero (D), onde $\boldsymbol{a}, \boldsymbol{b}$, e $\boldsymbol{c}$ formam um trímero, com os monômeros ligados por ligações dissulfeto [18].
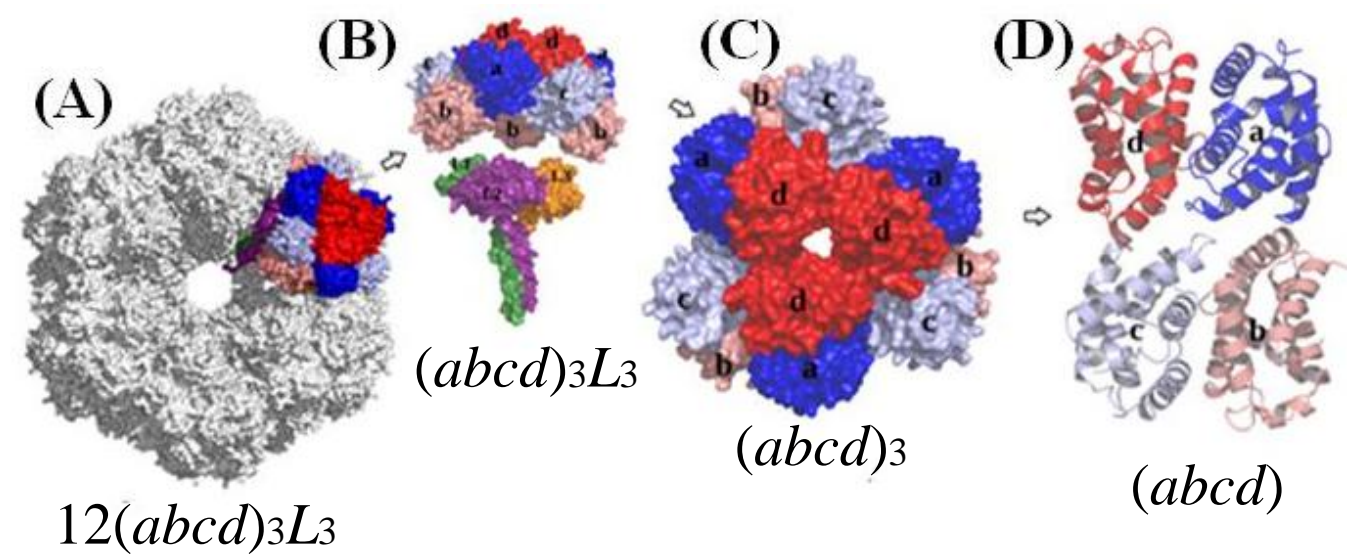

Fonte: TABAK, M.; CARVALHO, F. A. O.; CARVALHO, J. W. P.; BACHEGA, J. F. R;. SANTIAGO, P.S. Recent new characterizations on the giant extracellular hemoglobin of Glossoscolex paulistus and some other giant hemoglobins from different worms. In: INNOCENTIN, A. (Ed.) Stoichiometry and research - the importance of quantity in Biomedicine. Rijeka, Croatia: In Tech, 2012. v.1, p.337-356.

Estudos espectroscópicos da $\mathrm{HbGp}$ na presença de surfactantes, realizados anteriormente, mostraram sua grande importância interdisciplinar, uma vez que os mesmos são largamente empregados em bioquímica e biotecnologia para a solubilização, purificação e caracterização proteicas [20].

Santiago e colaboradores [21] analisaram a interação da HbGp com o surfactante catiônico cloreto de cetiltrimetilamônio (CTAC) e o surfactante aniônico dodecil sulfato de sódio (SDS) por absorção óptica, fluorescência, espalhamento e dicroísmo . Alterações significativas, tais como, a redução no conteúdo de $\alpha$-hélice na estrutura da proteína, diminuição na intensidade da banda de Soret e formação da espécie meta-HbGp foram observadas. Além disso, observou-se que o CTAC interage fortemente com a HbGp levando a uma modificação na estrutura oligomérica que afeta a primeira esfera de coordenação, promovendo a oxidação do ferro. Cabe destacar que as mudanças como a dissociação oligomérica e oxidação do ferro do grupo heme foram observadas em baixas concentrações de CTAC, sendo provavelmente associadas a interações eletrostáticas. No entanto, essas mudanças foram verificadas em altas concentrações de SDS, quando comparadas às de CTAC, uma vez que nos valores de $\mathrm{pH}$ 7,0 e 9,0, o balanço das cargas na superfície da 
proteína é negativo e o SDS é um surfactante aniônico, ou seja, é bastante provável a existência de forças de repulsão eletrostática, nestes valores de $\mathrm{pH}$.

O efeito dos surfactantes CTAC e SDS na estrutura oligomérica da HbGp também foi estudado por MALDI-TOF-MS [22]. Os resultados deste trabalho mostraram uma interação efetiva de CTAC com as duas isoformas do monômero $\boldsymbol{d}, \boldsymbol{d}_{\boldsymbol{1}}$ e $\boldsymbol{d}_{\mathbf{2}}$. Foi verificado que até 10 moléculas de CTAC se ligam a cada isoforma do monômero. Por outro lado, o espectro de massas obtido para o sistema SDS-HbGp mostrou que a adição do SDS não origina qualquer incremento de massa da subunidade monomérica, indicando que a interação SDSHbGp é provavelmente menos efetiva quando comparada com a interação CTAC-HbGp. Em vista disso, o ponto isoelétrico ácido desta proteína em torno de 5,5, é, provavelmente, responsável por este comportamento.

Moreira e colaboradores [20] discutiram o efeito do surfactante zwiteriônico, Nhexadecil-N-N-dimetil-3-amônio-1-propano sulfonato (HPS), onde foi observado que a presença desse surfactante induz a dissociação da $\mathrm{HbGp}$, bem como, a sua auto-oxidação. No entanto, a interação do HPS com a proteína foi evidentemente menos intensa do que a interação com os surfactantes iônicos CTAC e SDS. Possivelmente, esta menor interação do HPS com a macromolécula pode ser atribuída a uma menor interação eletrostática entre o HPS e os sítios iônicos da HbGp, assim como ao baixo valor de cmc (concentração micelar crítica) do HPS em relação à dos outros dois surfactantes citados previamente.

Vale ressaltar que a HbGp vem sendo pesquisada há alguns anos através de técnicas espectroscópicas, calorimétricas e hidrodinâmicas no grupo de Biofísica Molecular. Entretanto, a adição de sondas espectroscópicas de fluorescência a este sistema é inédita em relação às pesquisas em andamento. Logo, o estudo da interação das sondas extrínsecas 1Anilino-8-naftaleno-sulfonato (ANS) e Fluoresceína isotiocianato (FITC) com a HbGp se torna relevante, visto que estudos anteriores de fluorescência da HbGp limitaram-se a observação da emissão dos triptofanos. Devido a forte supressão de fluorescência pelos grupos heme, esses experimentos foram bastante limitados uma vez que a fluorescência inicial intrínseca da proteína é bastante reduzida e vários fenômenos distintos, tais como, dissociação oligomérica e a maior exposição dos triptofanos ao solvente aquoso contribuem para o aumento acentuado de emissão de proteína. Portanto, a utilização dessas sondas de fluorescência possibilita obter uma melhor caracterização dos efeitos de agentes externos na estabilidade oligomérica da $\mathrm{HbGp}$, com o propósito de aprofundar os conhecimentos sobre a estrutura desta macromolécula. 


\subsection{Desnaturação das proteínas}

O processo de desnaturação das proteínas está associado à baixa estabilidade conformacional protéica e ocorre devido à alteração no balanço das forças fracas (de natureza não covalente) que mantém a conformação nativa [1]. Perturbações no ambiente em que a proteína se encontra podem induzir as alterações estruturais que afetam a sua função.

Uma proteína pode estar no estado nativo $(\mathrm{N})$, em que desempenha a função para a qual foi produzida, ou no estado desnaturado (D), onde, a proteína perde sua estrutura tridimensional ocasionando a perda de função [2]. Porém, uma vez desnaturada, continua sendo uma fonte de aminoácidos, que podem ser usados no catabolismo energético e em vários processos de biossíntese dos organismos [23].

A maioria das proteínas pode ser desnaturada através do aumento de temperatura, logo, as propriedades como atividade óptica, viscosidade e absorção no UV-VIS mudam bruscamente [1]. Além disso, as proteínas são também desnaturadas por variações nos valores de $\mathrm{pH}$, o que altera a carga líquida da proteína causando rompimento de algumas ligações de hidrogênio e repulsão eletrostática, e por agentes caotrópicos como ureia, cloridrato de guanidina, entre outros, que atuam interferindo nas interações hidrofóbicas que estabilizam as proteínas globulares [2].

Alguns trabalhos recentes têm reportado o processo de desnaturação da $\mathrm{HbGp}$, provocado por diferentes agentes desnaturantes. Foi observado através dos estudos com variação de temperatura usando a técnica de espalhamento dinâmico de luz (DLS) que a $\mathrm{HbGp}$, no pH 7,0 e acima de $52^{\circ} \mathrm{C}$, desnatura-se aumentando o tamanho da partícula, de 27 $\mathrm{nm}$ para $65 \mathrm{~nm}$ [24]. Além disso, estudos por calorimetria diferencial de varredura (DSC) mostraram que a oxi-HbGp, no $\mathrm{pH} 7,0$, apresenta temperatura crítica de desnaturação de $60^{\circ} \mathrm{C}$ com uma única transição, enquanto que, no pH 8,0, a oxi-HbGp exibe termograma com duas transições, em 50 e $58^{\circ} \mathrm{C}$ [24,25]. No entanto, no meio ácido, a oxi-HbGp é consideravelmente mais estável sofrendo desnaturação térmica acima de $65^{\circ} \mathrm{C}$ [26].

Resultados adicionais discutidos por Carvalho e colaboradores [27], e obtidos através da espectroscopia de fluorescência, mostraram que a adição de ureia ao sistema leva à dissociação e desnaturação da oxi-HbGp, cianometa-HbGp e meta-HbGp. O aumento na concentração de ureia, acima de 4,0 mol/L, induz a oxidação do ferro na forma oxi-HbGp e à 
formação de espécies oxidadas. Através de estudos de dicroísmo circular foi verificada a perda nas estruturas secundária e terciária da proteína devido ao processo de desnaturação.

No presente trabalho foi realizado o estudo da interação da $\mathrm{HbGp}$ com o agente desnaturante brometo de dodeciltrimetilamônio (DTAB), mostrado na Figura 3 abaixo, em várias faixas de concentração, e que forneceu informações significativas relacionadas ao arranjo estrutural dessa macromolécula. Vale ressaltar que o surfactante reduz a tensão superficial do líquido aumentando o contato entre o líquido e outras substâncias. Uma das mais importantes aplicações dos surfactantes é no estudo de desnaturação protéica [28].

Figura 3: Estrutura química do surfactante brometo de dodeciltrimetilamônio (DTAB) [29].

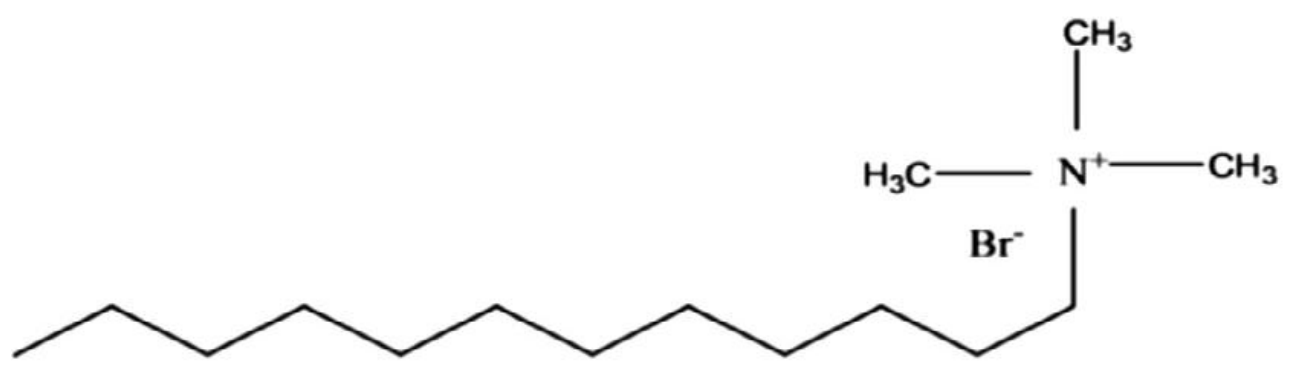

Fonte : CHAUHAN,S.; SHARMA Kundan. Effect of temperature and additives on the critical micelle concentration and thermodynamics of micelle formation of sodium dodecyl benzene sulfonate and dodecyltrimethylammonium bromide in aqueous solution: A conductometric study. J.Chem. Thermodynamics. V.71, p.205-211, 2014.

A desnaturação dessa proteína também foi investigada em relação aos agentes desnaturantes ureia e cloridrato de guanidina $(\mathrm{GuHCl})$, com o propósito de obter uma melhor compreensão sobre as forças que regulam a estabilidade e os mecanismos de enovelamento, tais como as ligações covalentes e iônicas, as ligações de hidrogênio, as interações hidrofóbicas e de Van der Waals.

Partindo desse pressuposto, estudos de dissociação e desnaturação da oxi-HbGp foram monitorados através da sonda 1,8-ANS, com variação nos valores de $\mathrm{pH}$ de solução, bem como, na presença e ausência dos agentes desnaturantes: DTAB, cloridrato de guanidina $(\mathrm{GuHCl})$ e ureia. 


\subsection{Sondas fluorescentes}

As sondas de fluorescência nos estudos de proteínas podem ser divididas em dois grupos diferentes denominados de sondas intrínsecas (existentes nas macromoléculas) e extrínsecas (acrescentadas ao sistema). Estes compostos são também denominados de fluoróforos ou corantes fluorescentes, possuem sistemas conjugados e /ou aromáticos e uma significativa emissão de fluorescência.

No caso das proteínas, existem somente três fluoróforos intrínsecos: triptofano, tirosina e fenilalanina. No entanto, pode-se dizer que o triptofano é responsável por noventa por cento do total de fluorescência uma vez que, a fenilalanina possui um rendimento quântico baixo e a emissão da tirosina é muito inferior devido ao efeito de supressão por grupos químicos vizinhos ou transferência de energia para o triptofano. O grupo indol do triptofano é o cromóforo, responsável pela emissão de fluorescência [30].

Além disso, o triptofano é um fluoróforo altamente sensível à polaridade de sua vizinhança, sendo assim, a finalidade de estudar a fluorescência intrínseca de proteínas é obter informações sobre sua conformação, uma vez que essa técnica depende fortemente do ambiente em que os fluoróforos estão expostos [30]. Quanto aos fluoróforos extrínsecos eles frequentemente exibem propriedades espectroscópicas que também dependem do ambiente químico em que se encontram, e que, consequentemente, revelam informações importantes sobre o sistema em estudo [30]. Por isso, ambas as sondas têm sido utilizadas em numerosas aplicações no estudo de caracterização de proteínas, tais como: monitorar os processos de enovelamento e desenovelamento; detectar intermediários "molten globule"; monitorar mudanças conformacionais induzidas por degradação química; caracterizar interações proteína-surfactante, etc [31].

\subsubsection{Características gerais da sonda ANS}

A sonda ANS é uma das sondas fluorescentes extrínsecas não covalentes muito utilizadas em estudos de proteína, possuindo um baixo rendimento quântico de fluorescência 
em ambientes polares, mas que é aumentado significativamente na ligação com muitas proteínas [32-34]. Essa ligação ocorre através da formação do par de íons entre o grupo sulfonato do ANS e as cadeias laterais de arginina, lisina e histidina, todos os aminoácidos carregados positivamente $[31,35]$.

Estudos mostram que o espectro de fluorescência dessa sonda em solução depende fortemente da natureza do solvente, especialmente da sua polaridade. Portanto, o aumento no momento de dipolo altera a interação do cromóforo com as moléculas vizinhas levando a uma diminuição de energia do estado excitado [31,36]. Sendo assim, o momento de dipolo das moléculas de ANS no estado excitado é maior do que no estado fundamental. Reorientação e translação das moléculas próximas à sonda permitem que as moléculas do ANS relaxem gradualmente para o equilíbrio no estado excitado. Em soluções de baixa viscosidade, onde estas relaxações são mais rápidas, praticamente todas as moléculas de ANS alcançam o estado fundamental antes da emissão do fóton. Entretanto, em soluções de maior viscosidade, as relaxações das moléculas de ANS são mais lentas, devido à baixa mobilidade e, consequentemente, o tempo requerido da relaxação para o equilíbrio do estado excitado é comparável ou mesmo maior do que o tempo de vida no estado excitado. Neste caso, muitas moléculas de ANS emitirão o fóton antes de atingir o equilíbrio do estado excitado [36].

Como discutido por Parul e colaboradores [37] o rendimento quântico de fluorescência e o tempo de vida no estado excitado do 1,8-ANS são bem conhecidos por serem altamente dependentes do solvente. O tempo de vida varia de aproximadamente $200 \mathrm{ps}$ em meio aquoso para $7 \mathrm{~ns}$ em metanol e $11 \mathrm{~ns}$ em etanol, ao passo que em solventes não polares varia a partir de aproximadamente $3,5 \mathrm{~ns}$ em etilbenzeno para 12-14 ns em dioxano.

Vale ressaltar que o rendimento quântico do 1,8-ANS em água é igual a 0,004 [ 32 ], e por ser um valor extremamente baixo, essa condição limita a obtenção do tempo de vida do ANS em meio aquoso por equipamentos de baixa resolução. Porém, a interação de sonda com os grupos hidrofóbicos da proteína resulta em um aumento considerável na intensidade de fluorescência [38]. Por isso, o rendimento quântico encontrado por Stryer da sonda ligada a apomioglobina foi 0,98 , um valor que aumentou 245 vezes em comparação ao valor obtido da molécula 1,8-ANS em água [38].

Esta sonda é altamente sensível ao ambiente, o que pode ser comprovado através de resultados de tempos de vida de fluorescência [30]. Este estudo foi realizado com a proteína albumina de soro bovino (BSA), que foi progressivamente saturada, através da ligação com 
muitas moléculas de ANS. Os valores de tempos de vida mais longos foram encontrados para as duas primeiras moléculas ligadas de ANS. Com o aumento de quantidade de ANS ligado, o tempo de decaimento diminui. Estes resultados foram interpretados como sendo devido ao ANS ligar-se a sítios menos protegidos do solvente proporcionando um ambiente mais polar para a sonda [30].

Cabe mencionar que o decaimento de fluorescência da molécula 1,8-ANS livre em solução aquosa é descrito por um processo mono-exponencial. Entretanto a interação dessa sonda com proteínas, por exemplo, em solução, resulta em um decaimento bi-exponencial ou multi-exponencial [ 38 ].

Syakkovich e colaboradores [39] mostraram que a oxi-hemoglobina apresenta dois tipos de sítios de ligação para o ANS. O primeiro foi caracterizado por um tempo de vida de fluorescência em torno de 3,1 - 5,5 ns, atribuído à sonda ligada na superfície da proteína, enquanto que o segundo tempo de vida de 12,4 - 15,1 ns, está associado à interação do ANS no interior hidrofóbico da hemoglobina nativa não dissociada [37,39].

Stryer [32] observou a especificidade dessa sonda para regiões hidrofóbicas de interesse funcional na superfície macromolecular. Observou-se que essa sonda liga-se estequiometricamente a sítios específicos da apomioglobina e apohemoglobina, seguido por um aumento na intensidade de fluorescência e um deslocamento do comprimento do máximo de emissão para o azul. Vários estudos têm mostrado que a sonda ANS é eficiente para caracterizar apo-globinas.

Além disso, muitos trabalhos que têm por finalidade estudar a interação e o comportamento dessa sonda em relação às proteínas buscam determinar os valores de constantes de ligação, medir a distância entre triptofanos e a sonda, obter informações das mudanças conformacionais das proteínas, e na sua maioria, observam o fenômeno de transferência de energia envolvendo os triptofanos. Nesses estudos, verifica-se, simultaneamente uma redução na intensidade de fluorescência da proteína e um aumento na intensidade de fluorescência da sonda. Este fenômeno de transferência de energia é evidenciado quando as amostras são excitadas em comprimentos de onda entre 275 e $295 \mathrm{~nm}$ [40,41].

Outra característica importante desta sonda é que ela possui isômeros estruturais, destacando-se dois no estudo com proteínas, o 2,6-ANS e o 1,8-ANS com diferentes intensidades de fluorescência. A molécula do isômero 2,6-ANS possui uma estrutura 
coplanar, maior intensidade de fluorescência com o máximo de emissão em $460 \mathrm{~nm}$. Por outro lado, o isômero 1,8-ANS não é coplanar e apresenta uma menor intensidade de fluorescência com o máximo centrado em $520 \mathrm{~nm}[36,42,43]$. Vale destacar que o isômero utilizado neste trabalho é 1,8-ANS.

Figura 4: Estruturas químicas das sondas 2,6-ANS (I) e 1,8-ANS (II) [42].

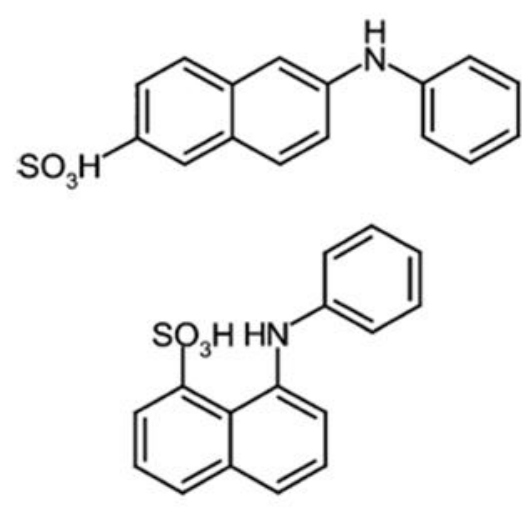

Fonte: SOMEYA, Y.; YUI, HIROHARU. Fluorescence Lifetime Probe for Solvent Microviscosity Utilizing Anilinonaphthalene Sulfonate. Anal. Chem. V. 82, p. 5470-5476, 2010.

A partir desses dois isômeros mostrados na Figura acima, Someya e Yui [42] investigaram a correlação existente entre a dinâmica do ANS no estado excitado e a microviscosidade das moléculas do solvente em torno da sonda, através de fluorescência resolvida no tempo. Os solventes utilizados foram à água e o glicerol. Através das curvas de decaimento de fluorescência verificou-se que os tempos de vida de 1,8-ANS foram gradualmente maiores com o aumento de glicerol.

De modo geral, o estudo da interação do ANS com proteínas foi iniciado há cinquenta anos, aproximadamente [34]. Mais recentemente, constata-se que esta sonda tem sido uma ferramenta informativa bastante utilizada para acompanhar estudos de caracterização de proteínas dentre outras aplicações. Por isso, ela foi escolhida neste trabalho para monitorar alterações na estabilidade da oxi-HbGp através de técnicas espectroscópicas e hidrodinâmica. 


\subsubsection{Características gerais da sonda Fluoresceína isotiocianato (FITC).}

Atualmente os derivados do corante fluoresceína são muito utilizados como sonda covalente, pois, apresentam rendimento quântico elevado e uma boa solubilidade em água. Um dos mais utilizados é a fluoresceína isotiocianato (FITC), que pode se ligar covalentemente às macromoléculas, e tem como característica primordial, a dependência da emissão de fluorescência do pH [ 44, 45]. Os sítios de ligação para FITC são principalmente o grupo amino do aminoácido lisina e o N-terminal da proteína [46].

A Fluorescência de FITC é altamente afetada pelo microambiente. Em solução, FITC ocorre nas formas carregadas (catiônica, aniônica e dianiônica) e neutra, em função da concentração de prótons do meio. Os vários estados de FITC mostram diferentes espectros de fluorescência e intensidades [47]. Além disso, a fluorescência da fluoresceína é tipicamente suprimida quando conjugada a biopolímeros [45,47]. O rendimento quântico de fluorescência de FITC ligada varia de 15 a 55 \% comparado com a FITC não ligada, e os tempos de vida são menores exibindo curvas de decaimento multi-exponencial. Isto pode ser explicado através da heterogeneidade fotofísica dos sítios de ligação [47].

Figura 5: Estrutura química da fluoresceína isotiocianato (FITC) [48].

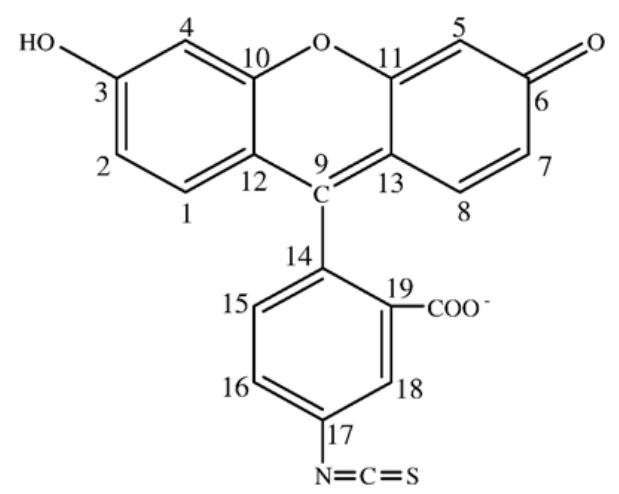

Fonte: HUANG, C.; ZHANG, K.; CI, Y. Sensitization of surfactants on the chemiluminescence reaction of fluorescein isothiocyanate labeled proteins. J. Biochem.Biophys. Methods. V.70, p. 341-347,2007.

FITC em solução absorve intensamente em torno de $480 \mathrm{~nm}$ e exibe um máximo de emissão centrado em $520 \mathrm{~nm}$, com comprimento de onda de excitação de $495 \mathrm{~nm}$. Vale destacar que as propriedades de fluorescência deste fluoróforo não são essencialmente alteradas quando conjugadas a proteínas [49]. Além disso, FITC exibe uma sobreposição considerável entre os espectros de absorção e de emissão e uma distância de transferência de energia variando de 42 a 56 angstroms. Isto a torna uma sonda comumente usada para medir 
distâncias entre resíduos de proteínas e estudar mudanças conformacionais, utilizando o mecanismo de transferência de energia de Forster [50].

Diante disso, Georgieva e colaboradores [51] discutiram propriedades espectroscópicas da enzima subtilisina DY marcada no aminoácido alanina por fluoresceína isotiocianato. As medidas de fluorescência demonstraram que $30 \%$ da luz absorvida pelos grupos fenólicos é transferida para a sonda FITC quando as amostras foram excitadas em 280 nm. Este processo é possível porque existe uma sobreposição dos espectros de emissão do doador (grupos fenólicos) e os espectros de absorção do aceptor (grupo fluoresceína). De acordo com a teoria de Forster, a eficiência da transferência de energia depende da distância entre os cromóforos, da orientação no espaço dos momentos de dipolo, do índice de refração do meio, da sobreposição dos espectros de absorção e emissão, e do rendimento quântico de fluorescência do doador [51].

Hungerford e colaboradores [50] estudaram o efeito da razão de marcação em diferentes proporções na fotofísica da fluoresceína isotiocianato conjugada com a Albumina do Soro Bovino (BSA) através de várias técnicas espectroscópicas. Os resultados mostraram deslocamento nos picos de absorção e emissão do FITC ligado a BSA para comprimentos de onda maiores, indicando mudanças no ambiente local. Além disso, foi verificado que quanto maior a proporção de marcação (FITC: BSA) menor foi o valor encontrado para a anisotropia de fluorescência, sugerindo transferência de energia. Vale ressaltar a evidência clara de interação entre as moléculas de sonda, na razão de marcação 3: 1 (FITC: BSA).

Com o propósito de observar as causas da reação de marcação da fibronectina (Fn) do plasma humano com FITC, Hoffmann et al [ 52 ] avaliou essa reação a partir de várias proporções de marcação diferentes de FITC: Fn. Neste estudo, a sonda foi utilizada para fornecer informações sobre a relação dinâmica existente entre fibronectina e as células. A fibronectina é uma glicoproteína de grande peso molecular $(550 \mathrm{KDa})$ e uma das maiores proteínas de adesão celular. Os dados espectroscópicos indicaram que a FITC ligada à proteína não induz desenovelamento na estrutura da Fn em nenhuma proporção de marcação. Além disso, foi constatado que acima de 10 moléculas de FITC para cada fibronectina, a fluorescência da sonda é suprimida, bem como, ocorre agregação da proteína.

Tendo em vista que as alterações causadas pela reação de marcação da Fluoresceína isotiocianato não induzem o desenovelamento de proteínas, este método se torna uma poderosa ferramenta para os estudos de mudanças conformacionais de proteínas, desde que as proporções de marcação sejam escolhidas adequadamente. 


\section{OBJETIVOS}

\subsection{Objetivo geral}

O presente projeto de mestrado propõe o estudo da estabilidade da proteína nativa frente aos processos de dissociação oligomérica e desnaturação da $\mathrm{HbGp}$ em diferentes condições experimentais. Mudanças nos valores de $\mathrm{pH}$, bem como a presença de surfactante e agentes caotrópicos (ureia e cloridrato de guanidina), serão utilizados como agentes externos indutores das alterações da proteína. Estes estudos serão realizados na presença de duas sondas fluorescentes 1-Anilino-8-naftaleno-sulfonato (1-8-ANS) e fluoresceína isotiocianato (FITC). Estudos na literatura mostram que ambas as sondas são sensíveis a mudanças estruturais de proteínas [34,50]. Assim, os processos de dissociação oligomérica, desnaturação e agregação da HbGp na presença destes agentes poderão ser monitorados.

Considerando que a dissociação alcalina leva à formação de subunidades menores em solução, o presente projeto tem por objetivo avaliar também o efeito desta dissociação na estrutura terciária das partículas em solução e tentar esclarecer quais são as subunidades mais estáveis neste processo de dissociação. Além disso, o presente estudo pretende verificar o efeito do surfactante dodecil trimetilamônio (DTAB), na dissociação da macroproteína, o que deverá contribuir para uma compreensão mais aprofundada a nível molecular das interações entre as subunidades responsáveis pela manutenção da estrutura oligomérica da macromolécula. As sondas espectroscópicas deverão monitorar as alterações da proteína através das mudanças espectrais.

\subsection{Objetivos específicos}

1) Estudar o processo de dissociação e desnaturação da oxi-HbGp $(0,1 \mathrm{mg} / \mathrm{mL})$ na presença da sonda ANS em diferentes valores de $\mathrm{pH}$ monitorados pelas técnicas de absorção 
óptica, espalhamento de luz no fluorímetro, emissão de fluorescência estática e resolvida no tempo;

2) Avaliar os efeitos dos agentes desnaturantes DTAB, ureia e cloridrato de guanidina $(\mathrm{GuHCl})$ na estabilidade oligomérica da hemoglobina de Glossoscolex paulistus (oxi-HbGp, 0,1 $\mathrm{mg} / \mathrm{mL}$ ), monitorados por ANS através de espectroscopias UV-vis, emissão de fluorescência e espalhamento de luz no fluorímetro, a $25^{\circ} \mathrm{C}$. Os experimentos com ureia e $\mathrm{GuHCl}$ serão realizados no $\mathrm{pH} 7,0$, enquanto que as medidas com DTAB serão feitas nos valores de $\mathrm{pH}$ 5,0 e 7,0.

3) Modificar a oxi-HbGp na concentração 3,0 mg/mL, em 2 valores de $\mathrm{pH}, 7,0$, e 9,0, com a sonda de fluorescência fluoresceína isotiocianato (FITC).

4) Estudar por absorção óptica e fluorescência, a $25^{\circ} \mathrm{C}$, a oxi-HbGp modificada no sentido de verificar o grau de modificação bem como as condições ótimas de reação sondaproteína.

5) Estudar a dissociação e desnaturação da oxi-HbGp modificada com FITC, na presença do surfactante DTAB, na faixa de concentração adequada, por absorção ótica e fluorescência, a $25^{\circ} \mathrm{C}$. 


\section{CAPÍTULO II}

MATERIAIS E MÉTODOS 


\section{MATERIAIS E MÉTODOS}

\subsection{Materiais e preparação das amostras}

\subsubsection{Obtenção e purificação da Hemoglobina de Glossoscolex paulistus}

A hemoglobina extracelular de Glossoscolex paulistus foi extraída do anelídeo Glossoscolex paulistus pertencente ao filo Anelidae, à classe Oligochaeta e à família Glossoscolecidae. Cada animal apresenta um comprimento que varia entre 280 a $305 \mathrm{~mm}$, um diâmetro de 10 a $11 \mathrm{~mm}$, e massa aproximada de $15 \mathrm{~g}$, sendo encontrado no interior de São Paulo, na região de Rio Claro e Piracicaba.

Figura 6: Anelídeo Glossoscolex paulistus após ter sido anestesiado em atmosfera de éter etílico.

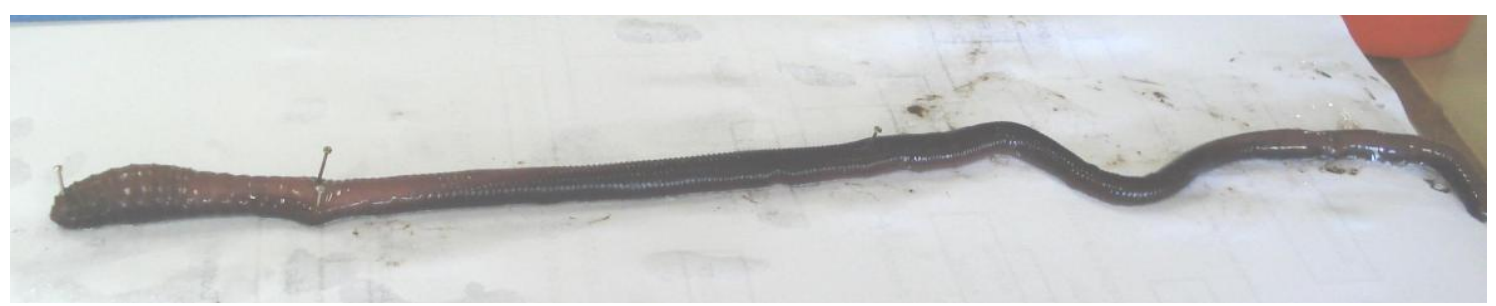

Durante a extração da hemolinfa foi feito um corte no dorso do animal anestesiado em atmosfera de éter etílico, a fim de coletar a hemolinfa. Em seguida, a mesma foi mantida em tampão Tris- $\mathrm{HCl}$, contendo o anticoagulante citrato de sódio $0,1 \mathrm{~mol} / \mathrm{L}, \mathrm{pH}$ 7,0, à temperatura de $4{ }^{\circ} \mathrm{C}$. Posteriormente, a amostra foi centrifugada a $5.000 \mathrm{rpm}$ por $15 \mathrm{~min}$ a $4{ }^{\circ} \mathrm{C}$ para eliminar as impurezas, e ultrafiltrada em uma membrana de corte $30 \mathrm{kDa}$ por $24 \mathrm{~h}$ contra Tris- $\mathrm{HCl} 0.1 \mathrm{~mol} / \mathrm{L}$, pH 7,0 [53]. Na sequência, uma etapa de ultracentrifugação a $50.000 \mathrm{rpm}$ por $3,5 \mathrm{~h}$ a $4{ }^{\circ} \mathrm{C}$ foi realizada para eliminar contaminantes proteicos de peso molecular baixo presentes no sobrenadante. Nesta etapa, obtém-se a hemoglobina pura na forma de pellet no fundo do tubo. A hemoglobina precipitada foi solubilizada em tampão idêntico ao utilizado na diálise. A etapa final de purificação da proteína constituiu da aplicação de 1,0 mL desta solução ressuspendida, após a ultracentrifugação, numa coluna de filtração de gel Sephadex G-200 de $100 \mathrm{~cm}$ de comprimento por 1,0 cm de diâmetro equilibrada com tampão Tris-HCl $0,1 \mathrm{~mol} / \mathrm{L}$, no $\mathrm{pH}$ 7,0. As concentrações das frações coletadas foram determinadas 
espectrofotometricamente (Shimadzu 1601P) utilizando o coeficiente de extinção molar da oxi-HbGp $\varepsilon_{415 \mathrm{~nm}}=5,5 \pm 0,8(\mathrm{mg} / \mathrm{mL})^{-1} \cdot \mathrm{cm}^{-1}[53]$.

\subsubsection{Preparação das amostras na presença e na ausência da sonda ANS}

Inicialmente foram preparadas amostras da oxi-HbGp numa concentração fixa de 0,1 $\mathrm{mg} / \mathrm{mL}$, na presença da sonda ANS na faixa de concentração de 2 a $10 \mu \mathrm{mol} / \mathrm{L}$ com um volume final de $1000 \mu \mathrm{L}$, seguido de homogeneização. Essas amostras foram preparadas pela diluição de uma solução estoque concentrada da oxi-HbGp, em tampão fosfato de sódio 30 $\mathrm{mmol} / \mathrm{L}, \mathrm{pH} 7,0$. Em seguida, as amostras foram incubadas por um período de $2 \mathrm{~h}$ antes das medidas espectroscópicas.

Na sequência, foram preparadas amostras da oxi-HbGp $(0,1 \mathrm{mg} / \mathrm{mL})$, na presença do surfactante brometo de dodeciltrimetilamônio (DTAB), na faixa de concentração de 0 a 20 $\mathrm{mmol} / \mathrm{L}$, em tampão fosfato $30 \mathrm{mmol} / \mathrm{L}$, nos valores de $\mathrm{pH}$ 5,0 e 7,0. Vale salientar que essas amostras foram feitas na ausência e na presença de $10 \mu \mathrm{mol} / \mathrm{L}$ da sonda ANS. Também foram preparadas amostras para determinar o tamanho das partículas em solução por meio do espalhamento dinâmico de luz (DLS do inglês "Dynamic Light Scattering") na mesma faixa de concentração de DTAB, em condições similares às citadas anteriormente, exceto o valor da concentração da oxi-HbGp que foi de $0,3 \mathrm{mg} / \mathrm{mL}, \mathrm{pH} 7,0$.

Além disso, foram realizadas outras medidas com a oxi-HbGp $(0,1 \mathrm{mg} / \mathrm{mL})$, na presença dos agentes desnaturantes cloridrato de guanidina ( $\mathrm{GuHCl}$ ) e ureia, cujas concentrações variaram de 0 a $3 \mathrm{~mol} / \mathrm{L}$ e de 0 a $8 \mathrm{~mol} / \mathrm{L}$, respectivamente, no $\mathrm{pH} \mathrm{7,0.} \mathrm{Vale}$ ressaltar mencionar ainda que essas medidas também foram realizadas na ausência e presença da sonda ANS, utilizando as técnicas espectroscópicas: absorção óptica e fluorescência. As concentrações das soluções estoques de cloridrato de guanidina e ureia a $25{ }^{\circ} \mathrm{C}$ foram estimadas através das fórmulas empíricas (Equações 1e 2), sugeridas por Pace [54 ].

$$
\begin{gathered}
{[\mathrm{GuHCl}]=57,147(\Delta n)+38,68(\Delta n)^{2}-91,60(\Delta n)^{3} \quad \text { (Eq. 1) }} \\
{[\text { Ureia }]=117,66(\Delta n)+29,753(\Delta n)^{2}+185,56(\Delta n)^{3} \quad \text { (Eq. 2) }}
\end{gathered}
$$

Onde $\Delta n$ é a diferença entre o índice de refração de cada agente caotrópico, ureia e cloridrato de guanidina, e a solução tampão. 
Outro conjunto de amostras foi preparado utilizando a oxi-HbGp $(0,1 \mathrm{mg} / \mathrm{mL}) \mathrm{em}$ diferentes valores de $\mathrm{pH}$, na faixa de 3,45 a 10,02, no tampão acetato- fosfato-borato 30 $\mathrm{mmol} / \mathrm{L}$. Os valores de $\mathrm{pH}$ foram ajustados adicionando pequenas alíquotas de soluções estoques diluídas de $\mathrm{NaOH}$ e $\mathrm{HCl}$. As amostras foram incubadas por $2 \mathrm{~h}$. Transcorrido o tempo de equilíbrio, foram realizadas medidas de absorção óptica e fluorescência. Posteriormente, foi adicionada a essas amostras uma alíquota de $10 \mu \mathrm{L}$ da sonda ANS para obter uma concentração final de $10 \mu \mathrm{mol} / \mathrm{L}$ e depois de $2 \mathrm{~h}$ de incubação as amostras foram medidas novamente.

\subsubsection{Preparação das amostras da oxi-HbGp marcada com FITC}

$\mathrm{Na}$ etapa inicial da reação de marcação, um estoque concentrado da oxi-HbGp foi dialisado por um período de 24 h contra tampão fosfato de sódio $30 \mathrm{mmol} / \mathrm{L}, \mathrm{pH}$ 7,0, com o propósito de remover o tampão Tris- $\mathrm{HCl}$ da proteína, uma vez que, esse tampão inibe a reação de marcação. Em seguida, por ser instável em água, a sonda fluoresceína isotiocianato foi dissolvida em dimetil sulfóxido (DMSO), porém, para a reação de marcação uma diluição em tampão fosfato de sódio foi realizada.

Posteriormente, foram preparadas as reações de marcação a partir de 3,0 mg/mL de oxi-HbGp que corresponde a $120 \mu \mathrm{mol} / \mathrm{L}$ de heme, as proporções de marcação (FITC: HbGp) foram 2:1 e 1:5. O tempo de reação foi de $48 \mathrm{~h}$, após isso, esses estoques foram dialisados por 24 h para remoção de sonda não ligada. Com esses estoques foram preparadas amostras, na presença de DTAB, na faixa de concentração de 0,0 a 20,0 mmol/L.

\subsubsection{Parâmetros experimentais utilizados}

As medidas foram monitoradas através das técnicas de absorção óptica, espalhamento dinâmico de luz (DLS), fluorescência estática e resolvida no tempo, realizadas no laboratório de Biofísica Molecular, Laboratório de Fotoquímica do Instituto de Química de São Carlos (IQSC) da Universidade de São Paulo e no Laboratório de Fotobiofísica da 
Faculdade de Filosofia, Ciências e Letras da USP de Ribeirão Preto. Os experimentos de absorção óptica foram realizados em um espectrofotômetro Shimadzu 1601P e os espectros foram coletados na faixa de 250 a $700 \mathrm{~nm}$. Por outro lado, as medidas de emissão de fluorescência estática foram realizadas no espectrofluorímetro da Hitachi F-4500, com excitação em 295 e $350 \mathrm{~nm}$ para as amostras monitoradas pela sonda ANS, com as emissões nos intervalos de comprimentos de onda, nas faixas de 305 a $570 \mathrm{~nm}$ e 360 a $650 \mathrm{~nm}$, respectivamente, e fendas de excitação e emissão de 5,0 $\mathrm{nm}$. Por outro lado, as amostras marcadas com FITC foram excitadas em 295 e $480 \mathrm{~nm}$, onde as emissões foram monitoradas, nas faixas de 305 a $575 \mathrm{~nm}$ e 485 a $590 \mathrm{~nm}$, respectivamente, e fendas de excitação 2,5 nm e emissão 5,0 nm. Medidas de espalhamento de luz no fluorímetro (LSI do inglês "Light scattering intensity") foram realizadas fixando os comprimentos de onda de excitação e emissão em $350 \mathrm{~nm}$. As medidas de espalhamento dinâmico de luz (DLS) foram realizadas no instrumento Zetasier Nano ZS (Malvern, UK).

Com relação às medidas de DLS, um laser de He-Ne é usado como fonte de luz com comprimento de onda de $633 \mathrm{~nm}$. A intensidade de luz espalhada em um ângulo de $173^{\circ}$ é monitorada por um fotodiodo do tipo avalanche. As soluções foram colocadas num portaamostra termostatizado, em $25 \pm 0,1^{\circ} \mathrm{C}$. Os diâmetros hidrodinâmicos das partículas foram estimados a partir da função de autocorrelação, utilizando o método de "Cumulantes", baseado num ajuste exponencial simples da função de autocorrelação para obter o tamanho médio das partículas (Z- diâmetro médio).

Para a realização dos experimentos de fluorescência resolvida no tempo utilizou-se o equipamento Easylife V. Nas amostras do ANS na presença do DTAB e com a oxi-HbGp foi utilizado o filtro de corte (emissão) de 475 nm e LED do inglês (Light Emitting Diode) de $370 \mathrm{~nm}$ para monitorar a emissão da sonda 1,8-ANS. Além disso, nas medidas da oxi-HbGp na presença e ausência do 1,8-ANS foi utilizado o filtro de corte de $320 \mathrm{~nm}$ e o LED de 280 nm com o propósito de monitorar a emissão dos triptofanos.

Além disso, outras medidas de fluorescência resolvida no tempo foram realizadas em um espectrofluorímetro de alta resolução temporal, baseado no método de correlação temporal de fótons únicos TCSPC do inglês (Time Correlated Single Photon Counting). O método consiste na excitação da amostra com pulsos de luz, onde os fótons da excitação são correlacionados temporalmente com os fótons emitidos pela amostra. Cabe destacar que a fonte de excitação é um laser pulsado Tsunami 3950 (Spectra Physics) de titânio-safira (Ti: sapphire) bombeado por laser de estado sólido Millenia Xs ( Spectra Physics). 


\subsection{Técnicas de estudo}

\subsubsection{Absorção óptica no $U V$-Vis}

O processo de absorção de energia por uma molécula biológica (ou qualquer sistema químico) provoca a promoção de elétrons do estado fundamental para um estado mais energético, ocorrendo num intervalo de tempo de aproximadamente $10^{-15}$ segundos, ou seja, é extremamente rápido [55]. Sendo assim, a absorção de um fóton no UV-Vis ocorre a partir da excitação dos elétrons de um pequeno grupo de átomos, ou seja, os cromóforos, responsáveis pelas transições eletrônicas [56].

As energias envolvidas nas transições eletrônicas correspondem à absorção de fótons no ultravioleta $(200-400 \mathrm{~nm})$ e visível $(400-750 \mathrm{~nm})$, regiões do espectro eletromagnético. Vale ressaltar que as transições eletrônicas estão associadas com a interação da radiação eletromagnética com a matéria, podendo manifestar-se como, cor, visão, e a conversão de luz solar em energia para as plantas [56].

A Figura 7 ilustra os quatro tipos de transições eletrônicas que podem ocorrer: $\sigma \rightarrow$ $\sigma^{*}, \mathrm{n} \rightarrow \sigma^{*}, \mathrm{n} \rightarrow \pi^{*}$ e $\pi \rightarrow \pi^{*}$, onde as energias dos vários tipos de orbitais moleculares diferem significativamente [55]. No entanto, as transições de elétrons $n$ ou $\pi$ para o estado excitado $\pi^{*}$ são as que estão presentes na maioria das aplicações da espectroscopia de absorção dos compostos orgânicos, uma vez que, as energias necessárias para esses processos encontram-se em uma região espectral conveniente do ponto de vista experimental (200 a 700 $\mathrm{nm}$ ). Vale salientar ainda que ambas as transições requerem a presença de um grupo funcional insaturado para fornecer os orbitais $\pi$. 
Figura 7: Diagrama representativo dos níveis de energia eletrônica molecular [55].

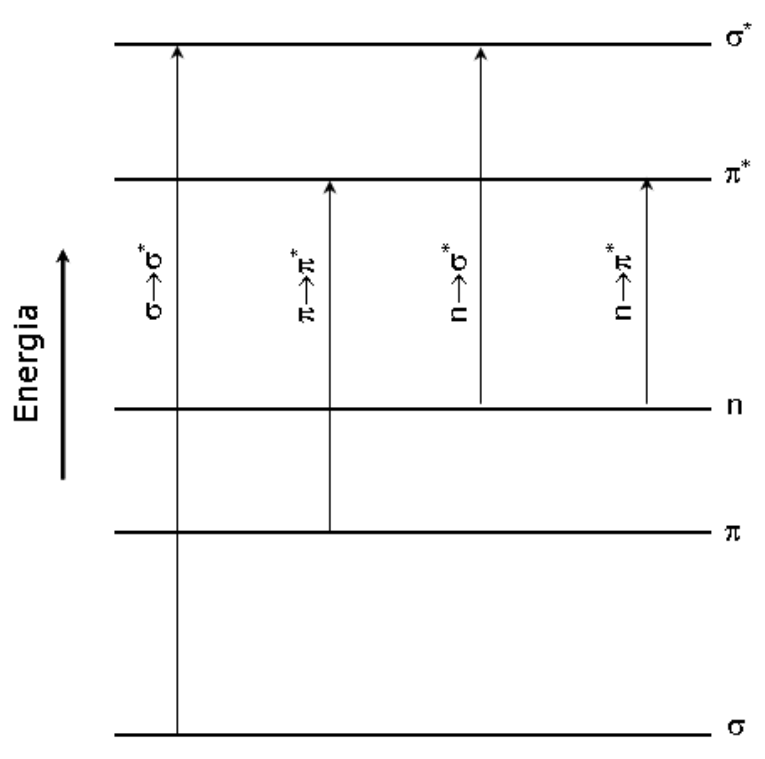

Fonte: SKOOG, D. A.; HOLLER, F. J.; NIEMAN, T. A. Princípios de análise instrumental, Porto Alegre: Bookman, 2002, 838 p.

Dessa forma, muitos sistemas biológicos podem ser investigados através da absorção óptica, por exemplo, as proteínas, que possuem resíduos e ligações peptídicas que absorvem na região do UV- visível. Esses resíduos são os aminoácidos aromáticos fenilalanina, tirosina e triptofano que exibem bandas de absorção na faixa de 300 a $230 \mathrm{~nm}$, enquanto que as ligações peptídicas absorvem luz abaixo de $220 \mathrm{~nm}$ [57].

Para caracterizar uma banda de absorção dois parâmetros são essenciais: a posição do comprimento do máximo de absorção $\left(\lambda_{\max }^{a b s}\right)$ e o coeficiente de absorção molar $(\varepsilon)$ [56]. A relação existente entre o coeficiente de absorção e a concentração é dada pela lei de BeerLambert.

Segundo essa lei em um dado comprimento de onda, a absorbância (A), ou densidade óptica de uma amostra depende tanto da concentração (c) quanto do comprimento do caminho óptico (b) percorrido pela luz na amostra [55,56]. Essa relação é definida como sendo:

$$
\mathrm{A}=\varepsilon b c
$$

E no caso em que a concentração (c) é dada em mol.L $\mathrm{L}^{-1}$, o parâmetro $\varepsilon$ corresponde à absortividade molar, cuja unidade, geralmente é $\mathrm{L} \mathrm{mol}^{-1} \mathrm{~cm}^{-1}$, e cujo valor é, normalmente, determinado no comprimento de onda do máximo de absorção. O gráfico resultante da absorbância versus concentração é uma reta, tendo em vista que a absorção é diretamente proporcional à concentração da solução. Entretanto, altas concentrações causam um desvio 
nessa lei, que pode estar associado à dimerização, agregação, ou mudanças químicas do sistema em estudo.

Uma importante aplicação da espectroscopia de absorção óptica no UV- visível é a medida de concentrações, por exemplo, de proteínas, da nicotinamida adenina dinucleotídeo reduzido (NADH), e ácidos nucleicos [56]. Além disso, é uma técnica espectroscópica também utilizada durante os procedimentos de purificação e separação de proteínas para a quantificação das mesmas [57]. Porém, em amostras complexas é uma técnica limitada, uma vez que, diversas substâncias absorvem simultaneamente no ultra-violeta, tornando os resultados pouco confiáveis [57 ]. Neste trabalho essa técnica foi utilizada, além dos usos mencionados anteriormente de controle das amostras, para estudar os prováveis mecanismos dos processos de dissociação oligomérica e desnaturação da $\mathrm{HbGp}$, em função das mudanças espectrais observadas.

\subsubsection{Fluorescência}

Sistemas de interesse biológico envolvem moléculas que absorvem e emitem na faixa do UV-Visível. Com isso a técnica de fluorescência têm se mostrado valiosa no estudo de proteínas [58]. O processo de emissão de fluorescência ocorre no intervalo de $10^{-9} \mathrm{~s}$, sendo este um valor de tempo necessário para acompanhar os eventos que acontecem no estado excitado, como por exemplo, a interação das moléculas com o meio em que se encontram (solvente). Diante disso, a técnica de fluorescência têm se tornado atraente para o estudo de moléculas biológicas. Convém mencionar que a técnica de fluorescência no estado estacionário fornece informações sobre a posição espectral das bandas, rendimento quântico dos fluoróforos e anisotropia estática, enquanto que a fluorescência de resolução temporal proporciona perfis de decaimento da intensidade e da anisotropia de fluorescência [59].

A Figura 8 mostra o diagrama de Jablonski com os diferentes tipos de transições radioativas e não-radioativas que as moléculas podem participar. Observa-se que quando uma molécula absorve energia, um elétron é promovido do estado fundamental $\mathrm{S}_{0}$ para qualquer um dos níveis vibracionais do estado excitado $S_{1}$, após isso o elétron poderá retornar ao estado fundamental $\mathrm{S}_{0}$ através de vários processos [59]. 
Figura 8: Diagrama de Jablonski. (1) Absorção de radiação $\left(S_{0} \rightarrow S_{1}\right.$ e $\left.S_{0} \rightarrow S_{2}\right)$, (2) Emissão de fluorescência $\left(S_{1} \rightarrow S_{0}\right)$, (3) Conversão interna e relaxação vibracional $\left(S_{2} \rightarrow S_{1}\right)$, (4) Cruzamento intersistemas $\left(S_{1} \rightarrow T_{1}\right)$, (5) Emissão de fosforescência $\left(T_{1} \rightarrow S_{0}\right)$ [59].

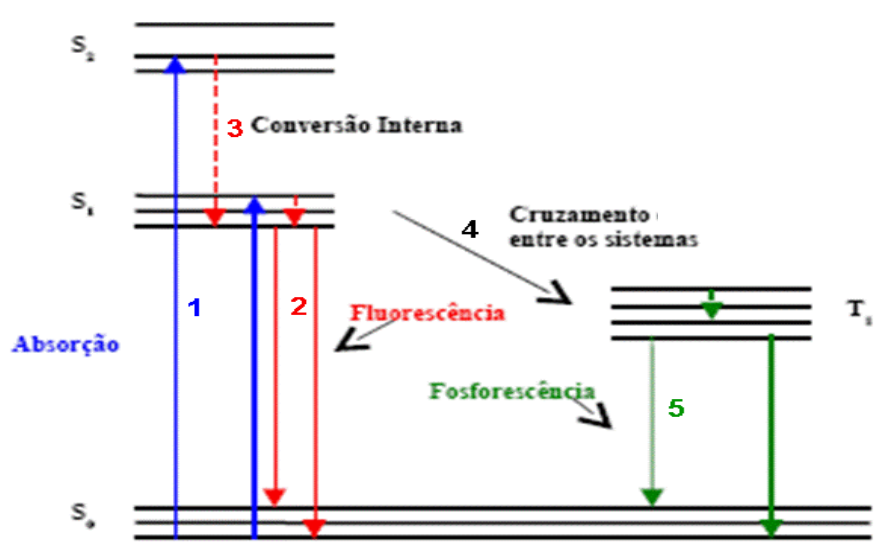

Fonte: LAKOWICZ, J. R. Principles of fluorescence spectroscopy. Baltimore: Springer, 2006. 974 p.

Desta forma, o processo de decaimento não radioativo que ocorre entre níveis de mesma multiplicidade por meio da dissipação dos modos vibracionais internos ou por colisões com as moléculas do solvente é conhecido como conversão interna. Por outro lado, o cruzamento intersistema acontece entre estados de diferentes multiplicidades (S-T), nesse caso, a molécula pode decair para o primeiro estado tripleto $\left(T_{1}\right)$ e em seguida, o decaimento para o estado fundamental ocorre por fosforescência, que corresponde a uma transição proibida pela regra de conservação de spin [58].

Além disso, transições ópticas permitidas pela regra de seleção da mecânica quântica podem ocorrer a partir do estado singleto $\left(\mathrm{S}_{1}\right)$ para um dos níveis vibracionais do estado fundamental $\left(\mathrm{S}_{0}\right)$, via decaimento radioativo, ou seja, com emissão de luz, sendo esse processo denominado de fluorescência.

Vale ressaltar que as interações dos cromóforos com as moléculas do solvente da solução ocorrem antes da emissão. Estas interações alteram a energia do estado excitado e também a frequência da emissão de fluorescência [56]. Por isso, o tempo de fluorescência ocorre em frequência mais baixa do que a radiação incidente [60].

Uma peculiaridade da fluorescência é apresentar alta sensibilidade ao ambiente em relação a vários parâmetros, tais como, comprimento do máximo de emissão, rendimento quântico, tempo de vida de fluorescência que podem ser afetados de várias formas [56]. Em geral, as moléculas no estado excitado interagem com o solvente polar para alinhar os dipolos do solvente. Este alinhamento diminui a energia do estado excitado e provoca o deslocamento 
do espectro de emissão para o vermelho [56]. Por outro lado, o rendimento quântico (intensidade de fluorescência) aumenta quando a polaridade do solvente (ou ambiente vizinho do cromóforo) diminui [56].

Os fluoróforos podem ser classificados em fluoróforos naturais (intrínsecos) e fluoróforos indicadores, ou sondas (extrínsecas). Fluoróforos naturais são os aminoácidos aromáticos, flavinas, vitamina A, clorofila, e NADH [56]. Cabe destacar que a fluorescência das proteínas é observada, predominante a partir dos triptofanos, uma vez que a fluorescência da tirosina é geralmente suprimida na presença dos triptofanos [56,59]. Devido à existência de um número reduzido de fluoróforos naturais, muitas das aplicações das técnicas de fluorescência envolvem a adição de sondas extrínsecas fluorescentes ao sistema em estudo $[56,59]$.

É importante mencionar ainda que a fluorescência mais intensa é encontrada em compostos contendo grupos funcionais aromáticos com níveis de transição $\pi \rightarrow \pi^{*}$ de baixa energia. A fluorescência está associada a esse tipo de transição $\pi \rightarrow \pi^{*}$ porque apresenta tempo de vida menor $\left(10^{-7}\right.$ a $\left.10^{-9} \mathrm{~s}\right)$ em comparação com o tempo de $10^{-5}$ a $10^{-7} \mathrm{~s}$ correspondente a uma transição $n \rightarrow \pi^{*}$, e porque os processos de desativação que competem com a fluorescência são de ocorrência menos provável [55].

De maneira geral, as medidas de fluorescência estática ocorrem sob iluminação constante, ou seja, a amostra é iluminada continuamente por um feixe de luz e os espectros de excitação e emissão são coletados. Contudo, a medida de fluorescência temporal, fornece o decaimento de intensidade em função do tempo. Neste caso, a amostra é colocada diante de um pulso de luz, onde a largura do pulso é, em geral, menor que o tempo de decaimento da amostra. Como o sistema de detecção deve ser de alta velocidade, o decaimento ou a intensidade de emissão é detectada na escala de nanosegundos [59].

O tempo de vida de uma substância fluorescente representa o tempo médio que uma molécula permanece no estado excitado antes de retornar ao estado fundamental. O conhecimento dos valores de tempo de vida é frequentemente necessário em espectroscopia de fluorescência, especialmente nos estudos de supressão, onde podem evidenciar a frequência de encontros colisionais com os agentes supressores, bem como, nos estudos de transferência de energia e reações no estado excitado [59]. Além disso, as análises dos tempos de vida e das curvas de decaimento de fluorescência podem revelar particularidades sobre as interações físico-químicas do fluoróforo com o ambiente ao qual ele está exposto, por 
exemplo, constantes de decaimentos multiexponenciais sugerem a presença do fluoróforo em vários ambientes diferentes, ou podem estar associadas aos processos no estado excitado [59].

Além disso, o tempo de vida de fluorescência do fluoróforo depende fortemente das propriedades das moléculas que se encontram em torno dele [59]. Vale destacar que essa dependência é similar ao rendimento quântico, estando associada a uma competição entre a transição radioativa (fluorescência) e as transições não radioativas, processos responsáveis pela desativação do estado excitado do fluoróforo. O tempo de vida $(\tau)$ pode ser definido como sendo:

$$
\tau=\frac{1}{k_{F}+k_{Q}+k_{I C}+k_{I S C}+k_{E T}}
$$

Onde $\mathrm{k}_{\mathrm{F}}$ é a constante associada à fluorescência; $\mathrm{k}_{\mathrm{Q}}$ a constante de supressão; $\mathrm{k}_{\mathrm{IC}}$ constante associada à conversão interna; $\mathrm{k}_{\mathrm{ISC}}$ constante relativa ao cruzamento intersistemas e $\mathrm{k}_{\mathrm{ET}}$ constante devido à transferência de energia. Convém ressaltar que existe uma relação entre o rendimento quântico e o tempo de vida de fluorescência, dada pela seguinte equação:

$$
\tau=\gamma \tau_{0}
$$

Onde $\tau_{0}$ representa o tempo de vida de fluorescência do cromóforo, ou seja, $\tau_{0}=1 / k_{F}$ é o tempo de vida de fluorescência, na ausência de transições não radioativas, e $\gamma$ é o rendimento quântico .

Para as amostras que contêm apenas um tipo de molécula fluorescente, o decaimento pode se descrito pela função exponencial:

$$
F(t)=F_{0} e^{-t / \tau_{0}}
$$

Onde $\mathrm{F}_{0}$ é a intensidade de fluorescência inicial no instante $\mathrm{t}=0$. Porém, a maioria das amostras apresenta decaimentos bem mais complicados do que um decaimento monoexponencial. Neste caso, o decaimento é dado por uma soma de exponenciais:

$$
F(t)=\sum_{i} \alpha_{i} e^{-t / \tau_{i}}
$$

Onde os coeficientes $\alpha_{i}$ são os fatores pré-exponenciais que correspondem às contribuições fracionais das componentes do decaimento. 
Neste trabalho as técnicas de fluorescência estática e resolvida no tempo foram utilizadas para monitorar os processos de dissociação e desnaturação da oxi-HbGp, além de auxiliar na interpretação dos processos que ocorrem no estado excitado e complementar os resultados obtidos com as técnicas de absorção óptica e DLS.

\subsubsection{Espalhamento dinâmico de luz}

Quando a radiação eletromagnética interage com a partícula, a radiação é espalhada. Análises detalhadas de espalhamento podem fornecer informações sobre a forma, tamanho e o movimento da partícula em solução [56]. A aplicação da radiação de uma dada frequência causa oscilações nas partículas. Estas oscilações produzem radiação secundária em todas as direções [56].

A diferença existente entre o espalhamento estático de luz (SLS do inglês " Static Light Scattering”) e o espalhamento dinâmico de luz (DLS do inglês “ Dynamic Light Scattering") consiste no tempo em que a intensidade de luz é espalhada. No espalhamento dinâmico de luz (DLS) as intensidades das flutuações são observadas instantaneamente, enquanto que no espalhamento estático de luz (SLS) são verificadas durante um certo intervalo de tempo longo, resultando numa medida que corresponde à média temporal.

Devido às diferenças de densidade causadas pela aglomeração acidental de partículas e variação do número de moléculas no volume disperso, as intensidades das flutuações de espalhamento de luz detectadas no DLS estão relacionadas com o movimento aleatório ou Browniano das partículas em solução [61].

A dependência da luz espalhada em um ângulo fixo em função do tempo é estimada através do espalhamento dinâmico de luz. Por isso, as medidas de espalhamento de luz são convenientes para determinar características estruturais de partículas, mantendo uma relação inversa entre o tamanho da partícula e o ângulo de espalhamento. Com isso, o coeficiente de difusão pode ser obtido, baseando-se na função de autocorrelação que é, em geral, uma função exponencial, e está diretamente relacionada com o tamanho da partícula na solução $[61,62]$.

Vale salientar que a dependência da intensidade de flutuação em relação ao tempo, é uma função do tamanho da partícula. Sendo assim, partículas pequenas movimentam-se 
rapidamente e a luz espalhada apresenta flutuações rápidas. Por outro lado, partículas grandes movem-se vagarosamente, dessa forma, o feixe de luz espalhado exibe flutuações lentas. Consequentemente, mudanças no nível de luz conduzem a informações valiosas sobre o tamanho da partícula.

Através da técnica de DLS é obtido o parâmetro Z-Average que representa o diâmetro médio das partículas espalhadoras, sendo o mesmo estimado pelo coeficiente angular da forma linear da função de correlação (método de Cumulante). Além disso, através de DLS o raio hidrodinâmico pode ser estimado, sendo definido como o raio de uma esfera equivalente à partícula espalhadora com o mesmo coeficiente de difusão. Outros raios tais como, o raio de rotação, o raio de massa e o raio de giro também podem ser encontrados. Com o coeficiente de difusão e a viscosidade do solvente conhecidos, o raio hidrodinâmico pode ser calculado através da equação de Stokes-Einstein (equação 8 ):

$$
D=\frac{k T}{6 \pi \eta R_{H}}
$$

onde k é a constante de Boltzman, T a temperatura absoluta, $\eta$ a viscosidade do meio e $R_{h} O$ raio hidrodinâmico das partículas espalhadoras, supondo que estas são esféricas [61,62]. 
CAPÍTULO III

RESULTADOS E DISCUSSÕES 


\title{
PARTE I
}

\section{ESTUDOS ESPECTROSCÓPICOS DA ESTABILIDADE DA OXI-HbGp MONITORADOS PELA SONDA ANS.}

\author{
Nesta seção a estabilidade \\ oligomérica da oxi-HbGp foi estudada na \\ presença do surfactante DTAB e dos agentes \\ caotrópicos cloridrato de guanidina, ureia e \\ também em diferentes valores de $\mathrm{pH}$ \\ monitorados pela sonda ANS. Esses estudos \\ mostram que esses agentes induzem \\ diferentes fenômenos na estrutura da oxi- \\ HbGp, tais como, agregação, dissociação \\ oligomérica e desenovelamento
}




\section{RESULTADOS E DISCUSSÕES}

\subsection{ESTUDOS ESPECTROSCÓPICOS DA ESTABILIDADE DA OXI- HbGp MONITORADOS PELA SONDA ANS.}

\subsubsection{Oxi-HbGp em concentrações diferentes de ANS.}

A Figura 9A mostra os espectros de absorção óptica da oxi-HbGp $(0,1 \mathrm{mg} / \mathrm{mL})$, no pH 7,0, em função da concentração da sonda ANS. Nesses espectros destacam-se a banda de Soret $(415 \mathrm{~nm})$ e as bandas Q $(\alpha$ e $\beta)$, centradas em 540 e $576 \mathrm{~nm}$, respectivamente, características da hemoglobina na forma oxi-HbGp, ou seja, do ferro no estado reduzido [21]. A Absorbância da banda de Soret (415 nm), em função da concentração de ANS, mostrada na Figura 9B, não apresenta variação significativa, sugerindo que o ambiente em torno do grupo heme não sofre alterações em função da concentração de ANS.

Figura 9: (A) Espectros de absorção óptica da oxi-HbGp $(0,1 \mathrm{mg} / \mathrm{mL})$ na presença da sonda ANS em tampão fosfato de sódio $30 \mathrm{mmol} / \mathrm{L}, \mathrm{pH}$ 7,0. (B) Gráfico da absorbância na banda de Soret $(415 \mathrm{~nm})$ em função da concentração de ANS.
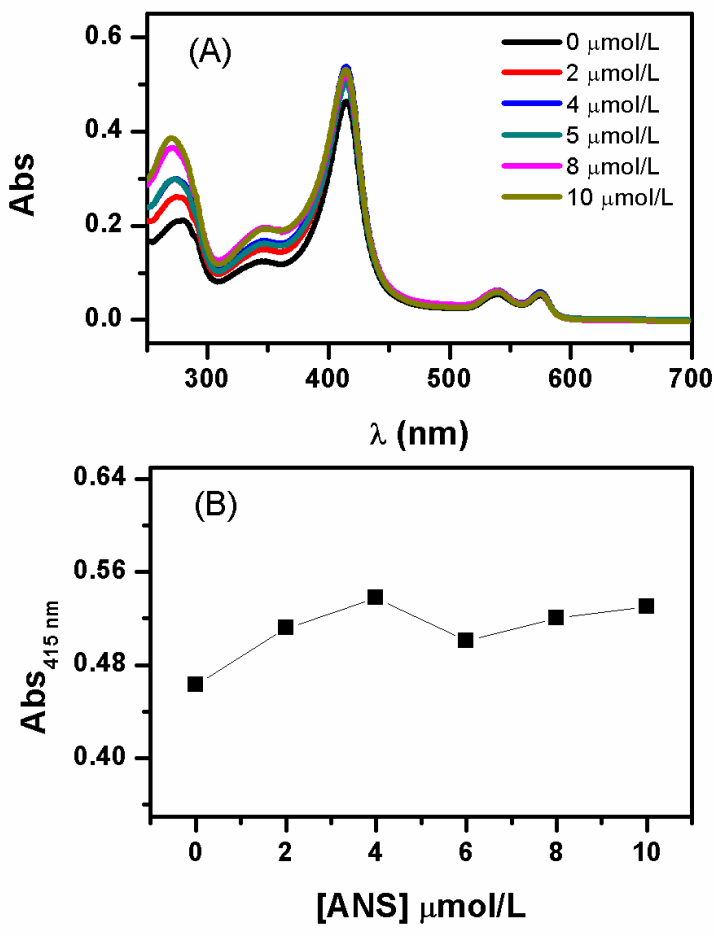
Os espectros de emissão da oxi-HbGp $(0,1 \mathrm{mg} / \mathrm{mL})$, na ausência e na presença de diferentes concentrações da sonda ANS, com excitação em 295 nm, são mostrados na Figura 10A. O pico I corresponde à emissão dos resíduos de triptofano e o pico II está associado à emissão da sonda ANS. A Figura 10B mostra às áreas dos espectros de emissão do ANS (pico II), com excitação em 295 e $350 \mathrm{~nm}$. Nessa figura observa-se que as amostras excitadas em $295 \mathrm{~nm}$ apresentam uma intensidade de fluorescência maior quando comparada à intensidade de emissão das amostras excitadas em $350 \mathrm{~nm}$. Este comportamento pode ser atribuído à transferência parcial de energia dos triptofanos da proteína para a sonda ANS [32,37, 40,41]. A intensidade do máximo de emissão referente ao pico I $(330 \mathrm{~nm})$, em função da concentração de ANS, é mostrada na Figura 10C onde se observa um comportamento praticamente constante. Na Figura 10D é mostrado o deslocamento do máximo de emissão, em função da concentração de ANS, onde se observa um comportamento de pouca variação, indicando que a sonda, está num ambiente protegido do solvente, uma vez que, em solução aquosa esta sonda apresenta um comprimento de onda do máximo de emissão de fluorescência em torno de $515 \mathrm{~nm}$ [32]. Desta forma, pode-se concluir que esta sonda encontra-se, provavelmente, totalmente ligada aos sítios hidrofóbicos da proteína. 
Figura 10: (A) Espectros de emissão de fluorescência da oxi-HbGp $(0,1 \mathrm{mg} / \mathrm{mL})$ na presença de diferentes concentrações da sonda ANS em tampão fosfato de sódio $30 \mathrm{mmol} / \mathrm{L}, \mathrm{pH}$ 7,0. (B) Gráficos das áreas do pico II em função da concentração da sonda ANS. (C) e (D) Gráficos da intensidade de emissão de fluorescência do pico I e do máximo de emissão de fluorescência referente ao pico II em função da concentração da sonda ANS, respectivamente.
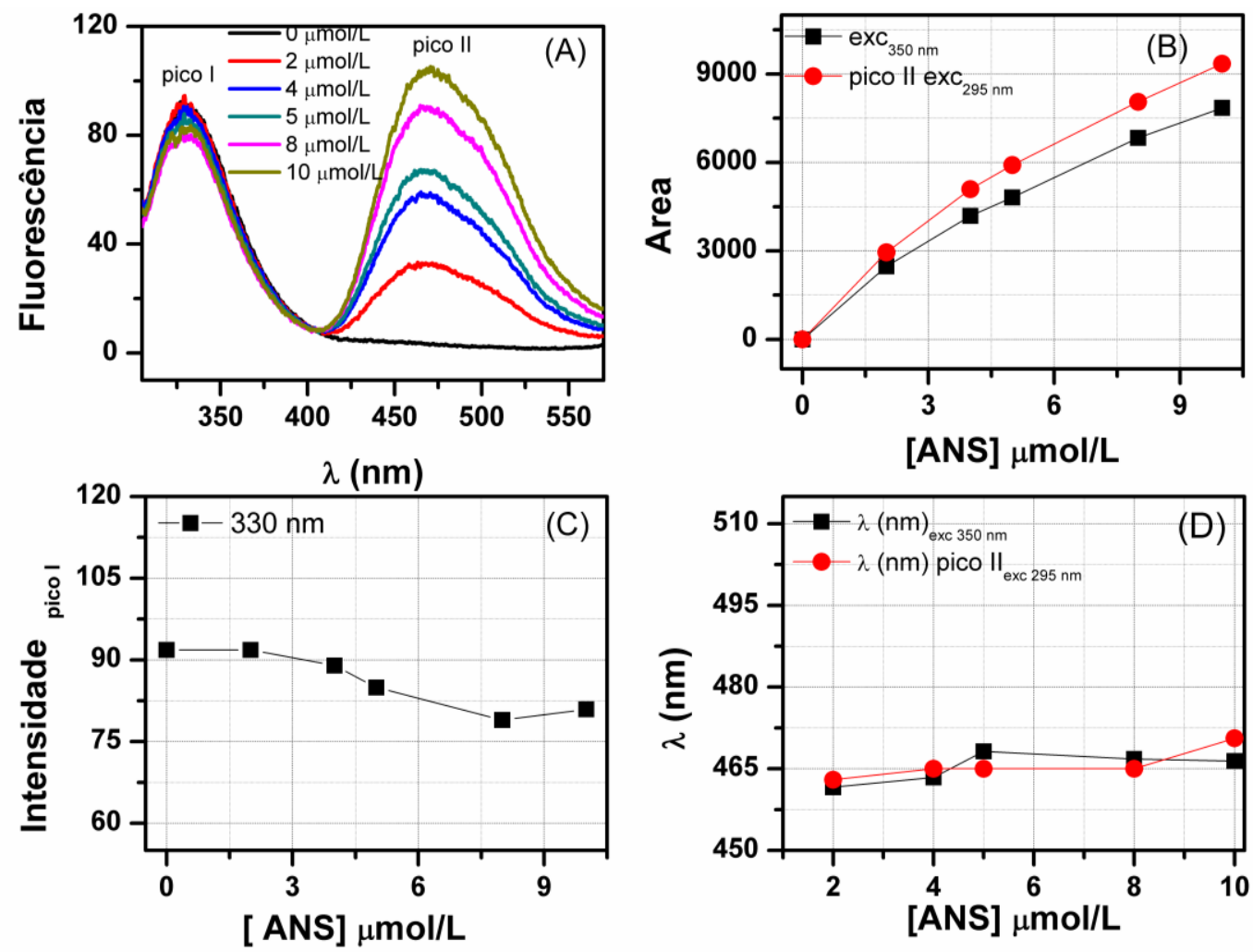

4.1.2. Efeitos das diferentes concentrações de DTAB na sonda ANS, no pH 7,0.

\subsubsection{Dados de absorção óptica}

A Figura 11A mostra os espectros de absorção óptica no UV-Visível da sonda ANS, na presença e na ausência de DTAB. Na ausência de DTAB duas bandas centradas em 266 e 360 nm são características da absorção da sonda em solução aquosa [63]. As Figuras 11B e $11 \mathrm{C}$ exibem o deslocamento para o vermelho de ambas as bandas, para $272 \mathrm{~nm}$ e $375 \mathrm{~nm}$, respectivamente, o que ocorre na faixa até 5,0-8,0 $\mathrm{mmol} / \mathrm{L}$ de surfactante. Vale ressaltar que o 
deslocamento em altas concentrações de surfactante pode ser associado, provavelmente, à interação das micelas com o ANS, promovendo mudanças no ambiente da sonda.

Figura 11: (A) Espectros de absorção óptica da sonda ANS $(10 \mu \mathrm{mol} / \mathrm{L})$ com diferentes concentrações de DTAB em tampão fosfato de sódio $30 \mathrm{mmol} / \mathrm{L}, \mathrm{pH}$ 7,0. (B) e (C) Gráficos da variação do comprimento de onda das respectivas bandas da sonda ANS em função da concentração de DTAB.
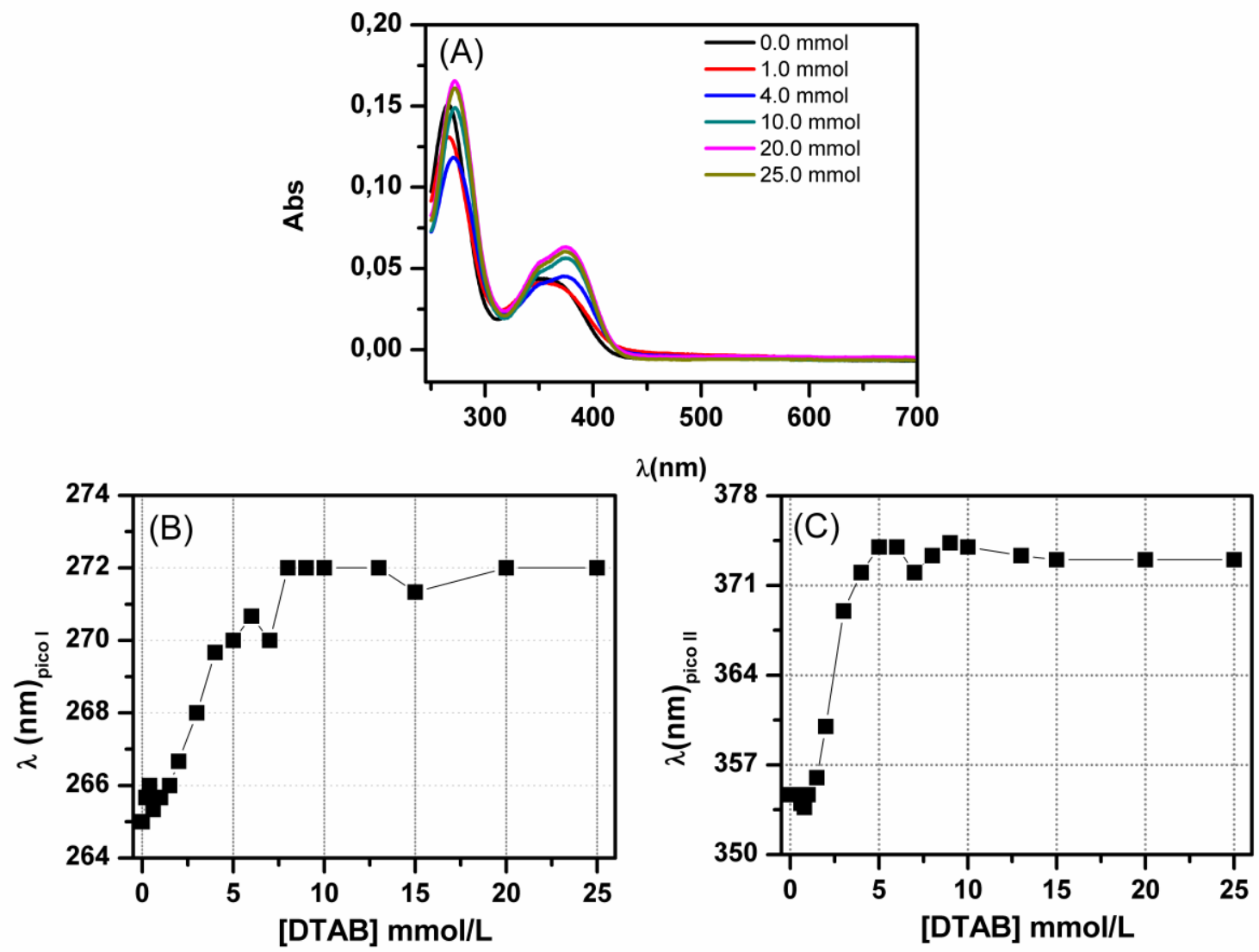

\subsubsection{Dados de emissão de fluorescência.}

Os espectros de emissão de fluorescência da sonda ANS, em função da concentração de DTAB, com excitação em $350 \mathrm{~nm}$, estão apresentados na Figura 12A. O aumento na concentração de DTAB leva a um aumento na intensidade de fluorescência e um deslocamento para o azul ,. A Figura 12B mostra a área normalizada de emissão de fluorescência do ANS em função da concentração de DTAB, enquanto na Figura 12C são exibidos os gráficos das áreas de emissão de fluorescência total e a variação do comprimento de onda de emissão. 
Figura 12: (A) Espectros de emissão de fluorescência da sonda ANS (10 $\mu \mathrm{mol} / \mathrm{L})$ na presença e na ausência de DTAB em tampão fosfato de sódio $30 \mathrm{mmol} / \mathrm{L}, \mathrm{pH}$ 7,0. (B) Gráfico da área total de emissão de fluorescência normalizada a partir da concentração de 0,0 mmol/L de DTAB. (C) Gráficos do deslocamento do máximo de emissão de fluorescência $\left(\lambda_{e m}^{\max }\right)$ e da área da curva de emissão de fluorescência em função da concentração de DTAB.
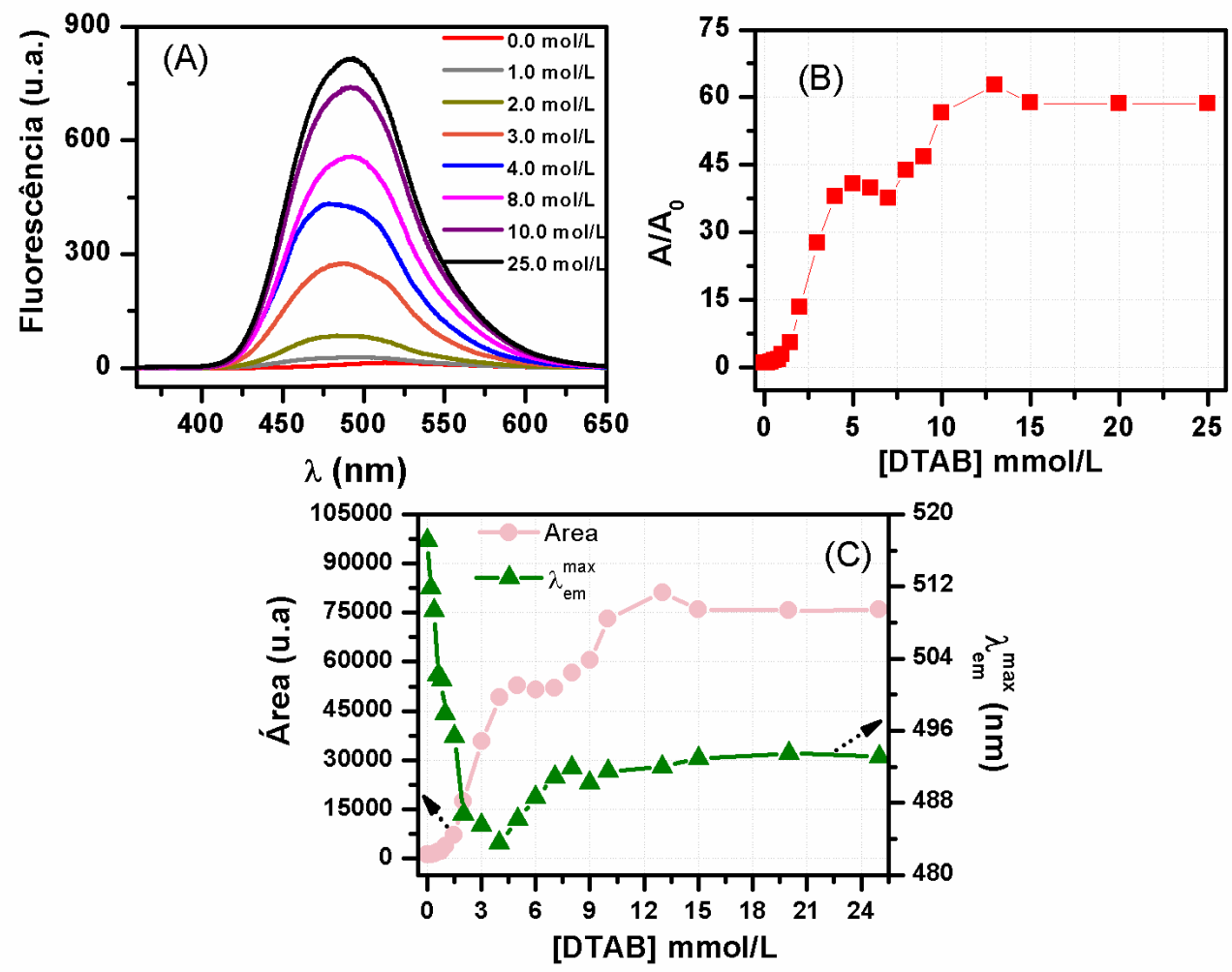

A partir desses resultados observa-se que em baixas concentrações de DTAB, até 1,0 mmol/L, a intensidade é bastante baixa e similar ao observado em tampão fosfato. A baixa emissão de fluorescência sugere que a sonda está totalmente exposta ao solvente (ambiente polar), onde a sonda tem um baixo rendimento quântico de 0,004 [37]. Na faixa de concentração de DTAB de 1,0 a 4,0 mmol/L, verifica-se um aumento na emissão de fluorescência com uma área em torno de 49200 u.a. que representa um aumento de 31 vezes comparado ao valor na ausência de surfactante (Figuras 12B e 12C). Além disso, observa-se um deslocamento do comprimento do máximo de emissão ( $\lambda_{e m}^{\max }$ ) para o azul, de 517 para 483 nm, mostrado na Tabela 01 e na Figura 12C. Essas mudanças podem estar associadas às interações da sonda ANS com grupos hidrofóbicos presentes em agregados pré-micelares. 
Tabela 1: Parâmetros espectroscópicos da sonda ANS na presença de DTAB com excitação a $350 \mathrm{~nm}$, em tampão fosfato $30 \mathrm{mmol} / \mathrm{L}, \mathrm{pH}$ 7,0.

\begin{tabular}{cccccc}
\hline & & \multicolumn{4}{c}{$[\mathrm{DTAB}] \mathrm{mmol} / \mathrm{L}$} \\
\hline Amostra & Propriedades & 0,0 & 4,0 & 10,0 & 20,0 \\
\hline \multirow{2}{*}{ DTAB-ANS } & Área (u.a.) $^{\mathbf{a}}$ & 1.300 & 49.200 & 73.050 & 75.670 \\
& $\lambda_{e m}^{\max }(\mathbf{n m})^{\mathbf{b}}$ & 517 & 483 & 491 & 493 \\
\hline
\end{tabular}

${ }^{a}$ Área total de emissão de fluorescência, em unidades arbitrárias (u.a.).

${ }^{\mathrm{b}}$ Comprimento de onda do máximo de emissão de fluorescência.

Estudos descritos na literatura sugerem que o intenso deslocamento para o azul é devido a que as moléculas de ANS estão menos expostas ao solvente [35]. Além disso, outros trabalhos têm atribuído o aumento brusco na intensidade de emissão de fluorescência em ambientes hidrofóbicos, encontrados em macromoléculas e micelas, ao elevado rendimento quântico da sonda, em torno de 0,98, nestes ambientes [37]. Vale mencionar ainda que estudos da sonda ANS na presença do surfactante Tween 20, mostraram que tais efeitos podem estar associados ao aumento da superfície hidrofóbica devido à adição de surfactante [35].

Na Figura 12C e na Tabela 01, verifica-se que, na faixa de concentração de DTAB de 4,0 a 8,0 mmol/L, o comprimento de onda do máximo de emissão apresenta pequenas mudanças e um deslocamento para o vermelho de 483 para $492 \mathrm{~nm}$. Este deslocamento pode estar relacionado com o aumento da exposição da sonda ao solvente devido às forças repulsivas entre as moléculas de DTAB nas micelas. Contudo, acima de $10 \mathrm{mmol} / \mathrm{L}$ de surfactante, a intensidade de emissão de fluorescência e os valores de $\lambda_{e m}^{\max }$, em torno de 76.000 u.a e $493 \mathrm{~nm}$, respectivamente, permanecem constantes até $25 \mathrm{mmol} / \mathrm{L}$ de DTAB. As pequenas mudanças na intensidade de emissão e $\lambda_{e m}^{\max }$ da sonda podem ser atribuídas às ligações das moléculas de ANS com as micelas de DTAB. Estudos na literatura descrevem que o valor da concentração micelar crítica $(\mathrm{cmc})$ do DTAB em tampão fosfato está em torno de $11,0 \mathrm{mmol} / \mathrm{L}$ [64]. Assim, a primeira transição observada em 2,50 \pm 0,05 mmol/L pode estar associada à interação da sonda ANS com agregados pré-micelares, e a segunda em 9,5 \pm 0,2 mmol/L, corresponde, provavelmente, à formação de micelas de DTAB. 


\subsubsection{Efeitos do DTAB na estrutura oligomérica da oxi-HbGp, nos valores de $p H$ 7,0 e 5,0.}

\subsubsection{Dados de absorção óptica}

A Figura 13A mostra os espectros de absorção óptica da oxi-HbGp, em diferentes concentrações de DTAB, na presença de $10 \mu \mathrm{mol} / \mathrm{L}$ da sonda ANS, em pH 7,0. O aumento da concentração de DTAB induz um espalhamento de luz significativo e um deslocamento do máximo de absorção da banda de Soret para o azul, de 415 para $405 \mathrm{~nm}$, especialmente no intervalo entre 2,0 e $8,0 \mathrm{mmol} / \mathrm{L}$ de surfactante (Figuras 13B e 13C). Na Figura 13C o espalhamento de luz, monitorado em 700 nm, é apresentado através de absorbância da HbGp que não absorve neste comprimento de onda. A alta intensidade de espalhamento nesta faixa de concentração está associada à agregação da proteína devido às interações DTAB-HbGp, visto que, o surfactante promove a neutralização das cargas na superfície da proteína $[21,65]$. Em concentrações maiores de surfactante (acima de 10,0 mmol/L) o espalhamento de luz não é mais observado, provavelmente, devido à re-solubilização de agregados proteínasurfactante. A Figura 13B mostra os gráficos do comprimento de onda do máximo de absorção $\left(\lambda_{a b s}^{\max }\right)$ e a absorção na banda de Soret $(415 \mathrm{~nm})$, em função da concentração de DTAB. O deslocamento para o azul do $\lambda_{a b s}^{\max }$ é consistente com a oxidação da oxi-HbGp e formação da espécie meta-HbGp, observado também em estudos anteriores [17,19]. Cabe destacar que esses resultados são similares aos obtidos previamente com a $\mathrm{HbGp}$, na presença de CTAC [21,66]. No pH 7,0, a interação HbGp-CTAC é maior quando comparada com à interação HbGp-DTAB, já que, efeitos semelhantes, na presença de DTAB, são observados para baixas concentrações de CTAC [21]. Assim, os resultados sugerem que a estabilidade oligomérica da proteína depende do tamanho da cadeia hidrofóbica do surfactante [21]. TahriKafrani e colaboradores [65] mostraram que o DTAB afeta a estabilidade da $\beta$-lactoglobulina, que é carregada negativamente nos valores de pH 6,7 e 8,0, induzindo a precipitação da proteína devido à formação de complexos neutros $\beta$-lactoglobulina-DTAB. Além disso, o aumento da concentração de surfactante promove a re-solubilização destes agregados devido à associação de moléculas adicionais de DTAB nos complexos, tornando-os carregados positivamente e mais suscetíveis de hidratação. 
Figura 13: (A) Espectros de absorção óptica da oxi-HbGp $(0,1 \mathrm{mg} / \mathrm{mL})$ com diferentes concentrações de DTAB e na presença de $10 \mu \mathrm{mol} / \mathrm{L}$ de ANS em tampão fosfato de sódio $30 \mathrm{mmol} / \mathrm{L}$, pH 7,0. (B) Gráficos da absorbância na banda de Soret $(415 \mathrm{~nm})$ e do deslocamento do máximo de absorção desta banda em função da concentração de DTAB. (C) Gráfico da absorbância em $700 \mathrm{~nm}$ em função da concentração de DTAB.

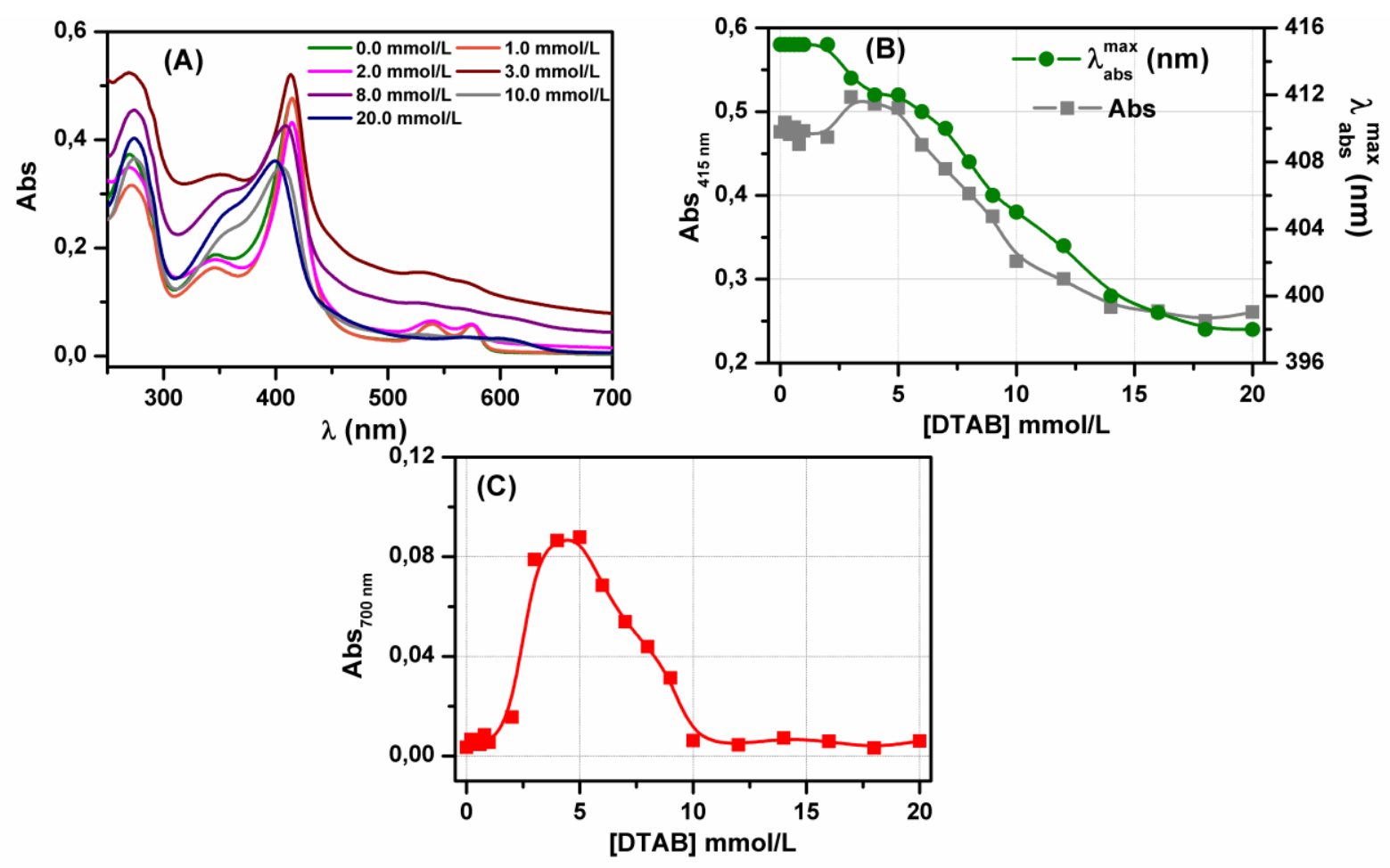

Os espectros de absorção óptica da oxi-HbGp, no pH 5,0, na presença de diferentes concentrações de DTAB, são mostrados na Figura 14A. Inicialmente, em baixas concentrações de $\mathrm{DTAB}$, até 2,0 mmol/L, não são observadas mudanças significativas no comprimento de onda do máximo de absorção da banda de Soret (Figura 14C), indicando que a oxi-HbGp permanece na forma nativa íntegra, similar ao observado no $\mathrm{pH}$ 7,0. Além disso, em altas concentrações de DTAB, na faixa de concentração de 2,0 a $10 \mathrm{mmol} / \mathrm{L}$, não foi observado espalhamento de luz, uma vez que, o DTAB, em meio ácido, não promove agregação da HbGp. Além disso, no pH 5,0, a carga total da superfície da proteína é positiva e as interações eletrostáticas entre DTAB e HbGp são menos intensas, enquanto que no pH 7,0, a carga total é negativa. O deslocamento do comprimento de onda do máximo de absorção da banda de Soret (415 nm) para o azul, de 415 para $399 \mathrm{~nm}$ (Figura 14C) sugere que o DTAB induz a oxidação da oxi-HbGp e a formação da meta-HbGp. Santiago et al [67], mostraram através de estudos de intensidade de espalhamento de luz, que CTAC, em valores de pH 5,0 e 6,0 induz a dissociação da $\mathrm{HbGp}$ em pequenas subunidades, seguida pelo desenovelamento proteico, sem a formação de agregados e precipitação da proteína. 
Figura 14: (A) Espectros de absorção óptica da oxi-HbGp $(0,1 \mathrm{mg} / \mathrm{mL})$ com diferentes concentrações de DTAB na presença de $10 \mu \mathrm{mol} / \mathrm{L}$ de ANS em tampão fosfato de sódio $30 \mathrm{mmol} / \mathrm{L}, \mathrm{pH}$ 5,0. (B) Inserto da Figura (A) mostrando a região das bandas $Q$ ampliada. (C) Gráficos da absorbância na banda de Soret $(415 \mathrm{~nm})$ e do deslocamento do comprimento de onda do máximo de absorção desta banda, em função da concentração de DTAB.
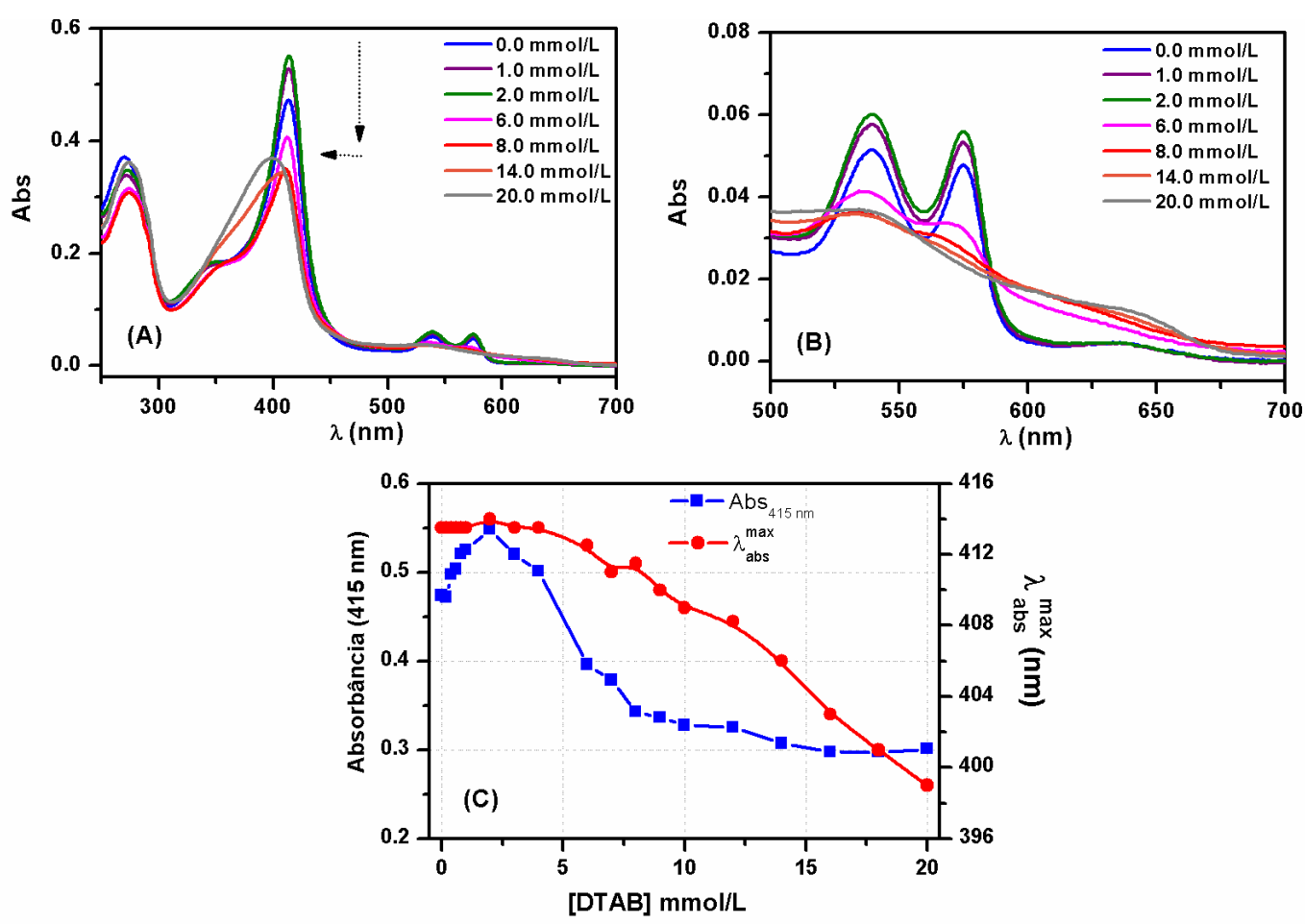

\subsubsection{Dados de emissão de Fluorescência e espalhamento}

Os espectros de emissão de fluorescência para oxi-HbGp, em diferentes concentrações de DTAB, na presença de $10 \mu \mathrm{mol} / \mathrm{L}$ de ANS, no pH 7,0, são mostrados nas Figuras 15A e 15B, com excitação em 295 e 350 nm, respectivamente. As áreas totais de emissão dos triptofanos (pico I, Figura 15C) e a área de emissão de fluorescência do ANS (pico II, Figura 15D), nos valores de $\mathrm{pH}$ 7,0 e 5,0 são também mostradas, em função da concentração de DTAB. 
Figura 15: Espectros de emissão de fluorescência da oxi-HbGp $(0,1 \mathrm{mg} / \mathrm{mL})$ com diferentes concentrações de DTAB e na presença de $10 \mu \mathrm{mol} / \mathrm{L}$ de ANS em tampão fosfato de sódio $30 \mathrm{mmol} / \mathrm{L}$, pH 7,0 com excitação em (A) 295 e (B) 350 nm. (C) Gráficos das áreas correspondentes ao pico I em função da concentração de DTAB. (D) Gráficos das áreas correspondentes ao pico II em função da concentração de DTAB.
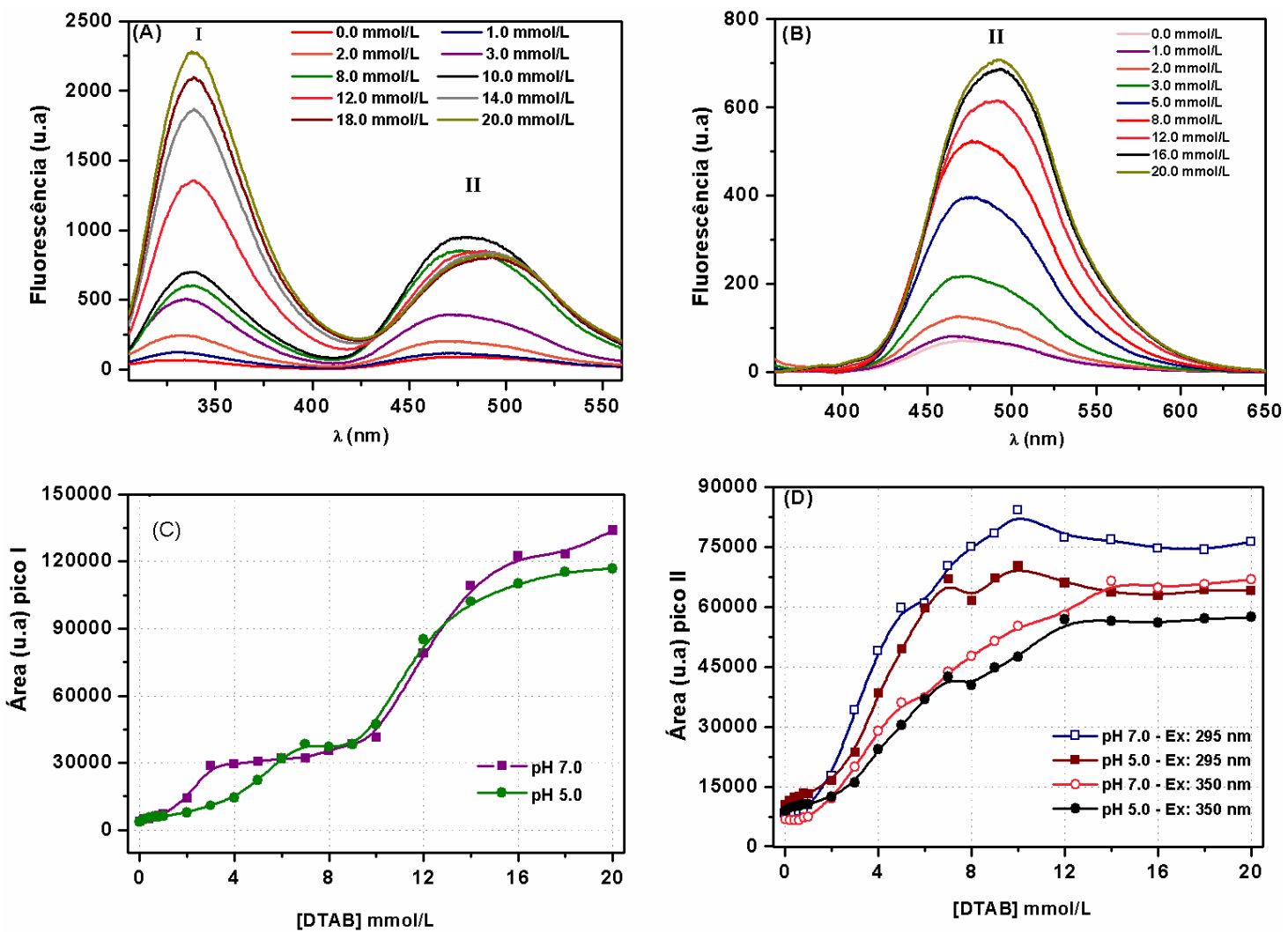

Tabela 2: Parâmetros espectroscópicos para oxi-HbGp na presença de diferentes concentrações de DTAB em tampão fosfato $30 \mathrm{mmol} / \mathrm{L}$.

$[\mathrm{DTAB}] \mathrm{mmol} / \mathrm{L}$

\begin{tabular}{ccccccc}
\hline Amostras & Propriedades & $\mathrm{pH}$ & 0,0 & 4,0 & 10,0 & 20,0 \\
\hline & Abs $^{\mathrm{a}}$ & 7,0 & 0,48 & 0,51 & 0,31 & 0,26 \\
& Área (u.a.) $^{\mathrm{b}}$ & 7,0 & 3.870 & 29.540 & 41.250 & 133.870 \\
HbGp-DTAB- & Área (u.a.) $^{\mathrm{b}}$ & 5,0 & 3.700 & 14.500 & 47.040 & 116.900 \\
ANS & $\lambda(\mathrm{nm})^{\mathrm{c}}$ & 7,0 & 331 & 335 & 337 & 340 \\
& $\lambda(\mathrm{nm})^{\mathrm{c}}$ & 5,0 & 330 & 335 & 336 & 338 \\
\hline
\end{tabular}

\footnotetext{
${ }^{a}$ Absorbância em $415 \mathrm{~nm}$ (banda de Soret)

${ }^{\mathrm{b}}$ Área total de emissão de fluorescência dos triptofanos (trp), com excitação em $295 \mathrm{~nm}$.

${ }^{c}$ Comprimento de onda do máximo de emissão de fluorescência dos triptofanos (trp), com excitação em $295 \mathrm{~nm}$.
} 
Com base nas figuras apresentadas acima, percebe-se que a interação da HbGp com o DTAB induz fenômenos diferentes na estrutura oligomérica da proteína. Em concentrações baixas de surfactante, até 4,0 $\mathrm{mmol} / \mathrm{L}$ (primeira fase), um aumento da emissão de fluorescência dos triptofanos é observado, atingindo um valor em torno de 29.540 u.a (Figura 15C, Tabela 02), no pH 7,0. Na faixa de concentração de DTAB, entre 4,0 a $10 \mathrm{mmol} / \mathrm{L}$, a intensidade de fluorescência permanece praticamente constante (segunda fase), entre 10,0 e 20,0 mmol/L de DTAB (terceira fase) um aumento de emissão significativo (133.870 u.a.) é observado (Figura 15C, Tabela 02), no pH 7,0. Vale ressaltar que mudanças bem semelhantes são observadas no pH 5,0. Na primeira fase, a interação HbGp-DTAB induz o aumento de emissão de fluorescência dos triptofanos, provavelmente, devido a dissociação oligomérica e a formação de agregados proteína-surfactante. O aumento significativo na intensidade de espalhamento de luz em 2,0 mmol/L de DTAB é uma forte evidência do processo de agregação (Figura 16A) que ocorre no pH 7,0. A última fase, iniciando em 9,0 mmol/L de surfactante, está, provavelmente, associada ao desenovelamento da HbGp e a formação de micelas de DTAB em solução (Figuras 15C e 12C). Experimentos de emissão de fluorescência usando pireno como sonda foram realizados com o propósito de monitorar a interação entre a mioglobina de cavalo e CTAC [68]. Os resultados apresentaram uma tendência bastante similar com a reportada neste trabalho para o sistema DTAB-HbGp. Estudos prévios da $\mathrm{HbGp}$ sugerem que o surfactante CTAC induz os processos de dissociação e agregação em concentrações mais baixas de surfactante, quando comparadas as de DTAB $[21,67]$. Na fase intermediária, entre 4,0 e $10,0 \mathrm{mmol} / \mathrm{L}$ de DTAB, o surfactante, provavelmente, liga nos sítios hidrofóbicos da proteína promovendo um aumento no número de cargas positivas na superfície da proteína. Convém salientar que o aumento das cargas na superfície da proteína induz a solubilização dos agregados sem nenhuma mudança significativa na emissão de fluorescência dos triptofanos (Figura 15C), e promove uma ligeira diminuição na intensidade de espalhamento (Figura 16A). No entanto, o aumento na emissão de fluorescência dos triptofanos (Figura 15C) e o deslocamento do $\lambda_{e m}^{\max }$ para o vermelho, de 337 para $340 \mathrm{~nm}$ (Tabela 02), na terceira fase, é atribuído à desnaturação da proteína, com maior exposição dos resíduos de triptofanos ao solvente. Estudos na literatura mostram que a exposição dos triptofanos para o ambiente hidrofílico induz deslocamento do comprimento de onda do máximo de emissão $\lambda_{e m}^{\max }$ para o vermelho, bem como, um aumento na intensidade de fluorescência [67,69]. 
Figura 16: (A) Gráficos das intensidades de espalhamento de luz e do deslocamento do comprimento de onda do máximo de emissão de fluorescência $\left(\lambda_{e m}^{\max } \mathrm{em} \mathrm{pH} 7,0\right)$ em função da concentração de DTAB. (B) Gráficos das áreas referentes ao pico II normalizadas a partir da concentração de 0,0 mmol/L de DTAB em função da concentração de surfactante. (C) Gráficos das áreas referentes ao pico I normalizadas a partir da concentração de $0,0 \mathrm{mmol} / \mathrm{L}$ de DTAB em função da concentração de surfactante.
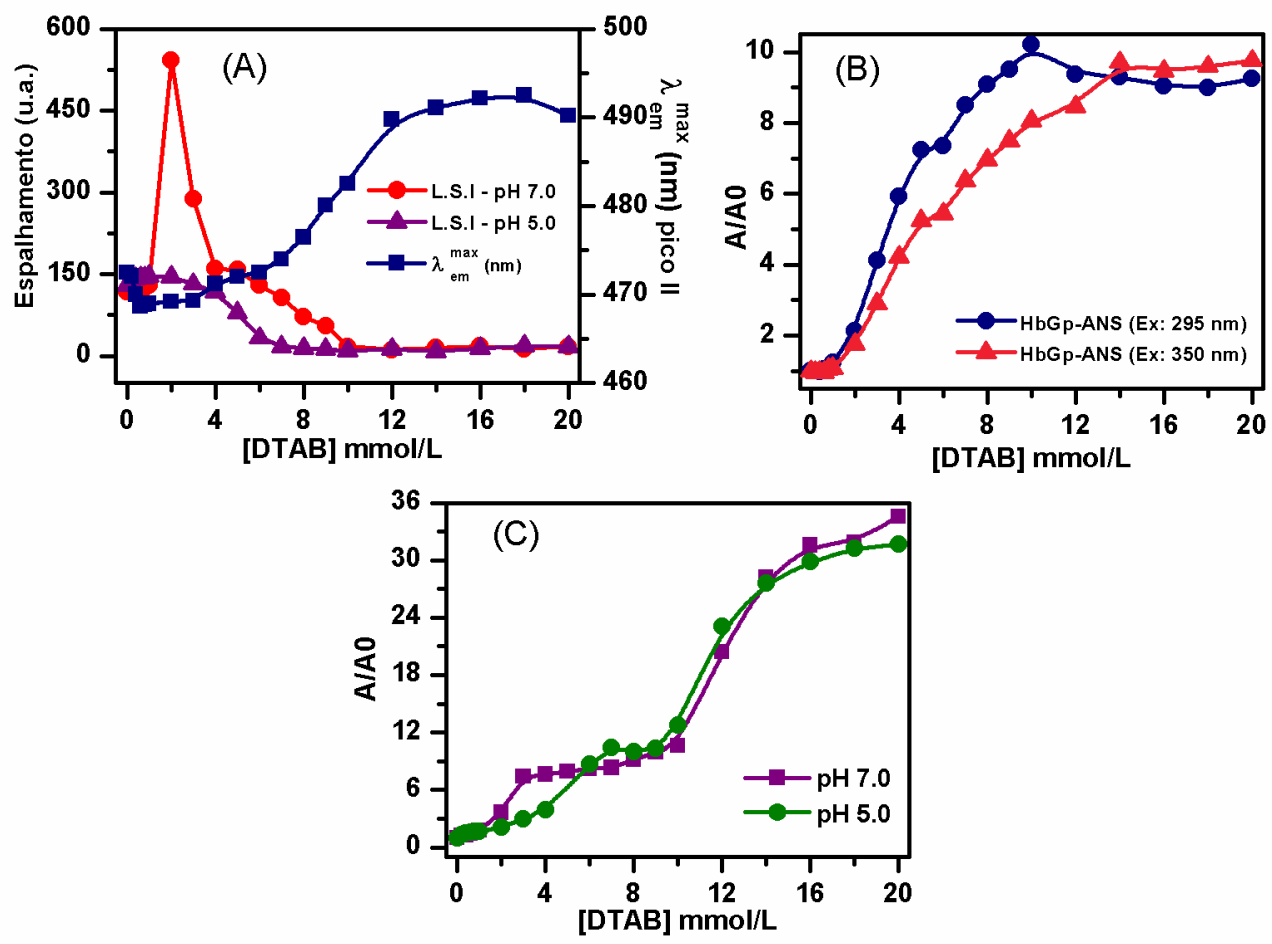

O aumento da concentração de DTAB até $12 \mathrm{mmol} / \mathrm{L}$, no $\mathrm{pH}$ 7,0, induz um aumento significativo na intensidade de emissão da sonda ANS como pode ser observado nas Figuras 15D e 16B. Por outro lado, o deslocamento do máximo de emissão para o vermelho, de 471 a 490 nm é mostrado na Figura 16A e Tabela 03. Como discutido anteriormente, o aumento na intensidade de emissão do ANS está relacionado à interação da sonda com os grupos hidrofóbicos da oxi-HbGp parcialmente desenovelada. Estudos na literatura sobre interações proteína-ANS sugerem que a sonda liga mais efetivamente a estados de proteínas parcialmente enovelados quando comparado aos estados nativo e desenovelado $[32,69]$. 
Tabela 3: Parâmetros espectroscópicos para a sonda ANS na presença da oxi-HbGp e de diferentes concentrações de DTAB em tampão fosfato $30 \mathrm{mmol} / \mathrm{L}, \mathrm{pH}$ 7,0.

\begin{tabular}{|c|c|c|c|c|c|c|}
\hline \multirow[b]{2}{*}{ Amostras } & \multirow[b]{2}{*}{ Propriedades } & \multirow[b]{2}{*}{$\lambda_{\text {exc }}(\mathrm{nm})$} & \multicolumn{4}{|c|}{ [DTAB] mmol/L } \\
\hline & & & 0,0 & 4,0 & 10,0 & 20,0 \\
\hline \multirow{4}{*}{$\begin{array}{c}\text { HbGp-DTAB- } \\
\text { ANS }\end{array}$} & Area (u.a.) $)^{a}$ & 295 & 8.240 & 59.670 & 84.000 & 76.300 \\
\hline & Area (u.a.) ${ }^{\mathrm{a}}$ & 350 & 6.850 & 28.890 & 55.220 & 66.870 \\
\hline & $\lambda(\mathrm{nm})^{\mathrm{b}}$ & 295 & 469 & 470 & 481 & 489 \\
\hline & $\lambda(\mathrm{nm})^{\mathrm{b}}$ & 350 & 472 & 471 & 483 & 490 \\
\hline
\end{tabular}

a Área total de emissão de fluorescência.

${ }^{\mathrm{b}}$ Comprimento de onda do máximo de emissão de fluorescência.

Embora os processos de agregação e dissociação oligomérica ocorram em baixas concentrações de DTAB, a baixa intensidade de emissão do ANS sugere que os grupos hidrofóbicos disponíveis são relativamente poucos para a sonda ligar na estrutura da oxiHbGp. Por outro lado, o máximo de emissão do ANS ( $\lambda_{e m}^{\max }$ ) em torno de $470 \mathrm{~nm}$ em baixas concentrações de surfactante indica que a sonda está menos exposta ao solvente, quando comparado ao valor de $\lambda_{e m}^{\max }$ em $490 \mathrm{~nm}$ em altas concentrações de DTAB (Figura 16A e Tabela 03). Quando a proteína encontra-se agregada, comparada ao estado parcialmente desnaturado, ocorre uma maior estabilização no estado excitado do ANS devido a uma menor exposição da sonda ao solvente [32]. Além disso, os dados obtidos neste trabalho mostram que a intensidade de emissão de fluorescência do ANS, excitado em $295 \mathrm{~nm}$, é sempre maior (por um fator em torno de 1,5) quando comparado aos obtidos com excitação em $350 \mathrm{~nm}$ (Figuras 15D e 16B). Esses resultados indicam que, provavelmente, ocorre transferência de energia parcial dos triptofanos da oxi-HbGp para a sonda ANS [32, 37, 40,41].

O processo de desenovelamento da proteína no $\mathrm{pH}$ 5,0 é semelhante ao observado no pH 7,0 (Figuras 15C, 15D e 16A). Entretanto, as áreas totais dos gráficos (pico I) mostram que a oxi-HbGp é mais estável no pH 5,0 do que no pH 7,0 (Figura 15C), uma vez que em meio ácido, o processo de agregação da oxi-HbGp provocado pelo DTAB não é observado, como pode ser visualizado a partir dos dados de espalhamento mostrados na Figura 16A. No pH 5,1, a oxi-HbGp apresenta um balanço de carga positiva em torno de $+4,0$, [67] na superfície da proteína, enquanto que no $\mathrm{pH}$ 6,5, a superfície apresenta balanço de carga negativa (em torno de - 7,0, [67]). Isto explica o fato das interações eletrostáticas em pH 5,0 serem desfavoráveis. Portanto, no sistema DTAB-HbGp não ocorre a neutralização das cargas 
na superfície da proteína e, consequentemente, o processo de agregação não é observado como verificado no $\mathrm{pH}$ 7,0. Estudos anteriores sobre os efeitos do CTAC na estabilidade oligomérica da oxi-HbGp apresentaram resultados similares [67]. As intensidades das curvas de emissão do ANS, em pH 5,0, exibem valores menores que em $\mathrm{pH}$ 7,0, sugerindo que os grupos hidrofóbicos da proteína são menos acessíveis para a sonda ANS em meio ácido (Figura 15D). Além disso, esses resultados mostram que, em pH 5,0 a estrutura oligomérica da oxi-HbGp é mais compacta do que em pH 7,0. Estudos recentes têm mostrado que a $\mathrm{HbGp}$, em $\mathrm{pH} 5,0$, exibe uma maior temperatura crítica para o desenovelamento quando comparado ao meio neutro [26], uma vez que para valores de $\mathrm{pH}$ próximos ao ponto isoelétrico $(\mathrm{pI}=5,5$, [67]) a proteína é mais estável. Estes resultados são bastante consistentes com os dados mostrados na Tabela 02, onde os dados de fluorescência indicam que os triptofanos estão menos expostos ao solvente, em pH 5,0 [67,70].

\subsubsection{Dados de DLS}

O diâmetro médio hidrodinâmico (Z-médio), em função da concentração de DTAB, é mostrado na Figura 17A. Inicialmente, até $1,0 \mathrm{mmol} / \mathrm{L}$ de DTAB, a $\mathrm{HbGp}$ apresenta $\mathrm{D}_{\mathrm{H}}$ em torno de 27,8 \pm 0,4 nm, característico da proteína íntegra (Tabela 04 e Figura 17A). O valor baixo do índice de polidispersão (PDI) observado até 1,0 mmol/L de surfactante sugere que a solução é bastante homogênea e monodispersa (Tabela 04). O aumento da concentração de DTAB induz um decréscimo simultâneo nos valores de $\mathrm{D}_{\mathrm{H}}$ de 27,8 para 9 nm, e de contagem, que são característicos da dissociação oligomérica (Tabela 04 e Figura 17A). Estudos recentes das subunidades isoladas da HbGp pura por ultracentrifugação analítica e DLS mostraram que os valores de $\mathrm{D}_{\mathrm{H}}$ na faixa de 8,7 - 10,0 nm são característicos do dodecâmero (abcd) 3 [71]. No entanto, o aumento nos valores de PDI pode estar associado à presença de uma mistura de diferentes espécies em solução (Tabela 04). As curvas de distribuição de intensidade de espalhamento e do número de partículas, em função da concentração de DTAB para oxiHbGp $(0,3 \mathrm{mg} / \mathrm{mL})$, pH 7,0, são mostradas nas Figuras 17B e 17C, respectivamente, para algumas concentrações de surfactante. As curvas de distribuição de intensidade de 0,0 e 1,0 $\mathrm{mmol} / \mathrm{L}$ de DTAB mostram um único pico centrado em $28 \mathrm{~nm}$, enquanto que em concentrações maiores de surfactante, duas contribuições são observadas. A primeira 
contribuição em torno de 8,6 nm é atribuída a espécies dissociadas e a segunda em $220 \mathrm{~nm}$ é devido à contribuição de agregados e proteína desnaturada. Além disso, em 2,0 mmol/L de surfactante, os perfis das curvas (Figura 17B), o índice de polidispersão (Tabela 04) e a largura em meia altura indicam a presença de agregados, como reportado anteriormente nos dados de espalhamento obtidos no espectrofluorímetro (Figura 16A). A distribuição do número de partículas sugere que, inicialmente, em baixa concentração de DTAB, a HbGp nativa é a espécie predominante em solução, e o aumento na concentração de surfactante promove a dissociação oligomérica e a formação de subunidades menores ( Figura 17C). Por outro lado, a contribuição de espécies agregadas e/ou desnaturadas nas curvas de distribuição do número de partículas não é observada e, provavelmente, isto é atribuído à concentração baixa dessas espécies no equilíbrio (Figura 17C). Portanto, os dados de DLS mostram claramente que a primeira transição descrita na seção de emissão de fluorescência (1.3.2), em 2,0 mmol/L de DTAB (Figura 17C), é devida à dissociação oligomérica.

Figura 17: (A) Diâmetro hidrodinâmico $\left(\mathrm{D}_{\mathrm{H}}\right)$ para oxi-HbGp, $(0,3 \mathrm{mg} / \mathrm{mL})$ em função de diferentes concentrações de DTAB. (B) Curvas da distribuição de intensidade de espalhamento. (C) Curvas de distribuição do número de partículas.
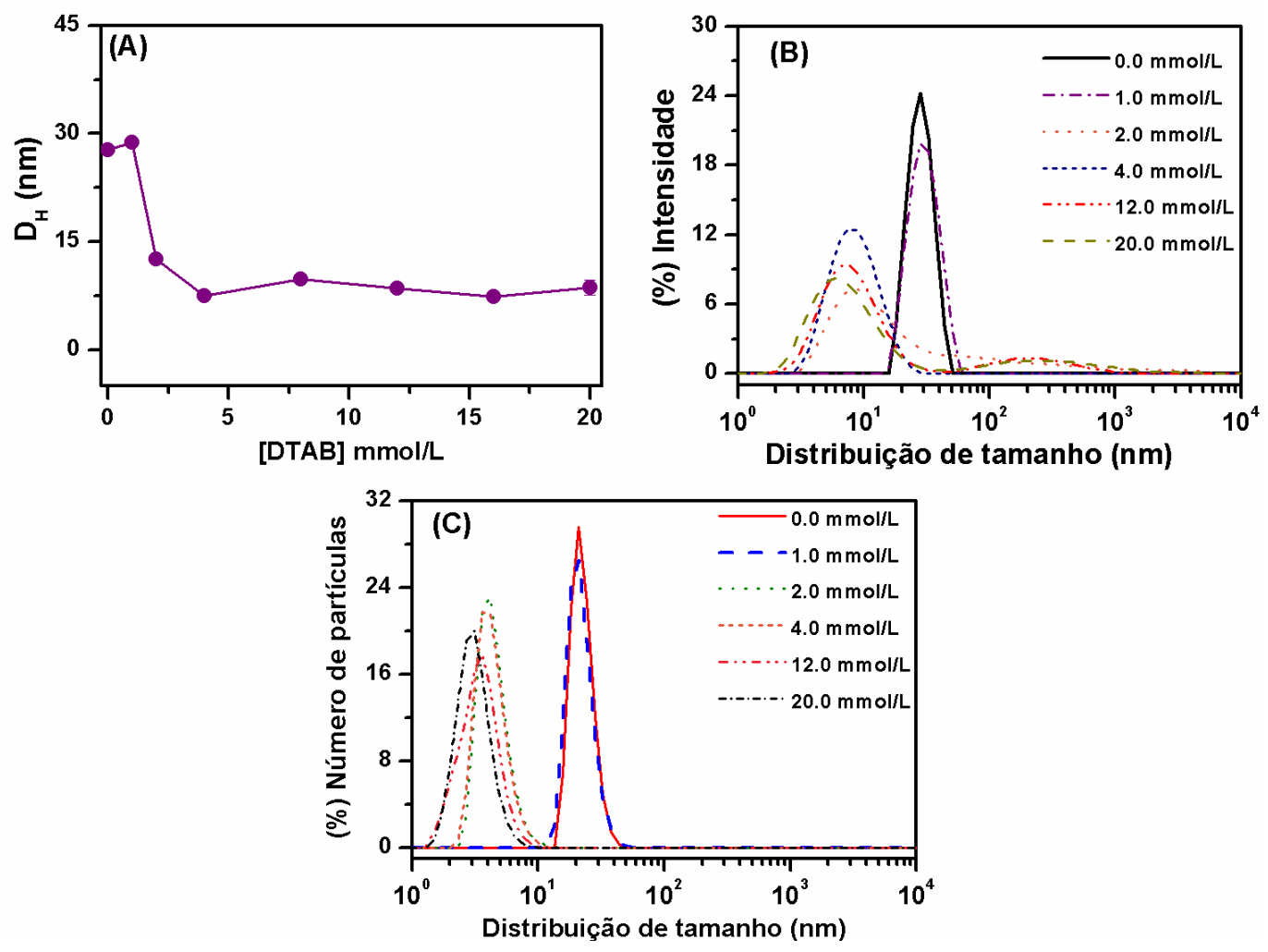
Tabela 4: Propriedades hidrodinâmicas da oxi-HbGp $(0,3 \mathrm{mg} / \mathrm{mL})$, em concentrações diferentes de DTAB em tampão fosfato $30 \mathrm{mmol} / \mathrm{L}$, $\mathrm{pH}$ 7,0, obtidas dos dados de DLS.

\begin{tabular}{cccccc}
\hline & \multicolumn{5}{c}{ Propriedades Hidrodinâmicas } \\
\hline$[\mathrm{DTAB}] \mathrm{mmol} / \mathrm{L}$ & $\mathrm{D}_{\mathrm{H}}(\mathrm{nm})^{\mathrm{a}}$ & $\mathrm{D}_{\mathrm{H}}(\mathrm{nm})^{\mathrm{b}}$ & $\mathrm{PDI}^{\mathrm{c}}$ & $\begin{array}{c}\text { Largura } \\
(\mathrm{nm})^{\mathrm{d}}\end{array}$ & $\begin{array}{c}\text { Contagem } \\
(\mathrm{kcps})^{\mathrm{e}}\end{array}$ \\
\hline 0,0 & $27,8 \pm 0,4$ & $28,6 \pm 0,5$ & 0,004 & $11 \pm 1$ & $207 \pm 1$ \\
1,0 & $28,8 \pm 0,2$ & $30,8 \pm 0,5$ & 0,006 & $12 \pm 1$ & $278 \pm 5$ \\
2,0 & $13 \pm 2$ & $10 \pm 1$ & 0,44 & $15 \pm 1$ & $96 \pm 5$ \\
4,0 & $8 \pm 1$ & $9 \pm 1$ & 0,22 & $10 \pm 1$ & $97 \pm 7$ \\
12,0 & $9 \pm 1$ & $8 \pm 1$ & 0,30 & $10 \pm 1$ & $86 \pm 8$ \\
20,0 & $9 \pm 1$ & $8 \pm 1$ & 0,25 & $9 \pm 1$ & $106 \pm 10$ \\
\hline
\end{tabular}

${ }^{\mathrm{a}}$ Diâmetro hidrodinâmico médio obtido por DLS.

${ }^{\mathrm{b}}$ Diâmetro hidrodinâmico do pico mais intenso mostrado na Figura 17B.

${ }^{c}$ PDI é o índice de polidispersão.

${ }^{\mathrm{d}}$ Largura da meia altura do primeiro pico das distribuições de tamanho, a $20^{\circ} \mathrm{C}$, mostrado na Figura 9B.

${ }^{\mathrm{e}}$ Contagem em kilociclos por segundo (kcps).

\subsubsection{Efeitos do Cloridrato de Guanidina (GuHCl) na estrutura oligomérica da oxi-HbGp, em} pH 7,0.

\subsubsection{Dados de absorção óptica}

A Figura 18A mostra os espectros de absorção óptica da oxi-HbGp, no pH 7,0, enquanto que a Figura 18B exibe a absorbância em $415 \mathrm{~nm}$ e o comprimento de onda do máximo de absorção da banda de Soret, $\lambda_{a b s}^{\max }$, em função da concentração de GuHCl. Vale salientar que as bandas de absorção características da forma nativa da proteína, banda de Soret centrada em $415 \mathrm{~nm}$, e bandas Q ( $\alpha$ e $\beta$ ) centradas em 540 e $575 \mathrm{~nm}$, respectivamente, são observadas até $1,3 \mathrm{~mol} / \mathrm{L}$ de $\mathrm{GuHCl}$, sugerindo que concentrações abaixo de 1,3 mol/L não promovem a oxidação do ferro do grupo heme [72]. Entretanto, em concentrações mais altas de cloridrato de guanidina, acima de $1,5 \mathrm{~mol} / \mathrm{L}$, um decréscimo abrupto na intensidade de absorção e o deslocamento da banda de Soret para o azul são observados, o que pode estar associado à oxidação do ferro e formação de novas espécies em solução (Figuras 18A e 18B). 
O alargamento das bandas espectrais e a diminuição da intensidade de absorção do grupo heme são típicos da alteração estrutural da proteína associada à dissociação oligomérica e desenovelamento da HbGp [21,72]. A espécie oxidada, meta-HbGp, que é formada em concentrações acima de 1,5 mol/L de $\mathrm{GuHCl}$, caracteriza-se por uma banda de Soret larga, com comprimento de onda máximo de absorção em torno de 402 - 405 nm.

Figura 18: (A) Espectros de absorção óptica da oxi-HbGp $(0,1 \mathrm{mg} / \mathrm{mL})$ na presença de diferentes concentrações de $\mathrm{GuHCl}$ e $10 \mu \mathrm{mol} / \mathrm{L}$ de ANS em tampão fosfato de sódio $30 \mathrm{mmol} / \mathrm{L}$, pH 7,0. (B) Gráficos da absorbância na banda de Soret $(415 \mathrm{~nm})$ e do máximo de absorção desta banda em função da concentração de GuHCl.
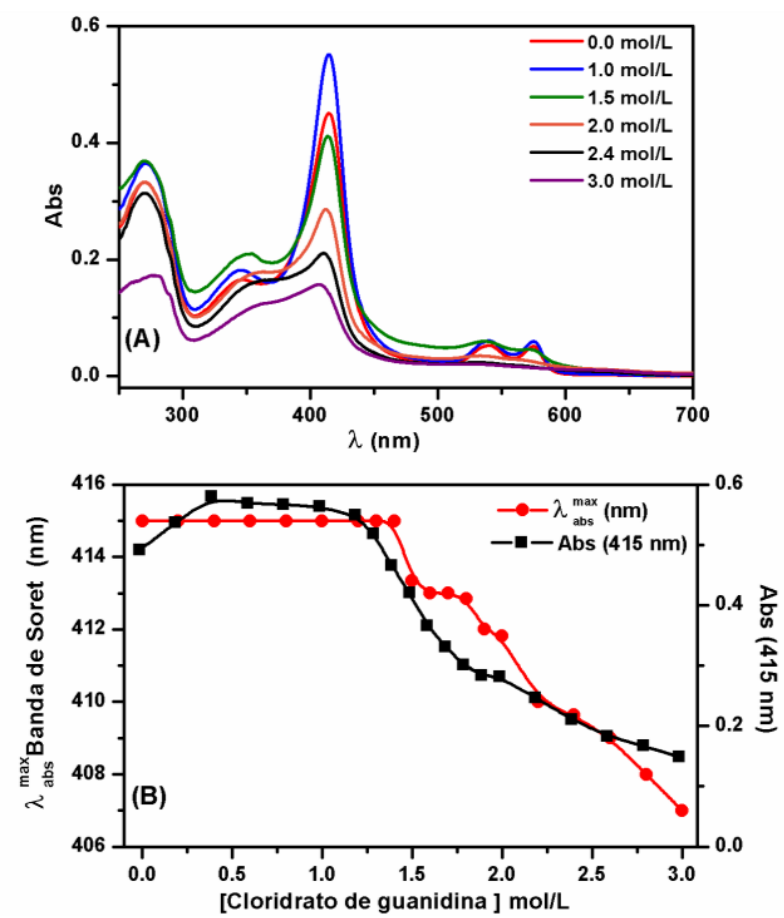

\subsubsection{Dados de emissão de fluorescência}

Os espectros de emissão de fluorescência da oxi-HbGp, em diferentes concentrações de cloridrato de guanidina, estão apresentados na Figura 19A. A intensidade de fluorescência dos triptofanos e o máximo de emissão $\left(\lambda_{e m}^{m a ́ x}\right)$ permanecem constantes até $0,8 \mathrm{~mol} / \mathrm{L}$ de $\mathrm{GuHCl}$, indicando que o agente desnaturante não induz mudanças significativas no ambiente dos triptofanos nesta faixa de concentração (Figuras 19B e 19C). No entanto, um decréscimo significativo na intensidade de espalhamento (Figura 19B), na faixa de 1,0 a 1,5 mol/L de desnaturante é observado, sendo atribuído, provavelmente, ao aumento de espécies de baixo 
peso molecular em solução devido à dissociação oligomérica. O aumento de GuHCl leva à dissociação oligomérica, sem mudanças significativas na estrutura terciária das espécies dissociadas [73].

Em altas concentrações de $\mathrm{GuHCl}$, acima de 1,0 mol/L, a emissão de fluorescência dos triptofanos (pico I) aumenta significativamente, atingindo o valor de 87.730 u.a (um aumento de 21 vezes quando comparado ao valor de emissão na ausência de $\mathrm{GuHCl}$ ) em 3,0 mol/L (Tabela 05, Figuras 19B e 20A).

Figura 19: Espectros de emissão de fluorescência da oxi-HbGp $(0,1 \mathrm{mg} / \mathrm{mL})$ na presença de diferentes concentrações de $\mathrm{GuHCl}$ e $10 \mu \mathrm{mol} / \mathrm{L}$ de ANS em tampão fosfato de sódio $30 \mathrm{mmol} / \mathrm{L}$, pH 7,0. (B) Gráficos da área total (pico I) de emissão de fluorescência e espalhamento em função da concentração de $\mathrm{GuHCl}$. (C) Gráficos da variação do comprimento de onda de emissão de fluorescência dos picos I e II em função da concentração de $\mathrm{GuHCl}$. (D) Gráficos da intensidade de emissão de fluorescência do ANS em função da concentração de $\mathrm{GuHCl}$.
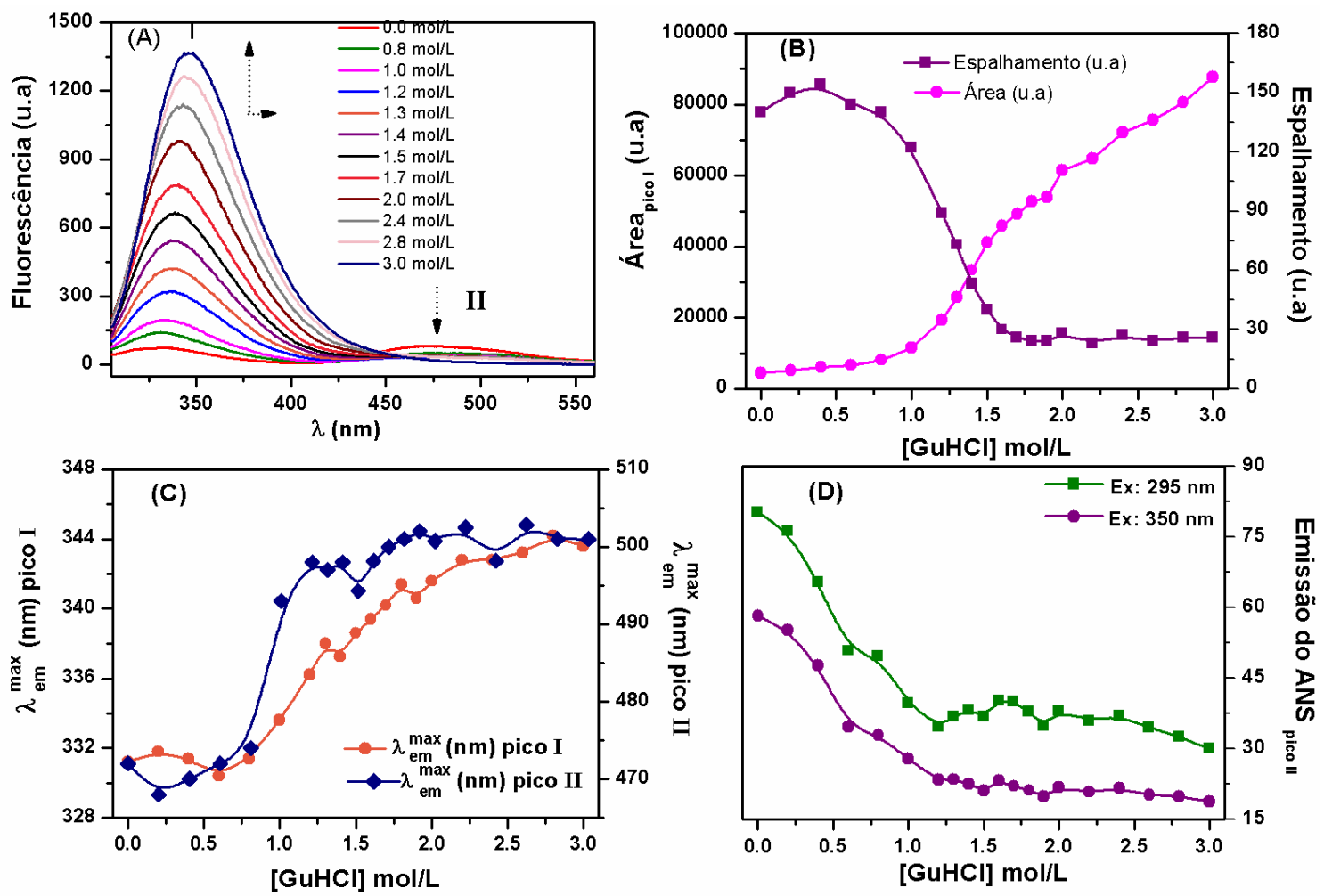
Tabela 5: Parâmetros espectroscópicos para oxi-HbGp em GuHCl e ANS, em tampão fosfato $30 \mathrm{mmol} / \mathrm{L}, \mathrm{pH} 7,0$.

\begin{tabular}{cccccc}
\hline & & \multicolumn{4}{c}{$[\mathrm{GuHCl}] \mathrm{mol} / \mathrm{L}$} \\
\hline Amostras & Propriedades & 0,0 & 1,0 & 1,7 & 3,0 \\
\hline \multirow{2}{*}{ HbGp-GuHCl- } & Abs $^{\mathrm{a}}$ & 0,49 & 0,56 & 0,33 & 0,14 \\
ANS & Área (u.a.) & 4.430 & 11.500 & 49.270 & 87.730 \\
& $\lambda_{e m}^{\max }(\mathrm{nm})^{\mathrm{c}}$ & 331 & 334 & 340 & 347 \\
\hline
\end{tabular}

${ }^{\mathrm{a}}$ Absorbância em $415 \mathrm{~nm}$ (banda de Soret).

b Área total de emissão de fluorescência dos triptofanos, com excitação em $295 \mathrm{~nm}$.

${ }^{c}$ Comprimento do máximo de emissão de Fluorescência $\left(\lambda_{e m}^{\max }\right)$ do triptofano (Trp), com excitação em $295 \mathrm{~nm}$.

Adicionalmente, altas concentrações de $\mathrm{GuHCl}$ induzem um deslocamento intenso para o vermelho do máximo de emissão $\lambda_{e m}^{\text {máx }}$ dos triptofanos de 331 para $347 \mathrm{~nm}$ (Tabela 05), consistente com o aumento de exposição dos fluoróforos ao solvente, devido ao desenovelamento da proteína $[35,67,70]$. A desnaturação da proteína promove um aumento na intensidade de emissão de fluorescência, em razão da diminuição de transferência de energia dos triptofanos para o átomo de ferro dos grupos heme [27, 67,70]. Contudo, os valores baixos na intensidade de espalhamento (Figura 19B) mostram que a oxi-HbGp acima de 1,5 mol/L de desnaturante, encontra-se totalmente dissociada em subunidades de pesos moleculares mais baixos.

Figura 20: Gráficos normalizados da (A) área correspondente ao pico I e da(B) intensidade de emissão de fluorescência a partir da concentração de $0,0 \mathrm{mmol} / \mathrm{L}$ de $\mathrm{GuHCl}$ em função da concentração de desnaturante.
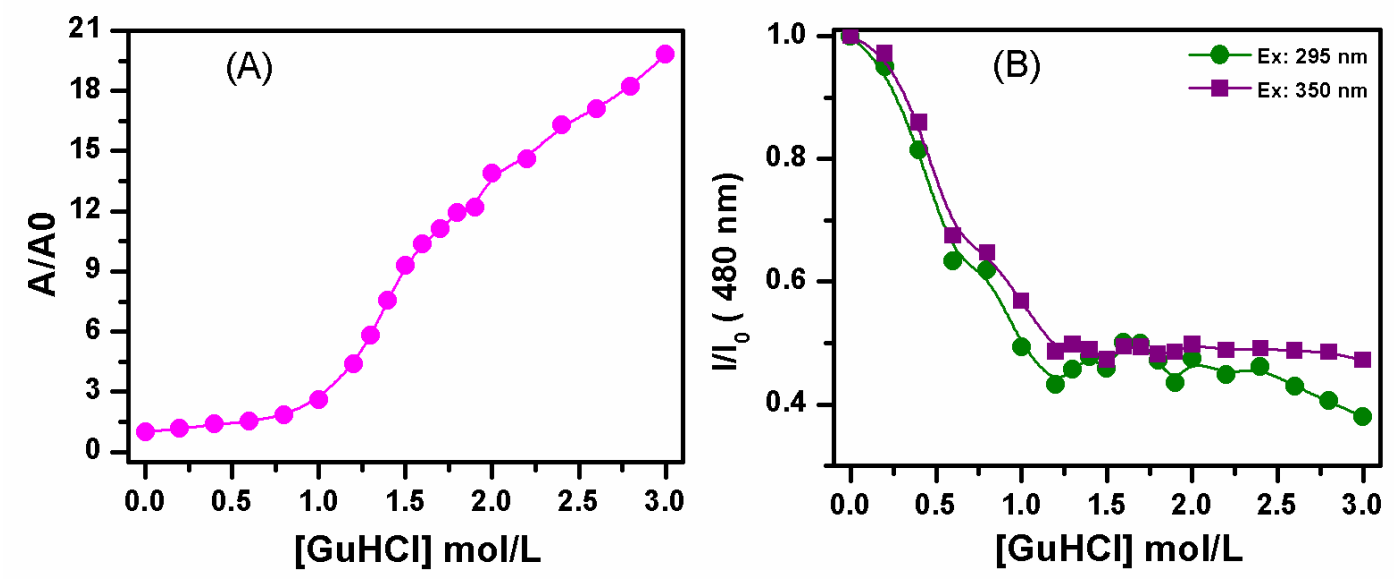
Tabela 6: Parâmetros espectroscópicos para a sonda ANS na presença da oxi-HbGp e GuHCl em tampão fosfato $30 \mathrm{mmol} / \mathrm{L}, \mathrm{pH} 7,0$.

\begin{tabular}{ccccccc}
\hline & & \multicolumn{5}{c}{$[\mathrm{GuHCl}] \mathrm{mol} / \mathrm{L}$} \\
\hline Amostra & Propriedades & $\lambda_{\text {exc }}(\mathrm{nm})$ & 0,0 & 1,0 & 1,7 & 3,0 \\
\hline \multirow{2}{*}{ HbGp-GuHCl- } & Intensidade (u.a.) $)^{\mathrm{a}}$ & 295 & 81 & 40 & 40 & 35 \\
ANS & ${\text { Intensidade (u.a.) })^{\mathrm{a}}}$ & 350 & 59 & 28 & 22 & 18 \\
& $\lambda_{e m}^{\max }(\mathrm{nm})^{\mathrm{b}}$ & 350 & 472 & 493 & 500 & 501 \\
\hline
\end{tabular}

${ }^{\mathrm{a}}$ Intensidade de emissão de fluorescência do ANS em $480 \mathrm{~nm}$.

${ }^{\mathrm{b}}$ Comprimento de onda do máximo de emissão de fluorescência $\left(\lambda_{e m}^{\max }\right)$.

O aumento da concentração de cloridrato de guanidina promove um decréscimo intenso na emissão de fluorescência da sonda ANS e um deslocamento do máximo de emissão para o vermelho $\left(\lambda_{e m}^{\max }\right)$ de 472 para $501 \mathrm{~nm}$ (Tabela 06, Figuras 19C e 19D). A redução de fluorescência do ANS é observada até $1,0 \mathrm{~mol} / \mathrm{L}$ de desnaturante, sugerindo que $\mathrm{GuHCl}$ reduz os grupos hidrofóbicos na superfície da oxi-HbGp (Figura 20B). Togashi e Ryder [74] mostraram que $\mathrm{GuHCl}$ promove uma diminuição significativa de todos os três tempos de vida do ANS na presença de BSA. Esta redução está, provavelmente, associada à exposição gradual dos sítios hidrofóbicos da BSA para o meio aquoso, com redução na intensidade de fluorescência. Portanto, a diminuição intensa na intensidade de fluorescência da sonda é atribuída ao desenovelamento completo da proteína em altas concentrações de $\mathrm{GuHCl}$, quando comparado ao estado parcialmente desenovelado da oxi-HbGp na presença do surfactante catiônico DTAB [29]. Além disso, o fluoróforo ANS está mais exposto ao solvente em altas concentrações de $\mathrm{GuHCl}\left(\lambda_{e m}^{\max }=501 \mathrm{~nm}\right.$, Tabela 06 e Figura 19C) do que na presença de DTAB ( $\lambda_{e m}^{\max }=490 \mathrm{~nm}$, Tabela 03 e Figura 16A), e a superfície hidrofóbica aumenta notavelmente com adição de surfactante [75]. A Figura 19D mostra ainda que a intensidade de emissão de fluorescência do ANS é maior quando as amostras são excitadas em $295 \mathrm{~nm}$ do que quando excitado em $350 \mathrm{~nm}$. Este comportamento é atribuído à transferência parcial de energia dos triptofanos da proteína para a sonda ANS [32,37, 40,41]. 
4.1.6. Efeitos da ureia na estrutura da oxi-HbGp, em $p H$ 7,0.

\subsubsection{Dados de absorção óptica}

Os espectros de absorção óptica da oxi-HbGp, no pH 7,0, em função da concentração de ureia são apresentados na Figura 21A, enquanto a Figura 21B mostra a absorbância em 415 nm (Banda de Soret) e o comprimento de onda de absorção desta banda, em função da concentração de ureia. A partir desses espectros observa-se um alargamento e redução na intensidade da banda de Soret [27]. Além disso, em concentrações altas de ureia, observa-se um deslocamento para o azul desta banda (Soret), que pode ser atribuído à oxidação do ferro, e a formação de espécies oxidadas, tais como, aquo-meta e hemicromo, e provavelmente, à dissociação oligomérica da oxi-HbGp. Efeitos semelhantes foram notados para a oxi-HbGp na presença do agente caotrópico cloridrato de guanidina $(\mathrm{GuHCl})$ descritos anteriormente, porém, em concentrações mais baixas desse agente desnaturante. Estudos prévios de ultracentrifugação analítica e espectroscópicos mostraram que a adição de $4.0 \mathrm{~mol} / \mathrm{L}$ de ureia induz a dissociação oligomérica da $\mathrm{HbGp}$ em diferentes subunidades, tais como, o dodecâmero $(\mathbf{a b c d})_{3}$, o tetrâmero abcd, o trímero abc e o monômero d, antes da oxidação do grupo heme, e, acima de 4,5 e 5,0 mol/L de ureia, as subunidades dissociadas se desnaturam [ $71,73]$. 
Figura 21: (A) Espectros de absorção óptica da oxi-HbGp $(0,1 \mathrm{mg} / \mathrm{mL})$ na presença de diferentes concentrações de ureia e $10 \mu \mathrm{mol} / \mathrm{L}$ de ANS em tampão fosfato de sódio $30 \mathrm{mmol} / \mathrm{L}, \mathrm{pH}$ 7,0. (B) Gráficos da absorbância na banda de Soret $(415 \mathrm{~nm})$ e do comprimento de onda do máximo de absorção desta banda em função da concentração de ureia.
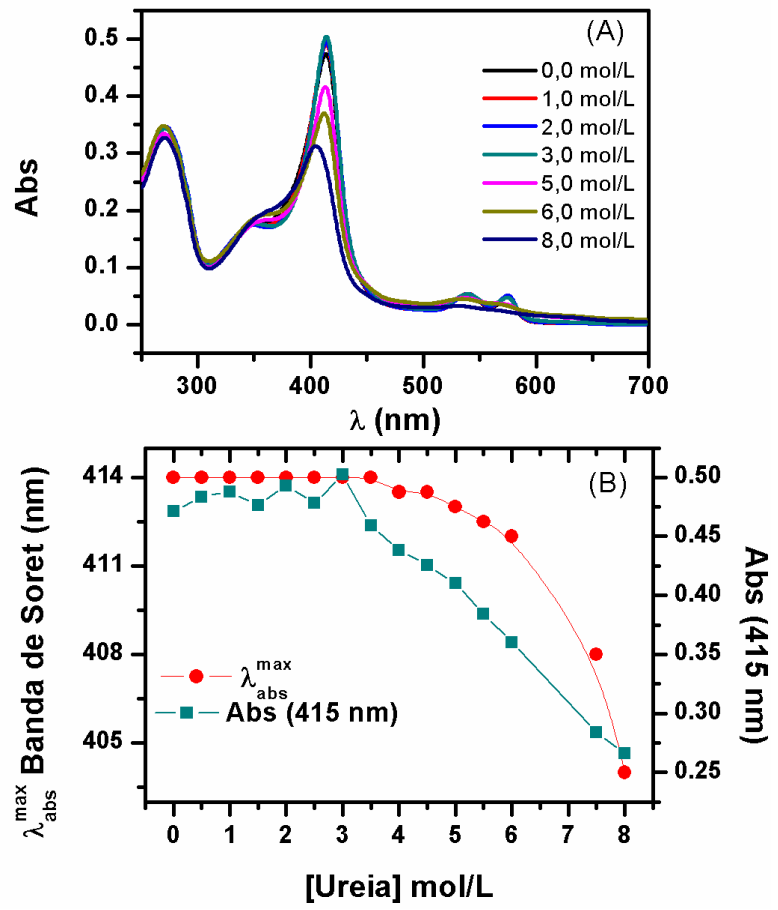

\subsubsection{Dados de emissão de fluorescência}

Na Figura 22A os espectros de emissão da oxi-HbGp são mostrados na presença da sonda ANS, em função da concentração de ureia. Os picos I e II correspondem à emissão dos resíduos de triptofanos e da sonda ANS, respectivamente. O comprimento de onda do máximo de emissão $\left(\lambda_{e m}^{\max }\right)$ e a intensidade de emissão dos triptofanos (área do pico I) mantêm-se constantes até $2,0 \mathrm{~mol} / \mathrm{L}$ de ureia, sugerindo que nesta concentração a ureia não provoca mudanças significativas no ambiente dos triptofanos (Figuras 22B, 22C e 23A). Entretanto, na Figura 22B observa-se um decréscimo significativo na intensidade de espalhamento, na faixa de 2,5 a $5,5 \mathrm{~mol} / \mathrm{L}$ de desnaturante, atribuído, provavelmente, à formação de espécies de baixo peso molecular em solução, uma vez que o acréscimo de agente desnaturante induz a dissociação do oligômero, sem mudanças significativas na estrutura terciária dessas espécies [73]. 
É importante destacar que em concentrações de ureia, acima de 2,0 mol/L, a emissão de fluorescência dos triptofanos (pico I) aumenta significativamente. Em 8,0 mol/L de ureia, o valor da intensidade de emissão é 86591 u.a. que corresponde a um aumento de aproximadamente 16 vezes comparado ao valor inicial na ausência de desnaturante (Tabela 07, Figuras 22B e 23A). Além disso, verifica-se um deslocamento do $\lambda_{e m}^{\max }$ para o vermelho, de 327 para $348 \mathrm{~nm}$, indicando aumento na exposição dos triptofanos ao solvente devido ao desenovelamento da proteína $[27,67,70]$.

Figura 22: (A) Espectros de emissão de fluorescência da oxi-HbGp $(0,1 \mathrm{mg} / \mathrm{mL})$ na presença de diferentes concentrações de ureia e $10 \mu \mathrm{mol} / \mathrm{L}$ de ANS em tampão fosfato de sódio $30 \mathrm{mmol} / \mathrm{L}$, pH 7,0. (B) Gráficos da área total (pico I) de emissão de fluorescência e espalhamento em função da concentração de ureia. (C) Gráficos da variação do comprimento de onda de emissão de fluorescência do pico I e II em função da concentração de ureia. (D) Gráficos de intensidade de emissão de fluorescência a $480 \mathrm{~nm}$ em função da concentração de ureia.
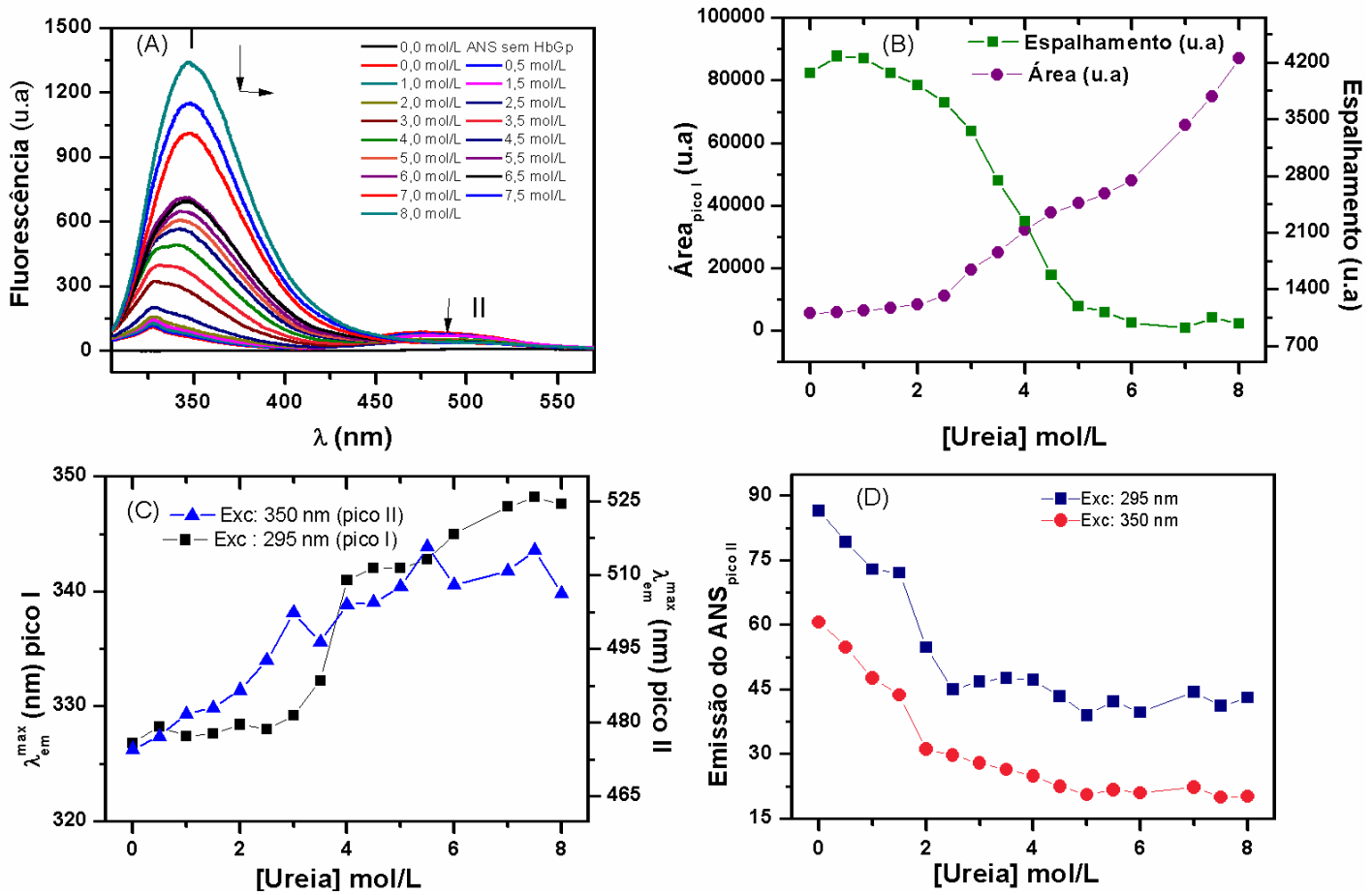
Tabela 7: Parâmetros espectroscópicos para oxi-HbGp na presença de ureia e ANS em tampão fosfato $30 \mathrm{mmol} / \mathrm{L}, \mathrm{pH} 7,0$.

\begin{tabular}{cccccc}
\hline & \multicolumn{5}{c}{ [Ureia] mol/L } \\
\hline Amostras & Propriedades & 0,0 & 2,0 & 5,5 & 8,0 \\
\hline HbGP-Ureia- & Área (u.a) ${ }^{\mathrm{a}}$ & 5.549 & 11.222 & 43.752 & 86.951 \\
ANS & $\lambda_{e m}^{\max }(\mathrm{nm})^{\mathrm{b}}$ & 327 & 328 & 343 & 348 \\
\hline
\end{tabular}

aÁrea total de emissão de fluorescência. ${ }^{\mathrm{b}}$ Comprimento de onda do máximo de emissão de fluorescência $\left(\lambda_{e m}^{\max }\right)$ dos triptofanos.

Figura 23: Gráficos normalizados da (A) área correspondente ao pico I e da(B) intensidade de emissão de fluorescência a partir da concentração de $0,0 \mathrm{mmol} / \mathrm{L}$ de ureia em função da concentração de desnaturante.
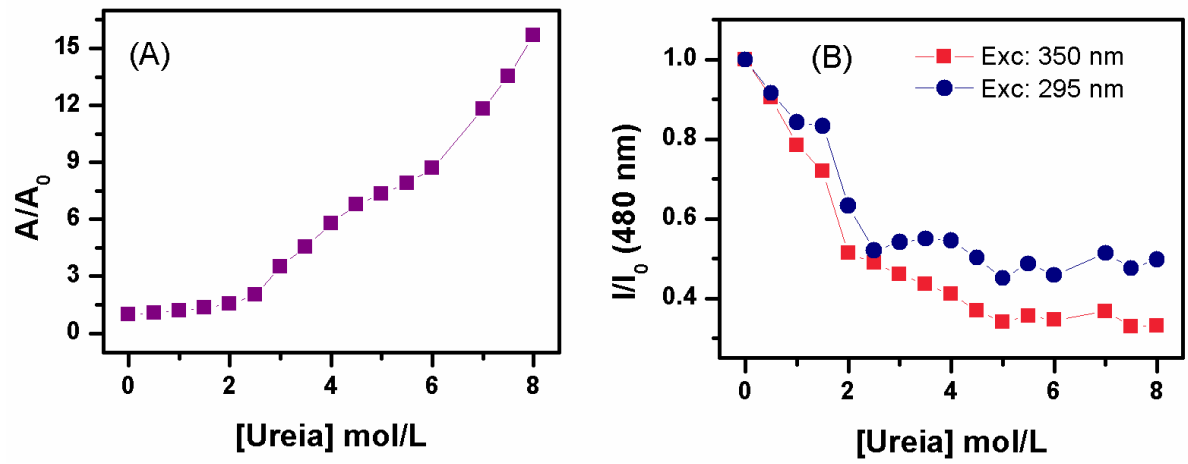

Tabela 8: Parâmetros espectroscópicos para a sonda ANS na presença da oxi-HbGp e ureia em tampão fosfato $30 \mathrm{mmol} / \mathrm{L}$, pH 7,0.

\begin{tabular}{ccccccc}
\hline & & \multicolumn{5}{c}{ [Ureia] mol/L } \\
\hline Amostra & Propriedades & $\lambda_{\text {exc }}(\mathrm{nm})$ & 0,0 & 2,5 & 5,5 & 8,0 \\
\hline \multirow{2}{*}{ HbGp-Ureia- } & Intensidade (u.a) $^{\mathrm{a}}$ & 295 & 86 & 45 & 43 & 42 \\
ANS & Intensidade (u.a) $^{\mathrm{a}}$ & 350 & 60 & 30 & 22 & 20 \\
& $\lambda_{e m}^{\max }(\mathrm{nm})^{\mathrm{b}}$ & 350 & 474 & 492 & 507 & 515 \\
\hline
\end{tabular}

${ }^{\mathrm{a}}$ Intensidade de emissão de fluorescência em $480 \mathrm{~nm}$.
${ }^{\mathrm{b}}$ Comprimento de onda do máximo de emissão de fluorescência $\left(\lambda_{e m}^{\max }\right)$ do ANS.

Por outro lado, o aumento da concentração de ureia causa um decréscimo considerável na emissão de fluorescência da sonda ANS e um deslocamento do comprimento de onda do máximo de emissão $\left(\lambda_{e m}^{\max }\right)$ para o vermelho, de 350 para $515 \mathrm{~nm}$ (Tabela 08, Figuras 22D e 23B), semelhante ao induzido pela $\mathrm{GuHCl}$. A redução de fluorescência do ANS é observada na faixa até $2,0 \mathrm{~mol} / \mathrm{L}$ de ureia, podendo ser atribuída ao fato do agente desnaturante diminuir a afinidade da sonda pela superfície da oxi-HbGp, deslocando-a para o meio aquoso (Figura 23B). Por isso, observa-se uma baixa intensidade de fluorescência da 
sonda ANS em altas concentrações de desnaturante, uma vez que essa sonda é praticamente não fluorescente em solução aquosa [32,35].

4.1.7. Oxi-HbGp em diferentes valores de $p H$, na presença da sonda ANS.

\subsubsection{Dados de absorção óptica}

A Figura 24A apresenta os espectros de absorção óptica da oxi-HbGp em diferentes valores de $\mathrm{pH}$, na presença da sonda ANS. Nesses espectros observa-se a redução na intensidade da banda de Soret. A absorbância na banda de Soret (415 nm) é mostrada na Figura 24B. Na faixa de $\mathrm{pH} 3,45$ a 5,0, mudanças abruptas no ambiente do grupo heme são observadas, indicando que a proteína encontra-se oxidada o que é consistente com os resultados apresentados por Santiago et al [67]. Além disso, na faixa de pH de 8,0 a 10,0, também ocorrem mudanças, porém, menos intensas que em meio ácido [21]. Na Figura 24C é mostrada a variação do comprimento de onda máximo da banda de Soret, onde se verifica um comportamento de pouca variação exceto para o valor de $\mathrm{pH} 3,45$, uma vez que, nesse valor de $\mathrm{pH}$ a proteína está, provavelmente, totalmente desenovelada e desnaturada [67]. É importante destacar que a presença da sonda ANS não apresenta mudanças significativas no sistema, detectadas no espectro de absorção. 
Figura 24: (A) Espectros de absorção óptica da oxi-HbGp $(0,1 \mathrm{mg} / \mathrm{mL})$, em diferentes valores de $\mathrm{pH}$ e na presença de $10 \mu \mathrm{mol} / \mathrm{L}$ de ANS em tampão fosfato de sódio $30 \mathrm{mmol} / \mathrm{L}$. (B) e (C) Gráficos da absorbância na banda de Soret $(415 \mathrm{~nm})$ e da variação do comprimento de onda nessa banda em função dos valores de $\mathrm{pH}$, respectivamente.

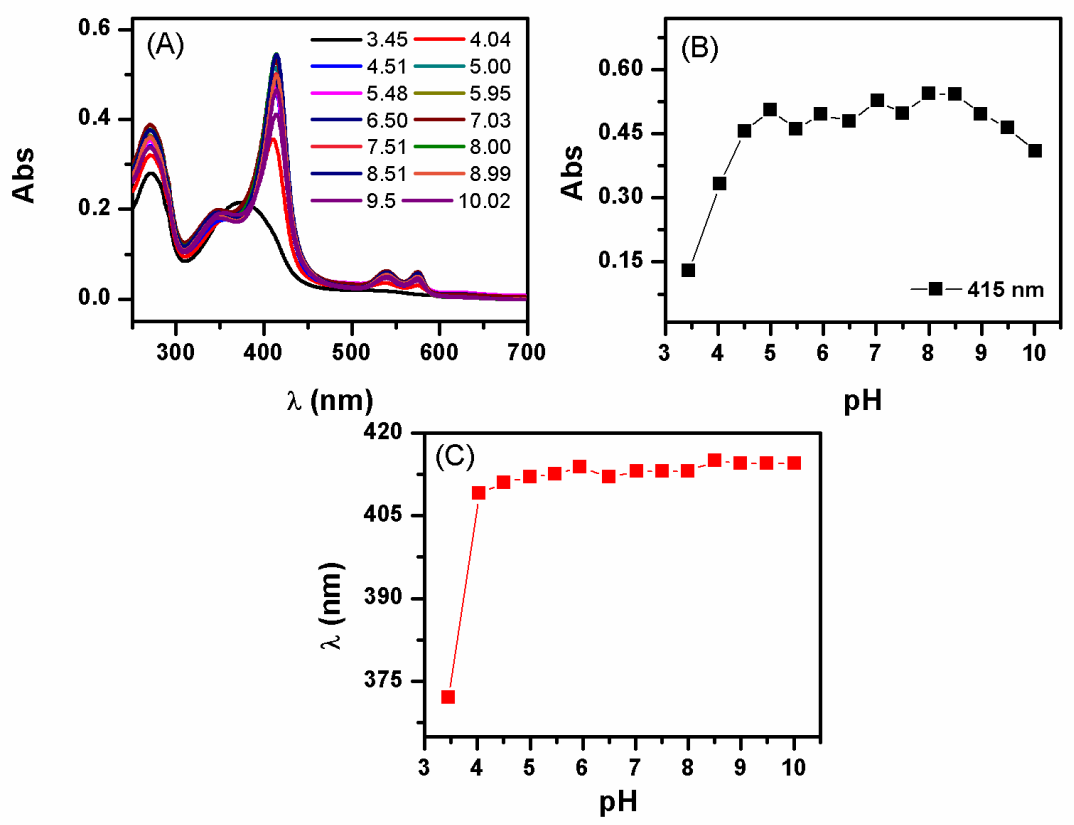

\subsubsection{Dados de emissão de fluorescência}

Os espectros de emissão de fluorescência da oxi-HbGp, na presença de $10 \mu \mathrm{mol} / \mathrm{L}$ da sonda ANS, em função do pH, com excitação em 295 nm, são mostrados na Figura 25A. O pico I refere-se à emissão dos triptofanos e o pico II à emissão da sonda ANS. A Figura 25B exibe as áreas de emissão de fluorescência normalizada, pela área observada no pH 7,0, correspondente ao pico I. Em meio ácido, na faixa de $\mathrm{pH}$ 3,5 a 5,0, observa-se um aumento na intensidade de fluorescência (Figura 25B) e um decréscimo na intensidade de luz espalhada (Figura 25C) sugerindo que a proteína encontra-se dissociada neste meio [67]. Por outro lado, na faixa de $\mathrm{pH}$ de 5,5 a 7,5, não são observadas mudanças significativas, provavelmente, devido a proteína encontrar-se na forma íntegra, conforme descrito nos resultados de absorção óptica (Figura 25B), de espalhamento de luz (Figura 25C) e os dados de ultracentrifugação analítica que foram obtidos por Carvalho et. al. [71]. Estudos anteriores realizados por Santiago e colaboradores [67], mostraram que a proteína encontra-se estável nessa faixa de pH. Em meio alcalino, na faixa de $\mathrm{pH}$ de 8,0 a 10,0 é verificado um aumento na intensidade 
de fluorescência e uma redução na intensidade de espalhamento (Figuras 25B e 25C), e, dados da literatura relatam que a oxi-HbGp também sofre dissociação em meio alcalino [21,71]. O aumento em meio alcalino é menor quando comparado em meio ácido, provavelmente, devido o meio ácido induzir a dissociação e a oxidação mais intensas da proteína [67].

A Figura 25D mostra a área normalizada do pico II correspondente à emissão de fluorescência da sonda ANS. Na faixa de $\mathrm{pH}$ de 3,5 a 5,0 nota-se um aumento acentuado quando comparado aos outros valores de $\mathrm{pH}$. Este aumento ocorre, provavelmente, devido a oxi-HbGp apresentar nesta faixa de $\mathrm{pH}$ carga total positiva ( $\mathrm{pI}=5,5,[67])$, interagindo mais efetivamente com a sonda ANS carregada negativamente, através de interações hidrofóbicas e eletrostáticas. Por outro lado, na faixa de pH de 5,48 a 7,51 a oxi-HbGp mantém-se estável e não se dissocia. Assim, provavelmente, poucos sítios hidrofóbicos da proteína, onde a sonda poderia ligar, estão disponíveis. Além disso, é provável a existência de forças de repulsão eletrostática nessa faixa de $\mathrm{pH}$, pois, a proteína apresenta a mesma carga superficial (negativa) do grupo sulfonato da sonda. Com relação ao meio alcalino observa-se um pequeno aumento na intensidade de fluorescência, o que pode estar associado, provavelmente, a uma maior disponibilidade de sítios hidrofóbicos já que a proteína encontra-se parcialmente dissociada neste meio.

Figura 25: (A) Espectros de emissão de fluorescência da oxi-HbGp $(0,1 \mathrm{mg} / \mathrm{mL})$ a diferentes valores de pH em tampão fosfato de sódio $30 \mathrm{mmol} / \mathrm{L}$. (B) Gráfico da área de emissão de fluorescência do pico I normalizada para o pH 7,03. (C) Gráfico do espalhamento de luz em função de diferentes valores de pH. (D) Gráficos das áreas do pico II normalizadas para o pH 7,03 em função de diferentes valores de $\mathrm{pH}$.
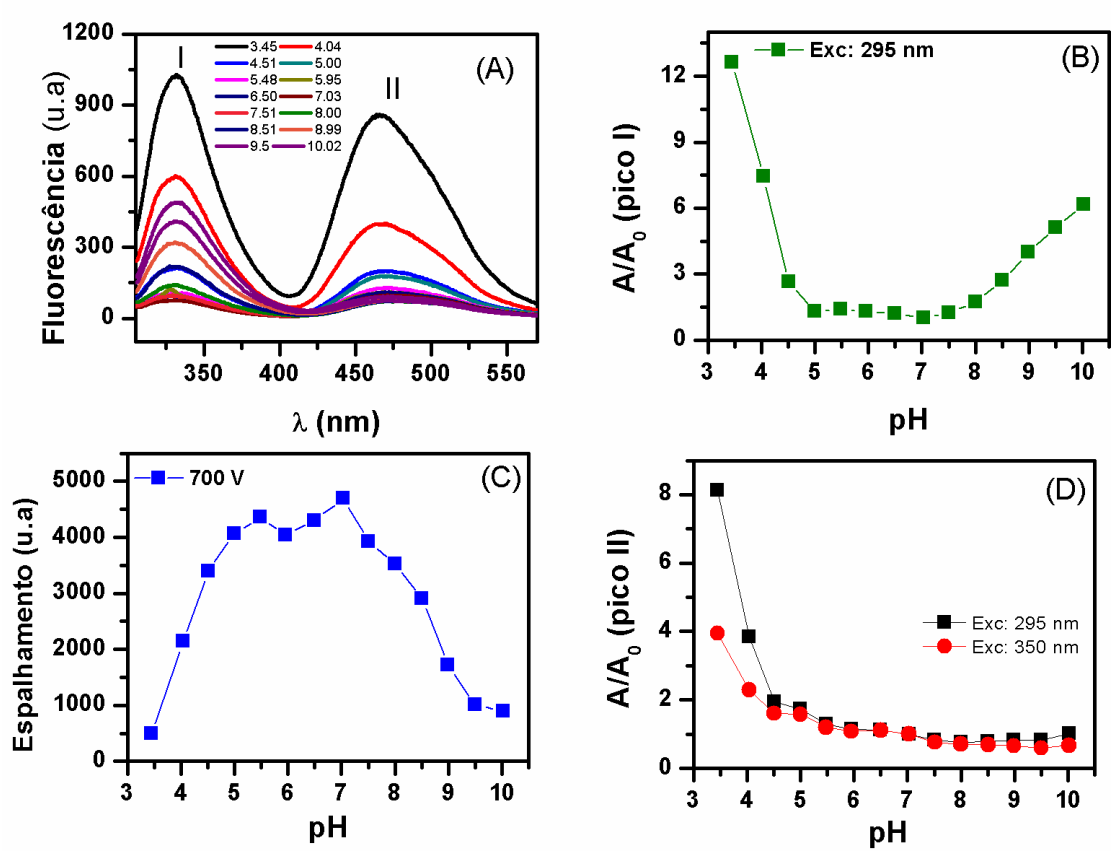
4.1.8. Tempos de vida de diferentes concentrações da sonda ANS e da oxi-HbGp $(1,0 \mathrm{mg} / \mathrm{mL})$ na presença e na ausência de DTAB.

Com o propósito de obter informações adicionais sobre a interação da sonda 1,8ANS com a HbGp em diferentes condições, inclusive na presença do surfactante DTAB, foram realizadas medidas de tempo de vida de fluorescência.

Os resultados apresentados na Tabela 9 são referentes às medidas de tempo de vida do ANS na presença de DTAB em diferentes concentrações. A análise dos dados mostra, em princípio, um único tempo de vida de fluorescência da sonda na micela de DTAB, já que o decaimento é mono-exponencial. O valor médio do tempo de vida em diferentes concentrações de surfactante, característico da sonda na micela, é em torno de $3.9 \pm 0.3 \mathrm{~ns}$. Convém ressaltar que outros estudos mostram dois tempos de vida, um mais curto, atribuído à sonda livre no tampão, e outro mais longo, associado à sonda ligada na micela [75]. A ausência do tempo curto nas nossas medidas pode ser atribuída à baixa resolução do equipamento. Além disso, esses resultados mostram que mesmo em condições de diferentes concentrações de DTAB, ou seja, em ambiente pré-micelar e micelar, o tempo de vida foi praticamente constante, uma vez que a sonda carregada negativamente se associa ao surfactante carregado positivamente através de interações eletrostáticas. Essa associação leva a uma contribuição, predominante no decaimento de fluorescência, da sonda associada ao surfactante, caracterizada pelo tempo mais longo. Vale mencionar que mesmo na concentração $20 \mathrm{mmol} / \mathrm{L}$ de DTAB, ou seja, concentração dez vezes maior que a concentração $2 \mathrm{mmol} / \mathrm{L}$, a diferença do tempo de vida é de $0,6 \mathrm{~ns}$, próxima do erro experimental.

Tabela 9: Parâmetros da fluorescência resolvida no tempo para a sonda 1,8-ANS $(10 \mu \mathrm{mol} / \mathrm{L})$ em tampão fosfato $30 \mathrm{mmol} / \mathrm{L}, \mathrm{pH} 7,0$, em diferentes concentrações de DTAB. $\lambda_{\mathrm{ex}}=370 \mathrm{~nm}$ e $\lambda_{\mathrm{em}}=475 \mathrm{~nm}$.

\begin{tabular}{cccc}
\hline $\begin{array}{c}\text { [DTAB] } \\
\mathbf{m m o l} / \mathbf{L}\end{array}$ & $\mathbf{B}_{\mathbf{1}}$ & $\mathbf{I}_{\mathbf{1}}(\boldsymbol{\%})$ & $\boldsymbol{\tau}_{\mathbf{1}}(\mathbf{n s})$ \\
\hline $\mathbf{2}$ & $1,9 \pm 0,5$ & $100 \pm 1$ & $4,3 \pm 0,3$ \\
$\mathbf{5}$ & $1,0 \pm 0,2$ & $100 \pm 1$ & $4,0 \pm 0,3$ \\
$\mathbf{1 0}$ & $1,5 \pm 0,2$ & $100 \pm 2$ & $3,80 \pm 0,02$ \\
$\mathbf{2 0}$ & $1,0 \pm 0,1$ & $100 \pm 3$ & $3,7 \pm 0,1$ \\
\hline
\end{tabular}


A Tabela 10 mostra os tempos de vida da sonda ANS em diferentes concentrações, na presença da oxi-HbGp $(1,0 \mathrm{mg} / \mathrm{mL})$.Verifica-se que a interação da sonda 1,8-ANS com a proteína resulta em um decaimento biexponencial, com tempos de vida em torno de $1.2 \pm 0.2$ ns e $7.3 \pm 0.6$ ns. A presença de dois tempos de vida pode ser devida a existência de, no mínimo, dois tipos de ambientes distintos em que a sonda se associa à proteína. Vale salientar que ambos os valores de tempos de vida, na faixa de ns, apresentados na tabela abaixo, excedem consideravelmente o tempo de decaimento do 1,8-ANS livre em água, reportado na literatura que é de aproximadamente 250 ps [38]. Provavelmente, este aumento pode ser atribuído à mudança de ambiente químico da sonda, ou melhor, deslocamento do 1,8-ANS para um meio menos polar. A não detecção do tempo de vida característico da sonda livre no tampão deve-se, provavelmente, a baixa sensibilidade do instrumento. Observa-se que os tempos de decaimento da Tabela 9 são diferentes dos tempos mostrados na Tabela 10. Estes resultados corroboram os dados de estudos mostrados na literatura, que evidenciam que a sonda ANS é extremamente sensível ao ambiente em que se encontra [30,36,37]. 
Tabela 10: Parâmetros da fluorescência resolvida no tempo para a sonda 1,8-ANS em diferentes concentrações, na presença da oxi-HbGp (1,0 $\mathrm{mg} / \mathrm{mL}$ ) em tampão fosfato $30 \mathrm{mmol} / \mathrm{L}, \mathrm{pH} 7,0 . \lambda_{\mathrm{ex}}=370 \mathrm{~nm}$ e $\lambda_{\mathrm{em}}=475 \mathrm{~nm}$.

\begin{tabular}{ccccccccc}
\hline $\begin{array}{r}\text { [ANS] } \\
\boldsymbol{\mu m o l} / \mathbf{L}\end{array}$ & $\mathbf{B}_{\mathbf{1}}$ & $\mathbf{I}_{\mathbf{1}}(\boldsymbol{\%})$ & $\boldsymbol{\tau}_{\mathbf{1}}(\mathbf{n s})$ & $\mathbf{B}_{\mathbf{2}}$ & $\mathbf{I}_{\mathbf{2}}(\boldsymbol{\%})$ & $\boldsymbol{\tau}_{\mathbf{2}}(\mathbf{n s})$ & $\mathbf{x}^{\mathbf{2}}$ & $\langle\boldsymbol{\tau}\rangle$ \\
\hline $\mathbf{1 0}$ & $0,558 \pm 0,003$ & $66,8 \pm 0,4$ & $1,15 \pm 0,01$ & $0,278 \pm 0,001$ & $33,24 \pm 0,04$ & $7,45 \pm 0,01$ & 1,1 & $5,97 \pm 0,01$ \\
$\mathbf{2 0}$ & $0,34 \pm 0,01$ & $55 \pm 1$ & $1,15 \pm 0,02$ & $0,273 \pm 0,002$ & $44,5 \pm 0,3$ & $6,89 \pm 0,03$ & 1,2 & $5,90 \pm 0,01$ \\
$\mathbf{4 0}$ & $0,38 \pm 0,01$ & $60 \pm 1$ & $1,30 \pm 0,01$ & $0,252 \pm 0,001$ & $39,8 \pm 0,1$ & $7,06 \pm 0,02$ & 1,1 & $5,81 \pm 0,01$ \\
$\mathbf{1 0 0}$ & $0,37 \pm 0,01$ & $65 \pm 1$ & $1,40 \pm 0,02$ & $0,201 \pm 0,001$ & $35,1 \pm 0.1$ & $7,90 \pm 0,02$ & 1,2 & $6,30 \pm 0,02$ \\
\hline
\end{tabular}

Tabela 11: Parâmetros da fluorescência resolvida no tempo para oxi-HbGp $(1,0 \mathrm{mg} / \mathrm{mL})$ em diferentes concentrações da sonda 1,8 -ANS em tampão fosfato $30 \mathrm{mmol} / \mathrm{L}, \mathrm{pH} \mathrm{7,0} . \lambda_{\mathrm{ex}}=280 \mathrm{~nm}$ e $\lambda_{\mathrm{em}}=320 \mathrm{~nm}$.

\begin{tabular}{cccccccc}
\hline $\begin{array}{c}{[\mathbf{A N S}]} \\
\boldsymbol{\mu m o l} / \mathbf{L}\end{array}$ & $\mathbf{B}_{\mathbf{1}}$ & $\mathbf{I}_{\mathbf{1}}(\boldsymbol{\%})$ & $\boldsymbol{\tau}_{\mathbf{1}}(\mathbf{n s})$ & $\mathbf{B}_{\mathbf{2}}$ & $\mathbf{I}_{\mathbf{2}}(\boldsymbol{\%})$ & $\boldsymbol{\tau}_{\mathbf{2}}(\mathbf{n s})$ & \multicolumn{2}{c}{$<$} \\
\hline $\mathbf{0}$ & $5,2 \pm 2,4$ & $97 \pm 2$ & $0,25 \pm 0,05$ & $0,12 \pm 0,05$ & $3 \pm 2$ & $2,3 \pm 0.1$ \\
$\mathbf{1 0}$ & $0,85 \pm 0,22$ & $74 \pm 2$ & $0,91 \pm 0,03$ & $0,30 \pm 0,05$ & $26 \pm 2$ & $5,5 \pm 0.3$ \\
$\mathbf{2 0}$ & $1,2 \pm 0,2$ & $76 \pm 4$ & $0,81 \pm 0,05$ & $0,37 \pm 0,03$ & $24 \pm 3$ & $4,0 \pm 0,01$ \\
$\mathbf{4 0}$ & $0,65 \pm 0,03$ & $71 \pm 3$ & $0,7 \pm 0,1$ & $0,27 \pm 0,04$ & $29 \pm 2$ & $4,8 \pm 0,2$ \\
$\mathbf{1 0 0}$ & $1,2 \pm 0,2$ & $79 \pm 4$ & $0,72 \pm 0,01$ & $0,33 \pm 0,03$ & $21 \pm 2$ & $4,39 \pm 0,03$ & $3,7 \pm 0,2$ \\
\hline
\end{tabular}


Além disso, esses e outros estudos mostram que o espectro de fluorescência dessa sonda em solução depende fortemente da natureza do solvente, especialmente da sua polaridade [30, 32, 36-38]. Sendo assim, os tempos de vida menores apresentados pelas amostras contendo DTAB, sugerem que o ANS, na presença de surfactante, está ligado a sítios menos protegidos do solvente, ou seja, a sonda encontra-se num ambiente mais polar. Por outro lado, o tempo de vida mais longo pode ser atribuído a uma maior interação da sonda com a oxi-HbGp, com uma localização num ambiente menos polar, no interior de um bolsão hidrofóbico da proteína.

Na Tabela 11 os tempos de vida da fluorescência da oxi-HbGp, na ausência e na presença de diferentes concentrações do ANS são apresentados, sendo observado um decaimento bi-exponencial. Entretanto, em experimentos realizados anteriormente por nosso grupo de pesquisa, um decaimento mais complexo, multiexponencial, havia sido obtido para oxi-HbGp em tampão, em concordância com estudo da literatura sobre a HbLt que mostra decaimentos com 4 tempos de vida [76]. Essa diferença nos decaimentos pode ser atribuída mais uma vez à baixa resolução temporal do equipamento em que essas medidas do presente trabalho foram realizadas. Especialmente, considerando a presença de tempos de vida curtos, na faixa de picosegundos (ps) e caraterísticos da supressão intensa de fluorescência observada nas hemoproteinas [76]. A partir dos dados mostrados na Tabela 11 é interessante destacar que na amostra de concentração zero de ANS, o valor do tempo médio é de 0,62 ns, aproximadamente seis vezes menor que nas demais amostras contendo ANS. Além disso, em todos os sistemas analisados observa-se uma maior contribuição de tempos curtos, sugerindo que ocorre supressão promovida pelos grupos hemes presentes na oxi-HbGp, sendo bem mais efetiva na amostra sem ANS. Vale destacar ainda que nas amostras contendo ANS, observa-se que o valor do tempo longo é aproximadamente duas vezes maior quando comparado à amostra sem ANS, sugerindo que ocorrem mudanças no ambiente químico dos triptofanos, provavelmente, moléculas da sonda ANS estão associadas a moléculas da oxi-HbGp em ambientes diferentes.

\subsubsection{Medidas de tempos de vida realizadas em um espectrofluorímetro de alta resolução.}

Com a finalidade de obter informações mais detalhadas sobre a interação da sonda 1,8-ANS com a oxi-HbGp em diferentes condições, inclusive na presença do surfactante 
DTAB, medidas foram realizadas num espectrofluorímetro de alta resolução, baseado no método de correlação temporal de fótons únicos (TCSPC do inglês "Time Correlated Single Photon Counting”). Vale ressaltar que tempos muito curtos, na escala de picosegundos, foram detectados utilizando este equipamento. Estes tempos não puderam ser detectados com o equipamento Easy Life V, conforme descrito na seção anterior.

Os resultados dos tempos de vida para a sonda 1,8-ANS em diferentes meios estão apresentados na Tabela 12. A primeira medida controle foi realizada para o ANS puro no tampão fosfato $30 \mathrm{mmol} / \mathrm{L}$, pH 7.0. Observa-se um decaimento multi-exponencial, com três tempos de vida de 34 ps, 195 ps e 1,065 ns. O valor de tempo de vida médio calculado de 280 ps é consistente com os valores descritos na literatura [38] bem como com o baixo rendimento quântico $(0,004)$ dessa sonda em meio aquoso. Na presença de $10 \mathrm{mmol} / \mathrm{L}$ de DTAB, observa-se um decaimento bi-exponencial para o ANS no mesmo tampão, corroborando os dados mostrados por Saroja e colaboradores [75]. Vale mencionar ainda a contribuição predominante no decaimento, de 92,6 \%, do tempo longo, indicando que esse tempo está associado à sonda ligada à micela. $\mathrm{O}$ tempo curto de 308 ps pode ser devido à contribuição no decaimento da sonda livre no solvente. Experimentos de fluorescência resolvida no tempo realizados para monitorar a interação da sonda 4-amino-ftalimida com micelas de SDS, CTAB e Triton-X apresentam tempos de vida similares com o reportado para a micela de DTAB do presente trabalho, com valores de 3.1-3.6 ns e 0.33-0.96 ns [75]. Além disso, esses autores discutiram a possibilidade de supressão do tempo de vida curto desta sonda pela presença dos íons brometo em solução, no caso do CTAB.

No caso da análise da interação da oxi-HbGp com a sonda ANS, na ausência e na presença de $12 \mathrm{mmol} / \mathrm{L}$ de DTAB, obteve-se um decaimento multi-exponencial com quatro tempos de vida, deve-se separar inicialmente a interação do ANS com HbGp, e, na sequência, analisar o efeito da adição de surfactante. O decaimento do sistema ANS-HbGp ( $3^{\mathrm{a}}$ e $4^{\mathrm{a}}$ linhas da Tabela 12) apresenta um tempo de 173 e 138 ps, que pode estar associado à presença de ANS livre no tampão. A contribuição percentual deste tempo mais curto é relativamente pequena, em torno de 5\%. Os tempos mais longos ( $\tau_{3}$ e $\tau_{4}$ ), de 6.3-6.5 ns e 2.6 e $2.7 \mathrm{~ns}$, provavelmente estão associados à sonda ligada à $\mathrm{HbGp}$. O tempo de vida mais longo deve corresponder à ligação da sonda num ambiente hidrofóbico, bem protegido do solvente aquoso. Por exemplo, esse tempo mais longo poderia estar associado ao interior de um bolsão hidrofóbico da proteína. É interessante que a contribuição percentual dos dois tempos de vida mais longos é de cerca de 70-80\% do total de intensidade de fluorescência. Convém enfatizar 
ainda que na presença de $12 \mathrm{mmol} / \mathrm{L}$ de $\mathrm{DTAB}$, a contribuição dos tempos de vida curtos é reduzida a menos de $10 \%$ do total. A contribuição dos tempos longos aumenta significativamente, sugerindo a permanência de sonda fortemente ligada à proteína (tempo de 6,5 ns) e sonda ligada a agregados micelares (3,28 ns). Não se pode descartar também, a possibilidade de uma maior interação da oxi-HbGp com a sonda, devido ao desenovelamento parcial da proteína, induzido pelo surfactante, com o aumento de exposição dos grupos hidrofóbicos proteicos às moléculas de ANS.

A Tabela 13 mostra os tempos de vida da oxi-HbGp em diferentes valores de $\mathrm{pH}$, sendo observado um decaimento multi-exponencial. Nos valores de $\mathrm{pH}$ 7,0 e 8,0 foram obtidos três valores de tempos de vida, enquanto que no $\mathrm{pH} \mathrm{9,0} \mathrm{foram} \mathrm{encontrados} \mathrm{quatro}$ tempos de vida, corroborando o trabalho da literatura sobre a HbLt que também apresenta decaimento com quatro tempos de vida [76]. Com base nos resultados mostrados na Tabela 13 para os valores de $\mathrm{pH}$ 7,0 e 8,0, observa-se uma maior contribuição dos tempos curtos, o que está refletido no valor de tempo de vida médio, essencialmente o mesmo, igual a 0,67 ns. Este resultado sugere que ocorre intensa supressão de fluorescência, promovida pelos grupos hemes da hemoproteína, com transferência de energia dos resíduos triptofanos para os grupos heme. Entretanto, no pH 9,0, essa supressão diminui, com concomitante aumento nos valores e contribuições percentuais de tempos longos, indicando que está ocorrendo uma diminuição de supressão da emissão dos triptofanos, bem como, uma maior exposição dos triptofanos para o solvente na interface da proteína, uma vez que em $\mathrm{pH}$ alcalino a proteína encontra-se dissociada nas subunidades menores [76], o que remove a supressão inter-subunidade. 
Tabela 12: Parâmetros de fluorescência resolvida no tempo da sonda ANS em tampão fosfato 30 mmol/L, pH 7,0, na presença de diferentes sistemas. $\lambda_{\mathrm{exc}}=294 \mathrm{~nm}$ e $\lambda_{\mathrm{em}}=470 \mathrm{~nm}$.

\begin{tabular}{|c|c|c|c|c|c|c|c|c|c|c|c|c|c|c|}
\hline & $\tau_{1}(\mathrm{ps})$ & $I_{1}(\%)$ & $\mathbf{B}_{1}$ & $\tau_{2}(\mathrm{~ns})$ & $\mathbf{I}_{2}(\%)$ & $\mathbf{B}_{2}$ & $\tau_{3}(\mathrm{~ns})$ & $\mathbf{I}_{3}(\%)$ & $\mathbf{B}_{3}$ & $\tau_{4}(\mathrm{~ns})$ & $\mathbf{I}_{4}(\%)$ & $\mathbf{B}_{4}$ & $\mathbf{x}^{2}$ & $\langle\tau\rangle($ ns $)$ \\
\hline $\begin{array}{c}\text { Tampão } \\
\text { puro }\end{array}$ & 34 & 10,7 & 0,027 & 0,195 & 77,1 & 0,033 & 1,065 & 12,1 & 0,001 & - & - & - & 4,028 & 0,28 \\
\hline $\begin{array}{c}10 \mathrm{mmol} / \mathrm{L} \\
\text { DTAB }\end{array}$ & 308 & 7,4 & 0,068 & 3,930 & 92,6 & 0,067 & - & - & - & - & - & - & 1,958 & 3,66 \\
\hline \multicolumn{15}{|c|}{ Oxi-HbGp (1.0 mg/mL) } \\
\hline $\begin{array}{c}20 \mu \mathrm{mol} / \mathrm{L} \\
\text { ANS }\end{array}$ & 173 & 5,0 & 0,065 & 0,77 & 17,0 & 0,045 & 2,6 & 38 & 0,029 & 6,3 & 40 & 0,013 & 1,217 & 3,64 \\
\hline $\begin{array}{c}40 \mu \mathrm{mol} / \mathrm{L} \\
\text { ANS }\end{array}$ & 138 & 5,9 & 0,076 & 0,69 & 20,8 & 0,053 & 2,7 & 38,4 & 0,025 & 6,5 & 34,9 & 0,010 & 1,069 & 3,51 \\
\hline $\begin{array}{c}12 \mathrm{mmol} / \mathrm{L} \\
\text { DTAB }\end{array}$ & 92 & 2,8 & 0,085 & 0,578 & 6,4 & 0,031 & 3,28 & 55 & 0,046 & 6,5 & 35,7 & 0,015 & 1,062 & 4,16 \\
\hline
\end{tabular}

Tabela 13: Parâmetros de fluorescência resolvida no tempo da oxi-HbGp (1,0 mg/mL) em tampão fosfato $30 \mathrm{mmol} / \mathrm{L}$, em diferentes valores de pH. $\lambda_{\text {exc }}=294 \mathrm{~nm}$ e $\lambda_{\text {em }}=340 \mathrm{~nm}$.

\begin{tabular}{cccccccccccccccc}
\hline Meios & $\boldsymbol{\tau}_{\mathbf{1}}(\mathbf{p s})$ & $\mathbf{I}_{\mathbf{1}}(\boldsymbol{\%})$ & $\mathbf{B}_{\mathbf{1}}$ & $\boldsymbol{\tau}_{\mathbf{2}}(\mathbf{n s})$ & $\mathbf{I}_{\mathbf{2}}(\boldsymbol{\%})$ & $\mathbf{B}_{\mathbf{2}}$ & $\boldsymbol{\tau}_{\mathbf{3}}(\mathbf{n s})$ & $\mathbf{I}_{\mathbf{3}}(\boldsymbol{\%})$ & $\mathbf{B}_{\mathbf{3}}$ & $\boldsymbol{\tau}_{\mathbf{4}}(\mathbf{n s})$ & $\mathbf{I}_{\mathbf{4}}(\boldsymbol{\%})$ & $\mathbf{B}_{\mathbf{4}}$ & $\mathbf{x}^{\mathbf{2}}$ & $<\boldsymbol{\tau}>(\mathbf{n s})$ \\
\hline pH 7,0 & 38 & 62 & 0,153 & 0,349 & 24 & 0,006 & 2,444 & 14 & 0,001 & - & - & - & 1,871 & 0,67 \\
pH 8,0 & 36 & 61 & 0,152 & 0,350 & 22 & 0,007 & 2,286 & 17 & 0,001 & - & - & - & 1,550 & 0,61 & \\
pH 9,0 & 45 & 26 & 0,378 & 0,367 & 12 & 0,022 & 1,68 & 24 & 0,009 & 5,12 & 38 & 0,005 & 1,022 & 2,43 \\
\hline
\end{tabular}


A Tabela 14 mostra os dados de fluorescência resolvida no tempo da oxi-HbGp na presença de diferentes sistemas. A oxi-HbGp apresenta três tempos de vida, na presença de 20 e $40 \mu \mathrm{mol} / \mathrm{L}$ da sonda ANS. Os tempos são bem similares aos observados para oxi-HbGp pura em pH 7.0, sendo que o tempo longo melhora o ajuste da curva de decaimento, tendo uma contribuição desprezível em termos percentuais . Isso torna o valor de tempo de vida médio bem menor do que o obtido em pH 7.0, na ausência de ANS. Na presença de 5 e $12 \mathrm{mmol} / \mathrm{L}$ de DTAB, o decaimento é caracterizado por quatro tempos de vida, onde as contribuições maiores são atribuídas aos tempos longos. A contribuição do tempo mais curto é reduzida drasticamente, sendo tanto menor quanto maior a concentração de DTAB. Nota-se mais uma vez a redução significativa da supressão de fluorescência dos triptofanos, associada, provavelmente, à dissociação oligomérica da proteína bem como sua desnaturação parcial. 
Tabela 14: Parâmetros de fluorescência resolvida no tempo da oxi-HbGp(1.0 mg/mL) em tampão fosfato $30 \mathrm{mmol} / \mathrm{L}$, pH 7,0, na presença de diferentes sistemas. $\lambda_{\text {exc }}=294 \mathrm{~nm}$ e $\lambda_{\text {em }}=340 \mathrm{~nm}$.

\begin{tabular}{|c|c|c|c|c|c|c|c|c|c|c|c|c|c|c|}
\hline & $\tau_{1}(\mathrm{ps})$ & $I_{1}(\%)$ & $\mathbf{B}_{1}$ & $\tau_{2}(\mathrm{~ns})$ & $\mathbf{I}_{2}(\%)$ & $\mathbf{B}_{2}$ & $\tau_{3}(\mathrm{~ns})$ & $\mathbf{I}_{3}(\%)$ & $\mathbf{B}_{3}$ & $\tau_{4}(\mathrm{~ns})$ & $\mathbf{I}_{4}(\%)$ & $\mathbf{B}_{4}$ & $x^{2}$ & $<\boldsymbol{\tau}>$ (ns) \\
\hline \multicolumn{15}{|c|}{ Oxi-HbGp + ANS } \\
\hline $20 \mu \mathrm{mol} / \mathrm{L}$ & 33 & 67 & 0,166 & 0,340 & 19 & 0,005 & 2,556 & 14 & 0,000 & - & - & - & 1,794 & 0,106 \\
\hline $40 \mu \mathrm{mol} / \mathrm{L}$ & 32 & 70 & 0,172 & 0,337 & 16 & 0,004 & 2,427 & 14 & 0,000 & - & - & - & 1,857 & 0,092 \\
\hline \multicolumn{15}{|c|}{ Oxi-HbGp + DTAB } \\
\hline $5 \mathrm{mmol} / \mathrm{L}$ & 99 & 7,5 & 0,113 & 0,62 & 17,5 & 0,042 & 2,30 & 37 & 0,024 & 5,6 & 38 & 0,010 & 1,083 & 3,08 \\
\hline $12 \mathrm{mmol} / \mathrm{L}$ & 98 & 4,3 & 0,085 & 0,63 & 13,9 & 0,042 & 2,10 & 36 & 0,033 & 4,96 & 46 & 0,018 & 1,066 & 3,10 \\
\hline \multicolumn{15}{|c|}{ Oxi-HbGp + DTAB + ANS $(20 \mu \mathrm{mol} / \mathrm{L})$} \\
\hline $5 \mathrm{mmol} / \mathrm{L}$ & 96 & 8,4 & 0,116 & 0,57 & 18,2 & 0,043 & 2,1 & 40 & 0,023 & 5,5 & 36,5 & 0,009 & 1,078 & 2,92 \\
\hline $12 \mathrm{mmol} / \mathrm{L}$ & 99 & 2,9 & 0,085 & 0,57 & 6,2 & 0,030 & 3,1 & 49,6 & 0,044 & 6,1 & 41,3 & 0,019 & 1,079 & 4,12 \\
\hline
\end{tabular}




\title{
PARTE II
}

\section{ESTUDO PRELIMINAR DA INTERAÇÃO DA FLUORESCEÍNA ISOTIOCIANATO (FITC) COM A OXI- HbGp.}

\author{
Nesta seção a oxi-HbGp foi \\ marcada com a sonda covalente \\ fluoresceína isotiocianato (FITC) em dois \\ valores de $\mathrm{pH}$ 7,0 e 9,0, e nas proporções \\ sonda: heme 1:5 e 2:1, a fim de verificar e \\ quantificar o grau de modificação, bem \\ como, as condições ótimas de reação \\ sonda-proteína. Além disso, estudos de \\ dissociação e desnaturação da oxi-HbGp \\ marcada com FITC, na presença do \\ surfactante DTAB, foram realizados \\ através das técnicas de absorção ótica e \\ fluorescência.
}




\subsection{ESTUDO PRELIMINAR DA INTERAÇÃO DA FLUORESCEÍNA ISOTIOCIANATO (FITC) COM A OXI-HbGP.}

\subsubsection{Oxi-HbGp marcada com FITC}

\subsubsection{Experimentos controle de absorção óptica e fluorescência}

A Figura 26 mostra os espectros de absorção óptica para a fluoresceína isotiocianato (FITC) em tampão, bem como, para oxi-HbGp pura e oxi-HbGp modificada covalentemente através da reação com a sonda fluorescente. O pico da sonda (FITC) próximo a $500 \mathrm{~nm}$ é observado na proteína modificada. Os picos da oxi-HbGp são típicos das hemoglobinas, exibindo uma banda intensa em $415 \mathrm{~nm}$ (banda de Soret), as bandas Q centradas em 540 e $576 \mathrm{~nm}$, e o pico próximo a $280 \mathrm{~nm}$ correspondente aos aminoácidos aromáticos.

Figura 26: Espectros de absorção óptica de FITC pura, oxi-HbGp pura e oxi-HbGp $(0,1 \mathrm{mg} / \mathrm{mL})$ marcada com FITC nas razões de 1:5 e 2:1 em tampão fosfato $30 \mathrm{mmol} / \mathrm{L}, \mathrm{pH} \mathrm{7,0}$. As razões correspondem à sonda/heme, ou seja, a proteína foi quantificada pela concentração de heme. A reação de marcação foi realizada a $20^{\circ} \mathrm{C}$ por $48 \mathrm{~h}$, seguido por $24 \mathrm{~h}$ de diálise.

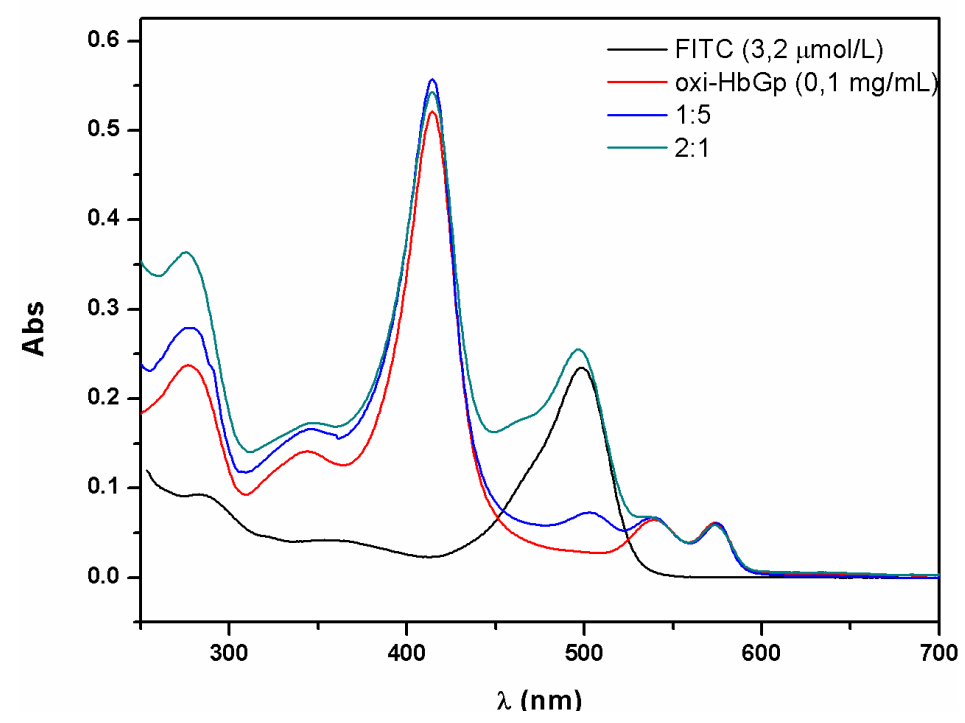

Os espectros de emissão de fluorescência de FITC pura no tampão e da oxi-HbGp marcada com FITC nas razões sonda/heme 1:5 e 2:1, com excitação em 480 nm e emissão na 
faixa de comprimentos de onda entre 485 e 590 nm, são mostrados na Figura 27. A análise desses espectros permite estimar o rendimento quântico da sonda ligada a oxi-HbGp. Supondo que o rendimento quântico de FITC no tampão é 100\%, os rendimentos quânticos estimados para FITC ligada a oxi-HbGp, no $\mathrm{pH} 7,0$, foram 0,10 e 0,04 , enquanto que no valor de $\mathrm{pH}$ 9,0 foram 0,09 e 0,03, respectivamente, para as razões de sonda/heme 1:5 e 2:1 (Tabela $15)$.

Figura 27: Espectros de emissão de fluorescência de FITC pura nas respectivas concentrações correspondentes às razões sonda/heme de 1:5 (vermelho) e 2:1 (azul) em tampão fosfato $30 \mathrm{mmol} / \mathrm{L}$, $\mathrm{pH} 7,0$. O inserto corresponde à expansão da figura mostrando as curvas da oxi-HbGp marcada com FITC nas razões 1:5 e 2:1. Note a diferença nos valores das ordenadas.

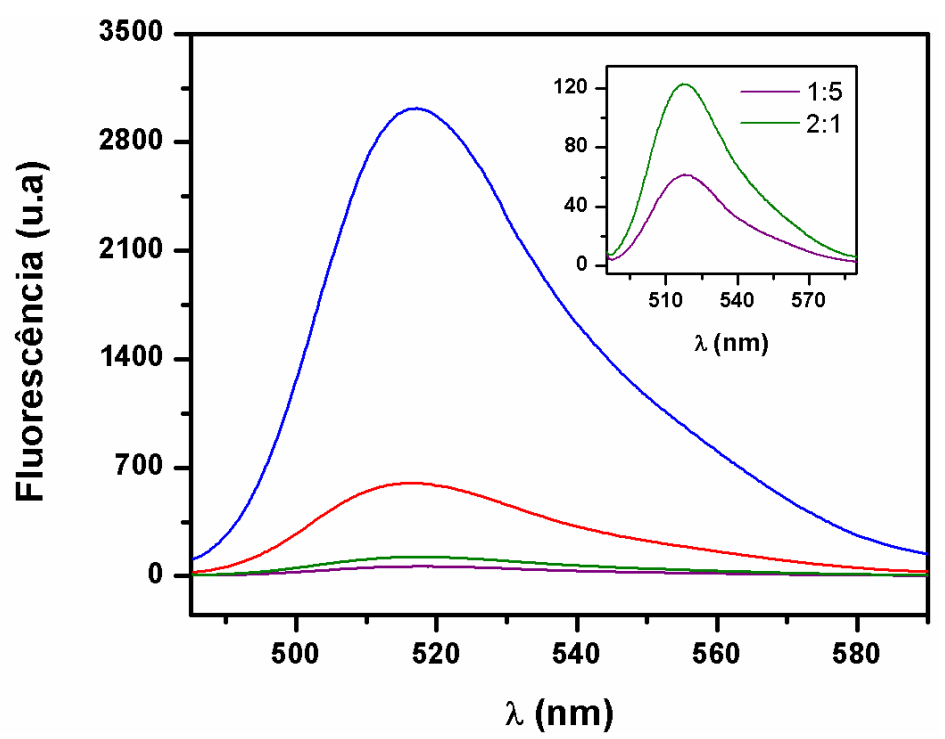

Neste estudo, a quantidade de FITC efetivamente ligada a oxi-HbGp foi estimada para as duas razões de marcação, 1:5 e 2:1, nos valores de pH 7,0 e 9,0, a partir dos espectros de absorção óptica. Os cálculos das concentrações de FITC e oxi-HbGp foram realizados utilizando os coeficientes de extinção molar $\varepsilon_{492}=68500 \mathrm{M}^{-1} . \mathrm{cm}^{-1}$ para FITC [47] e $\varepsilon_{415}=5,5$ $\mathrm{mg} / \mathrm{mL}$ para oxi-HbGp [53]. A partir de concentração de sonda e de proteína foram estimados os números de sondas ligadas por heme e os números de sondas ligadas por subunidade, considerando a concentração de hemes (144 hemes por molécula de oxi-HbGp), e de subunidades (180 subunidades por molécula de oxi-HbGp). Os resultados obtidos estão apresentados na Tabela 15. 
Tabela 15: Quantidade de FITC efetivamente ligada a oxi-HbGp, por heme e por subunidade, estimada a partir das absorbâncias a 492 (FITC) e 415 nm (oxi-HbGp) em tampão fosfato 30 mmol/L. Rendimento quântico (\%) da sonda ligada a oxi-HbGp.

\begin{tabular}{ccccc}
\hline FITC: HbGp & $\mathrm{pH}$ & FITC: HbGp $^{\mathrm{a}}$ & FITC: HbGp $^{\mathrm{b}}$ & $\begin{array}{c}\text { Rendimento } \\
\text { quântico (\%) }\end{array}$ \\
\hline $1: 5$ & 7,0 & 0,12 & 0,10 & 10 \\
$2: 1$ & 7,0 & 0,79 & 0,63 & 4 \\
$1: 5$ & 9,0 & 0,10 & 0,08 & 9 \\
$2: 1$ & 9,0 & 0,56 & 0,45 & 3 \\
\hline
\end{tabular}

${ }^{\mathrm{a}}$ Cálculo baseado na concentração de hemes.

${ }^{\mathrm{b}}$ Cálculo baseado na concentração de subunidades.

${ }^{c}$ Rendimento de FITC no tampão definido como sendo $100 \%$.

Observando-se os resultados dos rendimentos quânticos mostrados na Tabela 15, verifica-se que a fluorescência da sonda FITC é fortemente suprimida quando ligada covalentemente à proteína, principalmente na razão de marcação 2:1. Esta forte supressão é consistente com dados na literatura [47], que atribuem a ocorrência desse processo a dois possíveis mecanismos: 1) supressão intermolecular fluoróforo-fluoróforo e 2) a presença de aminoácidos que possuam carga negativa, localizados próximos à sonda, produzindo repulsão eletrostática e um efetivo decaimento não radiativo. No pH 9,0, nota-se um decréscimo tanto na quantidade de sonda ligada por heme e por subunidade quanto nos valores dos rendimentos quânticos, o que pode ser atribuído, provavelmente, a menor estabilidade da fluoresceína isotiocianato, em meio aquoso alcalino.

4.2.2. Oxi-HbGp marcada com FITC, na presença de DTAB.

\subsubsection{Dados de absorção óptica e fluorescência}

A Figura 28 A exibe os espectros de absorção óptica da oxi-HbGp 0,1 mg/mL em função da concentração de DTAB, na faixa de comprimento de onda entre 250 a $700 \mathrm{~nm}$. Observa-se que até 1,0 $\mathrm{mmol} / \mathrm{L}$ de $\mathrm{DTAB}$, os espectros não apresentam mudanças significativas. Por outro lado, a partir de 2,0 mmol/L a ocorrência de espalhamento é evidente, 
devido à formação de agregado. A absorbância em 700 nm, mostrada na Figura 28B, mostra este efeito de agregação, que é reduzido acima de $8 \mathrm{mmol} / \mathrm{L}$ de surfactante, em virtude da resolubilização dos agregados proteína-surfactante. Além disso, o gráfico da Figura 28 B mostra o deslocamento do comprimento do máximo de absorção da banda de Soret para o azul, sugerindo a oxidação gradual do ferro do grupo heme, com a formação da espécie metaHbGp. Vale destacar que as bandas Q características da oxi-HbGp não são mais observadas acima da concentração de 3,0 mmol/L de DTAB.

Figura 28: (A) Espectros de absorção óptica da oxi-HbGp $(0,1 \mathrm{mg} / \mathrm{mL})$ marcada com FITC na presença de diferentes concentrações de DTAB em tampão fosfato $30 \mathrm{mmol} / \mathrm{L}, \mathrm{pH}$ 7,0. (B) Gráficos da absorbância em $700 \mathrm{~nm}$ e variação do comprimento de onda da banda de Soret (415 nm) em função da concentração de DTAB.
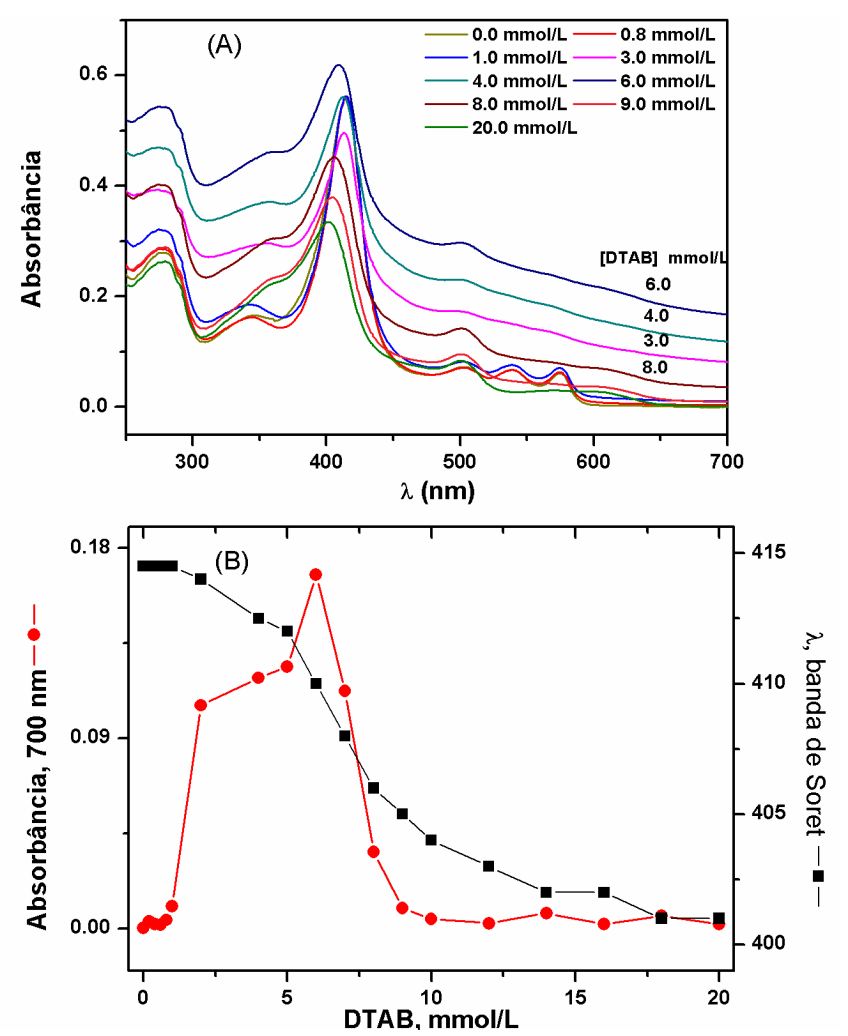

Os espectros de emissão de fluorescência da oxi-HbGp marcada com FITC, na presença de DTAB, na faixa de concentração de 0,0 a 20 mmol/L, com excitação em $295 \mathrm{~nm}$ e emissão na faixa de comprimento de onda entre 305 e 575 nm, são mostrados na Figura 29 A. O pico I corresponde à emissão dos resíduos de triptofanos e o pico II é referente à emissão da sonda fluoresceína isotiocianato (FITC). Com base nestes resultados, observa-se que o DTAB induz um aumento de trinta vezes na emissão de fluorescência dos triptofanos enquanto que na emissão da sonda ocorre um aumento menor de dez vezes. Este aumento tão significativo na emissão dos triptofanos pode estar associado a vários processos diferentes, 
tais como, a dissociação oligomérica da oxi-HbGp, a formação de agregados proteínasurfactante e o desenovelamento da oxi-HbGp, conforme foi descrito na seção 4.3.2. No entanto, o aumento de fluorescência apresentado pela sonda, pode estar associado, provavelmente, à dissociação oligomérica e maior exposição da sonda ao solvente aquoso. Em 2,0 mmol/L de DTAB verifica-se um aumento expressivo na intensidade de espalhamento de luz (Figura 29C) evidenciando o processo de agregação. Além disso, a Figura 29C mostra o deslocamento do máximo de emissão $\left(\lambda_{e m}^{\max }\right)$ dos triptofanos para o vermelho, em consequência da exposição dos grupos indol ao solvente.

Figura 29: (A) Espectros de emissão de fluorescência da oxi-HbGp $(0,1 \mathrm{mg} / \mathrm{mL})$ marcada com FITC na presença de diferentes concentrações de DTAB em tampão fosfato de sódio $30 \mathrm{mmol} / \mathrm{L}$, pH 7,0, com excitação em $295 \mathrm{~nm}$. (B) Gráficos das áreas referentes ao pico I e pico II normalizadas a partir da concentração de $0,0 \mathrm{mmol} / \mathrm{L}$ de DTAB em função da concentração de surfactante. (C) Gráficos das intensidades de espalhamento de luz e do deslocamento do comprimento do máximo de emissão de fluorescência dos triptofanos (pico I) em função da concentração de DTAB.
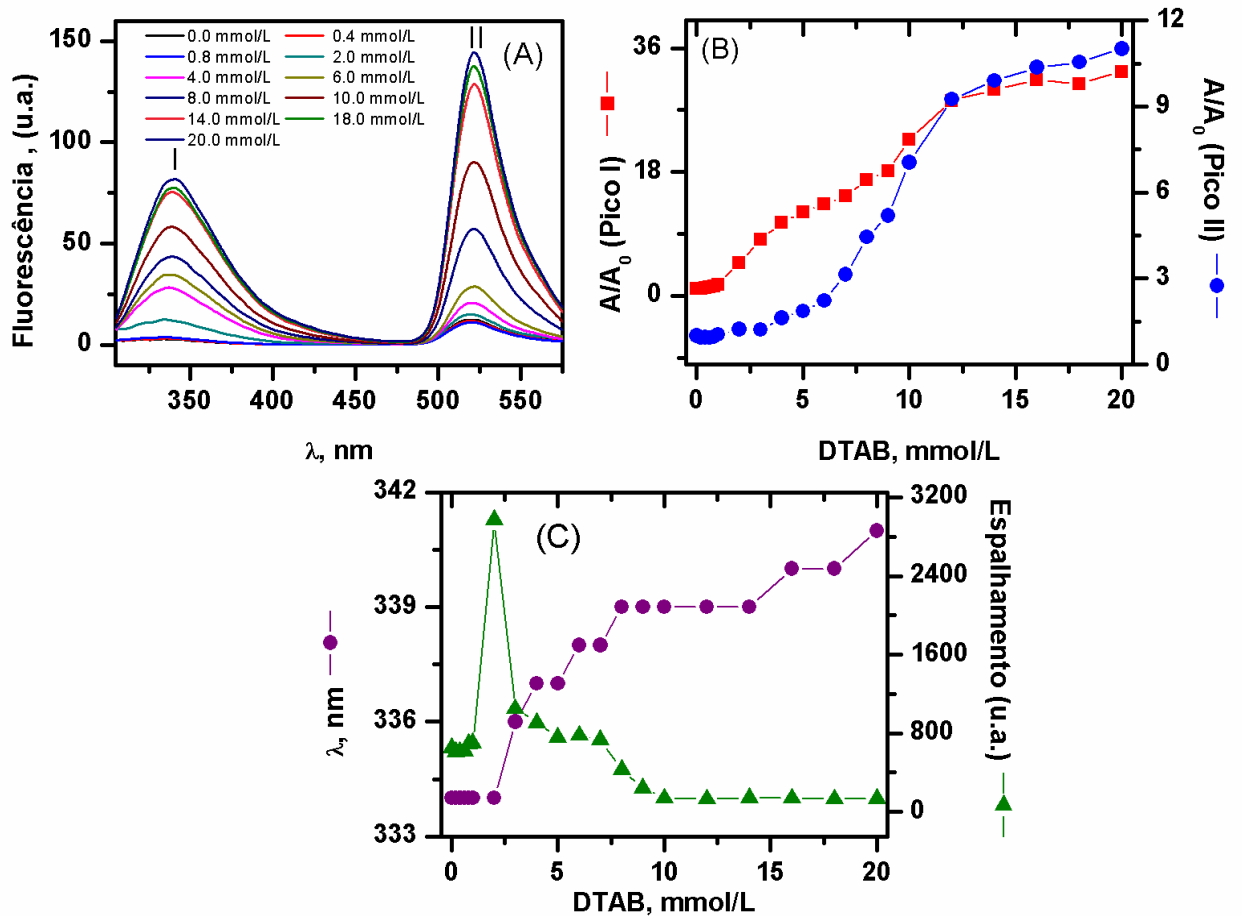
CAPÍTULO IV

\section{CONCLUSÕES}




\section{Conclusões}

Com base nos resultados apresentados conclui-se que, acima da concentração micelar crítica, a sonda ANS interage fortemente com as micelas de DTAB resultando em alta intensidade de fluorescência e um deslocamento do $\lambda_{e m}^{\max }$ para o azul. Na presença da oxiHbGp, observa-se uma baixa intensidade de emissão da sonda ANS quando comparada à observada nas micelas de DTAB, sugerindo que poucas moléculas de ANS estão ligadas a estrutura oligomérica da oxi-HbGp. Além disso, na interação da sonda com a proteína, verifica-se que ocorre transferência de energia dos triptofanos para a sonda. A adição de DTAB ao sistema HbGp-ANS promove um aumento na intensidade de fluorescência do ANS e um deslocamento para o vermelho do $\lambda_{e m}^{\max }$, sugerindo que o DTAB induz o desenovelamento parcial da oxi-HbGp, seguido da exposição dos sítios que se ligam ao ANS. Os agentes caotrópicos, $\mathrm{GuHCl}$ e ureia, parecem reduzir os grupos hidrofóbicos na superfície da proteína, induzindo o deslocamento do ANS para o meio aquoso, detectado pela redução de intensidade de fluorescência.

Por outro lado, no pH 7,0, o DTAB induz a oxidação do ferro do grupo heme, a dissociação oligomérica, a agregação e o desenovelamento parcial da oxi-HbGp. O processo de desenovelamento da oxi-HbGp, no pH 5,0, na presença de DTAB, é muito semelhante ao evidenciado no pH 7,0, apresentando duas transições, a primeira em virtude da dissociação oligomérica e a segunda, provavelmente, devido a desnaturação das subunidades dissociadas. Entretanto, a interação fraca do ANS em meio ácido, quando comparada ao pH 7,0, é muito consistente com a alta estabilidade da oxi-HbGp no $\mathrm{pH}$ 5,0.

Os estudos de fluorescência resolvida no tempo revelam que os tempos de vida observados para o ANS mostram uma forte dependência do ambiente em que se encontra, corroborando os dados descritos na literatura. Na presença de $10 \mathrm{mmol} / \mathrm{L}$ de DTAB, a sonda apresenta um decaimento bi-exponencial, enquanto que na presença da oxi-HbGp apresenta um decaimento multi-exponencial com quatro tempos de vida. Para oxi-HbGp foi verificado um tempo de decaimento de fluorescência multi-exponencial, com três tempos de vida tanto no $\mathrm{pH}$ 7,0 como no pH 8,0. Nestes valores de pHs observa-se uma maior contribuição dos tempos curtos, associada à intensa supressão de fluorescência. No entanto, a oxi-HbGp no pH 9,0 , apresenta quatro tempos de vida, com maior contribuição dos tempos longos devido a 
diminuição de supressão da emissão dos triptofanos e remoção da supressão intersubunidades, como consequência da dissociação oligomérica.

No estudo preliminar da interação da fluoresceína isotiocianato (FITC) com a oxiHbGp, a quantidade de FITC efetivamente ligada a oxi-HbGp por heme, foi estimada a partir dos dados de absorção óptica nas razões 1:5 e 2:1, nos valores de pH 7,0 e 9,0. Os valores encontrados foram 0,$12 ; 0,79 ; 0,10$ e 0,56 , respectivamente. Considerando que o rendimento quântico de FITC no tampão é 100 \%, os rendimentos quânticos de FITC ligada a oxi-HbGp evidenciam uma intensa supressão de fluorescência. A titulação de HbGp-FITC com DTAB mostra comportamento similar ao observado anteriormente na sonda ANS, com agregação da proteína em ambiente pré-micelar, seguido por re-solubilização em altas concentrações de surfactante. Além disso, observa-se um aumento significativo de fluorescência do FITC devido à dissociação oligomérica e maior exposição da sonda ao solvente aquoso. 


\subsection{Perspectivas}

Durante o desenvolvimento do presente projeto de mestrado, novas informações foram obtidas sobre a estabilidade da oxi-HbGp frente aos processos de dissociação oligomérica e desnaturação. A utilização das sondas fluorescentes 1,8-ANS e FITC mostrou ser uma poderosa ferramenta para a investigação deste sistema, tendo em vista os resultados alcançados. Por isso, estudos complementares usando estas sondas serão realizados, com o propósito de dar continuidade à abertura dessa nova linha de pesquisa do Laboratório de Biofísica Molecular do Instituto de Química de São Carlos.

Partindo deste pressuposto, pretendemos realizar titulações da fluoresceína isotiocianato (FITC) em função de diferentes concentrações de DTAB, com o propósito de obter uma melhor compreensão sobre as interações existentes entre a sonda e o surfactante. Estes experimentos serão acompanhados por medidas de absorção óptica, fluorescência estática e fluorescência resolvida no tempo. Além disso, medidas de fluorescência resolvida no tempo com a oxi-HbGp marcada com FITC nas proporções, 1:5 e 2:1, na presença e na ausência de DTAB, serão realizadas a fim de complementar os dados já coletados no presente estudo.

Finalmente, através da técnica de dicroísmo circular pretendemos avaliar mudanças conformacionais na estrutura da oxi-HbGp, ocasionadas pelo agente desnaturante DTAB em diferentes concentrações, tanto em amostras na presença da sonda 1,8-ANS como em amostras de oxi-HbGp marcada com FITC. 


\section{REFERÊNCIAS BIBLIOGRÁFICAS}

1. VOET, D.; VOET, J.G. Bioquímica. Tradução de A.B.G. da Veiga. et al. $3^{a}$ ed. Porto Alegre: Artemed, 2006. 1616 p.

2. NELSON, D.L.; COX,M.M. Lehninger princípios de bioquímica.Tradução de A. A. Simões e W.R.N. Lodi. New York: Almed, 2011. 975 p.

3. STRYER, L. Bioquímica. New York: W. H. Freemam, 1995. 1000 p.

4. REN, Z.; SRAJER, V.; KNAPP, J.E.; ROYER, W.E.J. Cooperative macromolecular device revealed by meta-analysis of static and time-resolved structures. Proceedings of the National Academy of Sciences, v.109, n.1, p. 107-112, 2012.

5. KUCHUMOV, A. R.; TAVEAU, J. C.; LAMY, J. N.; WALL, J. S.; WEBER, R. E.; VINOGRADOV, S. N. The role of linkers in the reassembly of the 3.6 MDa hexagonal bilayer hemoglobin from Lumbricus terrestris. Journal of Molecular Biology, v. 289, n. 5, p. 1361-1374, 1999.

6. ZHU, H.; OWNBY, D.W.; RIGGS, C.K.; NOLASCO, N.J.; STOOPS, J.K.; RIGGS, A.F. Assembly of the gigantic hemoglobin of the earthworm Lumbricus terrestris- Roles of subunit equlibrio, non- globin linker chains, and valence of the heme iron. Journal Biological Chemistry, v. 271, p. 30007-30021,1996.

7. ROUSSELOT, M.; DELPY, E.; LA-ROCHELLE, C. D.; LAGENTE, V.; PIROW, R.; REES, J.; HAGEGE, A.; LE-GUEN, D.; HOURDEZ, S.; ZAL, F. Arenicola marina extracellular hemoglobin: a new promising blood substitute. Biotechnology Journal, v. 1, n. 3, p. 333-345, 2006.

8. CARVALHO, F. A. O.; SANTIAGO, P. S.; BORGES, J. C.; TABAK, M. On the molecular mass of the extracellular hemoglobin of Glossoscolex paulistus: analytical ultracentrifugation reexamination. Analytical Biochemistry, v. 385, n. 2, p. 257-263, 2008.

9. OLIVEIRA, M. S.; MOREIRA, L. M.; TABAK, M. Partial characterization of giant extracellular hemoglobin of Glossoscolex paulistus: A MALDI-TOF-MS study.

International Journal of Biological Macromolecules, v. 40, n. 5, p. 429-436, 2007.

10. CARVALHO, F. A. O.; SANTIAGO, P. S.; BORGES, J. C.; TABAK, M. Molecular masses and sedimentation coefficients of extracellular hemoglobin of Glossoscolex paulistus: Alkaline oligomeric dissociation. International Journal of Biological Macromolecules, v. 48, n. 1, p. 183-19, 2011.

11. CARVALHO, F. A. O.; CARVALHO, J. W. P.; SANTIAGO, P. S.; TABAK, M. Further characterization of the subunits of the giant extracellular hemoglobin of Glossoscolex paulistus (HbGp) by SDS-PAGE electrophoresis and MALDI-TOF-MS. Process

Biochemistry, v. 46 n. 11, p. 2144-2151, 2011. 
12. OWNBY, D. W.; ZHUS, H.; SCHNEIDERS, K.; BEAVISSLL, R. C.; CHAITB, B. T.; RIGGS. A. F. The extracellular hemoglobin of the earthworm, Lumbricus terrestris determination of subunit stoichiometry. The Journal of Biological Chemistry, v. 268. n. 18, p.13539-13547,1993.

13. ZAL, F.; GREEN, B. N.; LALLIER, F. H.; VINOGRADOV, S. N.; TOULMOND, A. Quaternary structure of the extracellular haemoglobin of the lugworm Arenicola marina: a multi-angle-laser-light-scattering and electrospray-ionisation-mass-spectrometry analysis. European Journal of Biochemistry, v. 243, n. 1-2, p. 85-92, 1997.

14. KUCHUMOV, A. R.; TAVEAU, J. C.; LAMY, J. N.; WALL, J. S.; WEBER, R. E.; VINOGRADOV, S. N. The role of linkers in the reassembly of the $3.6 \mathrm{MDa}$ hexagonal bilayer hemoglobin from Lumbricus terrestris. Journal of Molecular Biology, v. 289, n. 5, p. 1361-1374, 1999.

15. BACHEGA, José Fernando Ruggiero. Estrutura cristalográfica da hemoglobina de Glossoscolex paulistus, um complexo de 3,6 mega Daltons. 2013. 165 f. Tese ( Doutorado em Física Aplicada) - Instituto de Física de São Carlos, Universidade de São Paulo, São Carlos, 2013.

16. ROYER, W. E.; KNAPP, J. E.; STRAND, K.; HEASLET, H. A. Cooperative hemoglobins: conserved fold, diverse quaternary assemblies and allosteric mechanisms. Trends in Biochemical Sciences, v. 26, n. 5, p. 297-304, 2001.

17. ROYER, W. E.; SHARMA, H.; STRAND, K.; KNAPP, J. E. Lumbricus erythrocruorin at 3.5 angstrom resolution: Architecture of a megadalton respiratory complex. Structure, v. 14, n. 7, p. 1167-1177, 2006.

18. TABAK, M.; CARVALHO, F. A. O.; CARVALHO, J. W. P.; BACHEGA, J. F. R;. SANTIAGO, P.S. Recent new characterizations on the giant extracellular hemoglobin of Glossoscolex paulistus and some other giants hemoglobins from different worms. In: INNOCENTIN, A. (Ed.) Stoichiometry and research: the importance of quantity in biomedicine. Rijeka, Croatia: In Tech, 2012. v. 1, p. 337-356.

19. MEIRELLES, N.C.; OLIVEIRA,B.; OLIVEIRA, A.R.; DE PAULA, E.; MARANGONI, S.; RENNEBECK, G.M. Erythrocruorin of Glossoscolex paulistus ( oligochaeta, glossoscolecidae ): dissociation at alkaline ph and its ligand properties as revealed by chemical, immunochemical and electron microscopy studies. Comparative Biochemistry and Physiology Part A, v. 88, n. 2, p. 377-379, 1987.

20. MOREIRA, L.M.; SANTIAGO, P.S.; DE ALMEIDA, E.V.; TABAK, M. Interaction of giant extracellular Glossoscolex paulistus hemoglobin (HbGp) with zwitterionic surfactant $\mathrm{N}$ hexadecyl-N,N-dimethyl-3-ammonio-1-propanesulfonate (HPS): effects of oligomeric dissociation.Colloids and Surfaces B: Biointerfaces, v . 61, p.153-163, 2008.

21. SANTIAGO, P. S.; MOREIRA, L. M.; DE ALMEIDA, E.V.; TABAK, M. Giant extracellular Glossoscolex paulistus hemoglobin ( $\mathrm{HbGp}$ ) upon interaction with cethyltrimethylammonium chloride (CTAC) and sodium dodecyl sulphate (SDS) surfactants: dissociation of oligomeric structure and autoxidation. Biochimica Biophysica Acta, v. 1770, n. 4, p. 506-517, 2007. 
22. OLIVEIRA, M. S.; MOREIRA, L. M.; TABAK, M. Interaction of giant extracellular Glossoscolex paulistus hemoglobin (HbGp) with ionic surfactants: a MALDI-TOF-MS study. International Journal of Biological Macromolecules, v. 42, n. 2, p. 111-119, 2008.

23. FONSECA, L. C.; CORRÊA, N.C.R.; GARROTE-FILHO, M.S.; DA CUNHA, C. C.; PENHA-SILVA. Efeito da composição do solvente sobre a estabilidade de proteínas em soluções aquosas. Química Nova, v.29, n. 3, p. 543-548, 2006.

24. SANTIAGO, P. S.; MOURA, F.; MOREIRA, L. M.; DOMINGUES, M. M.; SANTOS, N. C.; TABAK, M. Dynamic light scattering and optical absorption spectroscopy study of $\mathrm{pH}$ and temperature stabilities of the extracellular hemoglobin of Glossoscolex paulistus.

Biophysical Journal, v. 94, n. 6, p. 2228-2240, 2008.

25. SANTIAGO, P. S.; DOMINGUES, M. M.; CARVALHO, J. W. P.; SANTOS, N. C.; TABAK, M. Thermal stability of extracellular hemoglobin of Glossoscolex paulistus: determination of activation parameters by optical spectroscopic and differential scanning calorimetric studies. Biophysical Chemistry, v. 152, n. 1-2, p. 128-138, 2010.

26. CARVALHO, J. W. P.; CARVALHO, F. A. O.; SANTIAGO, P. S.; TABAK, M. Thermal denaturation and aggregation of hemoglobin of Glossoscolex paulistus in acid and neutral media. International Journal of Biological Macromolecules, v. 54, p. 109-118, 2013.

27. CARVALHO, F. A. O.; SANTIAGO, P. S.; TABAK, M. On the stability of the extracellular hemoglobin of Glossoscolex paulistus, in two iron oxidation states, in the presence of urea. Archives of Biochemistry and Biophysics, v. 519, p. 46-58, 2012.

28. ARIAEENEJAD, S.; HABIBI-REZAEI, M.; KAVOUSI, K.; JAMILI, S.; FATEMI, M. R.; HONG, J.; POURSASAN, N.; SHEIBANI, N.; MOOSAVI-MOVAHEDI, A.A. Denaturation and intermediates study of two sturgeon hemoglobins by $n$ dodecyltrimethylammonium bromide. International Journal of Biological Macromolecules, v. 53, p. 107-113, 2013.

29. CHAUHAN, S.; SHARMA Kundan. Effect of temperature and additives on the critical micelle concentration and thermodynamics micelle formation of sodium dodecyl benzene Sulfonate and dodecyltrimethylammonium bromide in aqueous solution: A conductometric study. The Journal of Chemical Thermodynamics, v.71, p.205-211,2014.

30. LAKOWICZ, J. R. Principles of fluorescence spectroscopy. Baltimore: Springer, 2006. $974 \mathrm{p}$.

31. HAWE, A.; SUTTER, M.; JISKOOT. Extrensic fluorescent dyes as tools for protein characterization. Pharmaceutical Research, v. 25, n.7, p.1487-1499 , 2007

32. STRYER, L. The interaction of a naphthalene dye with apomyoglobin and apohemoglobin a fluorescent probe of non-polar binding sites. Journal of Molecular Biology, v. 13, p. 482 - 495, 1965.

33. KUZNETSOVA, I. M.; SULATSKAYA, A. I.; POVAROVA, O. I.; TUROVEROV, K. K. Reevaluation of ANS binding to human and bovine serum albumins: key role of equilibrium microdialysis in ligand - receptor binding characterization. Plos One, v.7, n.7, p.1-9, 2012. 
34. SCHONBRUNN, E.; ESCHENBURG, S.; LUGER, K.; KABSCH, W.; AMRHEIN, N. Structural basis for the interaction of the fluorescence probe 8-anilino-1-naphthalene sulfonate (ANS) with antibiotic. Proceedings of the National Academy of Sciences, v. 97, n. 12, p. 63456349, 2000.

35. QADEER, A.; RABBANI, G.; ZAIDI, N.; AHMAD, E.; KHAN, J.M.; KHAN, R.H. 1Anilino-8-naphthalene sulfonate (ANS) is not a desirable probe for determining the molten globule state of chymopapain. Plos One, v. 7, n.11, p. 1-11, 2012.

36. SLAVIK, J. Anilinonaphthalene sulfonate as a probe of membrane composition and function. Biochimica et Biophysica Acta, v. 694, p. 1-25, 1982.

37. PARUL, D.A.; BOKUT, S.B.; MILYUTIN, A.A.; PETROV.E.P.; NEMKOVICK, N.A.; SOBCHUK, A.N. Time-resolved fluorescence reveals two binding sites of 1,8-ANS in intact human oxyhemoglobin. Journal of Photochemistry and Photobiology B: Biology, v. 58, p.156-162, 2000.

38. UVERSKY, V. N.; WINTER, S.; LOBER, G. Use of fluorescence decay times of 8-ANSprotein complexes to study the conformational transitions in proteins which unfold through the molten globule state. Biophysical Chemistry, v. 60, p. 79-88, 1996.

39. SYAKHOVICH, V. E.; PARUL, D.A.; RUTA, E.Y.; BUSHUK, B.A.; BOKUT, S.B. 1, 8- Anilinonaphthalene sulfonate binds to central cavity of human hemoglobin. Biochemical and Biophysical Research Communications, v. 317, p. 761-767, 2004.

40. HAWE, A.; POOLE R.; JISKOOT, W. Misconceptions over Forster resonance energy transfer between proteins and ANS/bis-ANS: Direct excitation dominates dye fluorescence. Analytical Biochemistry, v. 401, p. 99-106, 2010.

41. SARKAR, P.; BHARILL, S.; GRYCZYNSKI, I.; GRYCZYNSKI, Z.; NAIR, M.P.; LACKO, A.G. Binding of 8-anilino-1-naphthalenesulfonate to lecithin: cholesterol acyltransferase studied by fluorescence techniques. Journal of Photochemistry and Photobiology B: Biology, v. 92, p. 19-23, 2008.

42. SOMEYA, Y.; YUI, HIROHARU. Fluorescence lifetime probe for solvent microviscosity utilizing anilinonaphthalene sulfonate. Analytical Chemistry, v. 82, p. 5470-5476, 2010.

43. KOSOWER, E.M.; KANETY, H. Intramolecular donor-acceptor systems. 10. Multiple Fluorescences from 8- (Phenylamino)-1-naphthalenesulfonates. Journal of the American Chemical Society, v. 105, p. 6236-6243, 1983.

44. SJOBACK, R.; NYGREN, J.; KUBISTA, M. Absorption and fluorescence properties of fluorescein. Spectrochimica Acta Part A, v.51, p. L7-L21, 1995.

45. HAUGLAND, R.P. Handbook of fluorescent probes and research chemicals. Eugene: Molecular Probes, 1996. p. 19-21.

46. JACKSÉN, J.; DAHL, K.; KARLBERG, A.; REDEBY, T.; EMMER, A. Capillary electrophoresis separation and matrix-assisted laser desorption/ionization mass spectrometry characterization of bovine serum albumin-fluorescein isothiocyanate conjugates. Journal of Chromatography B, v. 878, p. 1125-1134, 2010. 
47. GRUNWALDT, G.; HAEBEL, S.; SPITZ, C.; STEUP, M.; MENZEL, R. Multiple binding sites of fluorescein isothiocyanate moieties on myoglobin: photophysical heterogeneity as revealed by ground- and excited-state spectroscopy. Journal of Photochemistry and Photobiology B: Biology, v. 67, p. 177-186, 2002.

48. HUANG, C.; ZHANG, K.; CI, Y. Sensitization of surfactants on the chemiluminescence reaction of fluorescein isothiocyanate labeled proteins. Journal of Biochemical and Biophysical Methods, v.70, p. 341-347, 2007.

49. KIM, P-S.G.; PETERSEN, N.O.; SHAM, T.K.; HU,Y.F. Soft X-ray excited optical luminescence (XEOL) studies of fluorescein isothiocyanate (FITC) and FITC-labeled proteins. Chemical Physics Letters, v. 392, p. 44-49, 2004.

50. HUNGERFORD, G.; BENESCH, J.; MANO, J.F.; REIS, R. L. Effect of the labeling ratio on the photophysics of fluorescein isothiocyanate (FITC) conjugated to bovine serum albumin. Photochemical \& Photobiological Sciences, v. 6, p.152-158, 2007.

51. GEORGIEVA, D. N.; DOLASHKA, P. Spectroscopic properties of Subtilisin DY selectively modified with fluorescein isothiocyanate. Spectrochimica Acta Part A, v. 53, p.1515-1520, 1997.

52. HOFFMANN, C.; DUDAL, J.L.; PATEL, S.; GALLET, O.; PAUTHE, E. Fluorescein isothiocyanate-labeled human plasma fibronectin in extracellular matrix remodeling. Analytical Biochemistry, v. 372, p. 62-71, 2008.

53. SANTIAGO, P.S.; MOREIRA, L.M.; DE ALMEIDA, E. V.; TABAK, M. Giant extracellular Glossoscolex paulistus Hemoglobin (HbGp) upon interaction with cethyltrimethylammonium chloride (CTAC) and sodium dodecyl sulphate (SDS) surfactants: Dissociation of oligomeric structure and autoxidation. Biochimica et Biophysica Acta, v. 1770 p. 506-517, 2007.

54. PACE, C. N.; HEBERT, E. J.; SHAW, K. L.; SCHELL, D.; BOTH, V.; KRAJCIKOVA, D.; SEVCIK, J.; WILSON, K. S.; DAUTER, Z.; HARTLEY, R. W.; GRIMSLEY, G. R. Conformational stability and thermodynamics of folding of ribonucleases $\mathrm{Sa}, \mathrm{Sa} 2$ and $\mathrm{Sa} 3$. Journal of Molecular Biology, v. 279, n. 1, p. 271-286, 1998.

55. SKOOG, D. A.; HOLLER, F. J; NIEMAN, T. A. Princípios de análise instrumental. Porto Alegre: Bookman, 2002. 836 p.

56. CAMPBELL, I. D.; DWEK, R. A. Biological spectroscopy. London: BenjaminCummings, 1984. 404 p.

57. ZAIA, D.A.M.; ZAIA, C. T.B.V.; LICHTIG, J. Determinação de proteínas totais via espectrofotometria: vantagens e desvantagens dos métodos existentes. Química Nova, v. 21 p. 787- 793, 1998.

58. VAN HOLDE, K.E.; JOHNSON, W.C.; HO, P.S. Principles of physical biochemistry. New York: Pearson Prentice Hall, 2006. 710 p.

59. LAKOWICZ, J. R. Principles of fluorescence spectroscopy. Baltimore: Springer, 2006. $974 \mathrm{p}$. 
60. ATKINS, P.; PAULA, J.D. Físico-química. Rio de Janeiro: Livros Técnicos e Científicos, 2004. v. 2.

61. SANTOS, N.C, CASTANHO, M.R.B. Teaching light scattering spectroscopy: the dimension and shape of Tabacco mosaic virsus. Biophysical Journal, v. 71, n. 3, p. 1541$1650,1996$.

62. PETTA, V.; MORADIAN-OLDAK, J.; YANNOPOULOS, S.N.; BOUROPOULOS, N. Dynamic light scattering study of an amelogenin gel-like matrix in vitro. European Journal of Oral Sciences, v. 114, n.1, p. 308-314, 2006.

63. KIRK, W. Photophysics of ANS: Charge transfer character of near-UV absorption and consequences for ANS spectroscopy. Biophysical Chemistry, v.125, p. 13-23, 2007.

64. BAHRI, M.A.; HOEBEKE,M.; GRAMMENOS, A.; DELANAYE, L.; VANDEWALLE, N.; SERET,A. Investigation of SDS, DTAB and CTAB micelle microviscosities by electron spin resonance. Colloids and Surfaces A: Physicochemistry, v. 290, p. 206-212, 2006.

65. TAHERI-KAFRANI, A.; ASGARI-MOBARAKEH, E.; BORDBAR, A.K.; HAERTLÉ, T. Structure-function relationship of $\beta$-lactoglobulin in the presence of dodecyltrimethyl ammonium bromide. Colloids and Surfaces B: Biointerfaces, v. 75, p. 268-274, 2010.

66. POLI, A.L.; MOREIRA, L.M.; TABAK, M.; IMASATO, H. SDS ( sodium dodecyl sulfate) effect on the autoxidation of the Glossoscolex paulistus giant extracellular hemoglobin: kinetic studies at $\mathrm{pH}$ 7,0 and 9,0. Colloids and Surfaces B: Biointerfaces, v. 52, p.96-104, 2006.

67. SANTIAGO, P.S.;CARVALHO, F.A.O.; DOMINGUES, M.M.; CARVALHO, J.W.P.; SANTOS, N.C,TABAK, M. Isoelectric point determination for Glossoscolex paulistus extracellular hemoglobin: oligomeric stability in acidic $\mathrm{pH}$ and relevance to Protein Surfactant Interactions. Langmuir, v. 26, n. 12, p. 9794-9801, 2010.

68. ANDERSEN, K.K.; WESTH, P.; OTZEN, D.E. A global study of myoglobin-surfactant interactions. Langmuir, v. 24, p. 399-407, 2008.

69. MISRA, P.P.; KISHORE, N. Biophysical analysis of partially folded state of $\alpha-$ lactalbumin in the presence of cationic and anionic surfactants. Journal of Colloid and Interface Science, v. 354, p. 234-247, 2011.

70. CARVALHO, F.A.O.; CARVALHO, J.W.P.; BIAZIN, E.; SANTIAGO, P.S.;

TABAK,M. Characterization of Rhinodrilus alatus hemoglobin (HbRa) and its subunits: Evidence for strong interaction with cationic surfactants DTAB and CTAC. Comparative Biochemistry and Physiology - Part B: Biochemistry \& Molecular Biology, v.167, p.2329, 2014.

71. CARVALHO, F.A.O.; CARVALHO, J.W.P.; ALVES, F.R.; TABAK, M. pH effect upon HbGp oligomeric stability: characterization of the dissociated species by AUC and DLS studies. International Journal of Biological Macromolecules, v. 59, p. 333-341, 2013. 
72. SANTIAGO, P.S.; MOURA, F.; MOREIRA, L.M.; DOMINGUES, M.M.; SANTOS, N.C.; TABAK, M. Dynamic light scattering and optical absorption spectroscopy study of $\mathrm{pH}$ and temperature stabilities of the extracellular hemoglobin of Glossoscolex paulistus.

Biophysical Journal, v. 94, p. 2228-2240, 2008.

73. TOGASHI, D.M.; RYDER, A.G. Time-resolved fluorescence studies on bovine serum albumin denaturation process. Journal of Fluorescence, v. 16, p.153-160, 2006.

74. QU, P.; LU, H.; YAN, S.; ZHOU, D.; LU, Z. Investigations of effects of environmental factors in unfolding/refolding pathway of proteins on 8-anilino-1-naphthalene-sulfonic acid (ANS) fluorescence. Journal of Molecular Structure, v. 936, p. 187-193, 2009.

75. SAROJA, G.; SAMANTA, A. Polarity of the micelle-water interface as seen by 4aminophthalimide, a solvent sensitive fluoresce probe. Chemical Physics Letters, v.246, p. 506-512, 1995.

76. HIRSCH, R. E.; VIDUGIRIS, G. J.A.; FRIEDMAN, J.M.; HARRINGTON, J. P. Alteration of tryptophan fluorescence properties upon dissociation of Lumbricus terrestris hemoglobin. Biochimica et Biophysica Acta, v. 1205, p. 248-251, 1994. 